\title{
INTERNATIONAL OUTSOURCING: AN OPEN-ECONOMY MODEL WITH INTERMEDIATE GOODS AND ECONOMIES OF SCALE
}

\section{By}

TING ZHANG

\begin{abstract}
A thesis submitted to the Faculty of Graduate Studies and Research in partial fulfillment of the requirement for the degree of Doctor of Philosophy
\end{abstract}

\author{
Department of Economics \\ Carleton University \\ Ottawa, Canada
}

CCopyright 2008. Ting Zhang 


$\begin{array}{ll}\begin{array}{l}\text { Library and } \\ \text { Archives Canada }\end{array} & \begin{array}{l}\text { Bibliothèque et } \\ \text { Archives Canada }\end{array} \\ \begin{array}{l}\text { Published Heritage } \\ \text { Branch }\end{array} & \begin{array}{l}\text { Direction du } \\ \text { Patrimoine de l'édition }\end{array} \\ \begin{array}{l}\text { 395 Wellington Street } \\ \text { Ottawa ON K1A 0N4 } \\ \text { Canada }\end{array} & \begin{array}{l}\text { 395, rue Wellington } \\ \text { Ottawa ON K1A 0N4 } \\ \text { Canada }\end{array}\end{array}$

Your file Votre référence

ISBN: 978-0-494-43921-0

Our file Notre référence

ISBN: 978-0-494-43921-0

NOTICE:

The author has granted a nonexclusive license allowing Library and Archives Canada to reproduce, publish, archive, preserve, conserve, communicate to the public by telecommunication or on the Internet, loan, distribute and sell theses worldwide, for commercial or noncommercial purposes, in microform, paper, electronic and/or any other formats.

The author retains copyright ownership and moral rights in this thesis. Neither the thesis nor substantial extracts from it may be printed or otherwise reproduced without the author's permission.
AVIS:

L'auteur a accordé une licence non exclusive permettant à la Bibliothèque et Archives Canada de reproduire, publier, archiver, sauvegarder, conserver, transmettre au public par télécommunication ou par l'Internet, prêter, distribuer et vendre des thèses partout dans le monde, à des fins commerciales ou autres, sur support microforme, papier, électronique et/ou autres formats.

L'auteur conserve la propriété du droit d'auteur et des droits moraux qui protège cette thèse. $\mathrm{Ni}$ la thèse ni des extraits substantiels de celle-ci ne doivent être imprimés ou autrement reproduits sans son autorisation.
In compliance with the Canadian Privacy Act some supporting forms may have been removed from this thesis.

While these forms may be included in the document page count, their removal does not represent any loss of content from the thesis.
Conformément à la loi canadienne sur la protection de la vie privée, quelques formulaires secondaires ont été enlevés de cette thèse.

Bien que ces formulaires aient inclus dans la pagination, il n'y aura aucun contenu manquant.

\section{Canada}




\begin{abstract}
A key current trade controversy concerns the impacts of international outsourcing on wage disparities and employment. To generate new insights into this debate, we develop a more relevant framework by extending the traditional trade model in two main directions.

First, a pure intermediate good exhibiting a positive externality at Home is introduced to the traditional two-sector two-factor framework. We show that a normal output response to price in final goods is a sufficient but not necessary condition to ensure the concavity of the PPF. When Home opens to free trade, the technology difference across countries prevents equalization of factor returns, which provides an incentive for outsourcing to occur.
\end{abstract}

For a large country with flexible wages and full employment, although there is always a cost saving, outsourcing could lead to either an improvement or a deterioration in the terms of trade. Then the net impact on social welfare is ambiguous as are the effects on the wage rates. However, it is possible for outsourcing to boost both countries' welfare because the production processes are allocated across borders more efficiently. The cost saving and the expansion of the industry with the positive externality lead to a net gain to a small open economy despite the fact that wage disparity is enlarged against unskilled labor.

Second, in order to examine the possible effects of free trade and outsourcing on employment, a binding minimum-wage constraint is introduced. We show that the domestic output response to price now becomes perverse. Relative to autarky, free trade leads to an increase (a decrease) in employment when Home exports (imports) the good which embodies the economies-of-scale intermediate input. Moreover, we find that outsourcing actually raises rather than threatens employment, but it aggravates another 
distortion by further contracting the industry exhibiting the positive externality. In contrast to the implications of free trade, these impacts on production and employment are independent of trade patterns. Welfare outcomes are also identified in each case. Due to distortions being present in both intermediate good and factor markets, outsourcing may yield a net welfare loss to the home country. 


\section{Acknowledgements}

I would like to thank my thesis supervisor, Richard Brecher, for all of his assistance and encouragement throughout the process. I also would like to thank Ehsan Choudhri, Zhiqi Chen and Yazid Dissou for their helpful comments and suggestions. Special thanks to Michael Burns. I am also grateful to my friend Bo Zhao for his assistance in mathematical programming.

Any remaining errors are solely my own responsibility. 


\section{Table of Contents}

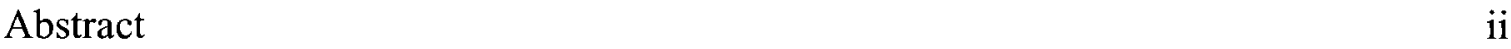

Acknowledgment $\quad$ iv

Table of Contents $\quad$ V

List of Tables $\quad$ vii

List of Figures $\quad$ viii

List of Appendices $\quad$ ix

$\begin{array}{ll}\text { Chapter 1: Introduction } & 1\end{array}$

Chapter 2: Basic Model and Assumptions 7

\section{Chapter 3: Some Properties of the Model}

3.1: The Slope of the PPF 12

3.2: Basic Relationships $\quad 14$

3.3: The Stolper-Samuelson Theorem 16

3.4: The Rybczynski Theorem 22

3.5: The Output Response to Price and the Curvature of the PPF 27

3.6: Multiple Production Equilibria 31

Chapter 4: Free Trade in Final Goods

4.1: The Absence of Factor-Price Equalization 34

4.2: Comparative Statics $\quad 40$

\section{Chapter 5: International Outsourcing}

5.1: Introduction 43

5.2: The Effect on Supply and Demand at Constant Terms of Trade 45 
5.3: The Effect on Terms of Trade

5.4: The Effect on Social Welfare 63

5.5: The Effect on Wage Ratio $\quad 67$

5.6: Small Open Economy $\quad 68$

Chapter 6: Minimum-Wage Economy

$\begin{array}{ll}\text { 6.1: Introduction } & 70\end{array}$

6.2: Analytical Relationships 71

6.3: The Constrained Transformation Curve 74

6.4: The Perverse Output Response to Price $\quad 78$

Chapter 7: Free Trade and Unemployment

7.1: The Excess Supply and Import Demand Curves 84

$\begin{array}{ll}\text { 7.2: } \text { Free Trade versus Autarky } & 87\end{array}$

7.3: Comparative Statics $\quad 88$

Chapter 8: Outsourcing and Unemployment

$\begin{array}{ll}\text { 8.1: Introduction } & 92\end{array}$

8.2: The Excess Supply and Import Demand Curves 93

8.3: The Implications of Outsourcing 99

$\begin{array}{ll}\text { Chapter 9: Conclusion } & 105\end{array}$

$\begin{array}{ll}\text { References } & 107\end{array}$

$\begin{array}{ll}\text { Appendix } \boldsymbol{A} & 111\end{array}$

$\begin{array}{lr}\text { Appendix } B & 128\end{array}$ 


\section{List of Tables}

Chapter 8: Outsourcing and Unemployment

Table 1: The Impacts of Outsourcing relative to Free Trade

104 


\section{List of Figures}

\section{Chapter 2: Basic Model and Assumptions}

Figure 1: Lerner Diagram: Modified for the Presence of an Externality

Chapter 3: Some Properties of the Model

Figure 2: Multiple Production Equilibria

\section{Chapter 4: Free Trade in Final Goods}

Figure 3: The Comparison between Domestic and Foreign Wage Ratios

Figure 4: The Comparison between Domestic and Foreign Intermediate Input Prices

Figure 5: The Effect of Outsourcing on Domestic Production at Constant Factor Prices

Figure 6: The Effect of Outsourcing on the Domestic Wage Ratio at Constant Terms of Trade

Figure 7: The Effect of Outsourcing on Foreign Production at Constant Terms of Trade

\section{Chapter 6: Minimum-Wage Economy}

Figure 8: The Effect of a Binding Minimum-Wage Constraint on the PPF

\section{Chapter 7: Free Trade and Unemployment}

Figure 9: The Constrained Transformation Curve with a

Perverse Output Response to Price

Figure 10: The Domestic Excess Supply and Foreign Import Demand Curves

\section{Chapter 8: Outsourcing and Unemployment}

Figure 11: The Effect of Outsourcing on Employment at Constant Terms of Trade 95 
Figure 12: Shifts of the Domestic Excess Supply and

Foreign Import Demand Curves

Figure 13: Decomposition of the Effects of Outsourcing on Production and Employment

Appendix $A 9$

Figure 14: Multiple Equilibria of the Minimum-Wage Model

Appendix $\boldsymbol{A 1 0}$

Figure 15: The Positive Relationship between the Real Wage of Unskilled Labor and the Demand for Unskilled Labor at Constant Terms of Trade 


\section{Lists of Appendices}

Appendix $A 1$ : The Equality between Price and Unit Cost for the Good

Embodying the Externality

Appendix $A 2$ : The Slope of the PPF

Appendix A3: Comparative Statics and Analytical Relationships

Appendix $A 4$ : The Normal Output Response to price of the

CRS Intermediate Good

Appendix $A 5$ : The Form of the Externality

Appendix A6: Discussion Regarding the Assumption of Complete Outsourcing

Appendix $A 7$ : The Slope of the $\mathrm{PPF}^{\mathrm{ZY}}$ at Outsourcing

Appendix $A 8$ : The Curvature of the $\mathrm{PPF}^{\mathrm{ZY}}$ at Outsourcing

Appendix $A 9$ : Multiple Equilibria of the Minimum-Wage Model

Appendix $A 10$ : The Positive Relationship between the Real Wage of Unskilled Labor and the Demand for Unskilled Labor at Constant Terms of Trade

Appendix $A 11$ : Analytical Relationships for the Minimum-Wage Model at Outsourcing

Appendix $B$ : The Curvature of the PPF: Some Special Cases 


\section{Introduction}

A distinctive feature of the recent evolution of the world economy is cross border outsourcing whereby some production activities (physical components or service) are performed abroad. Firms in one country try to exploit international differences in factor prices by moving production activity offshore so as to reduce the unit cost of final goods. Outsourcing is favored not only by a reduction of formal barriers to trade, but more importantly by a cut in the cost of linking individual fragments towards final goods. Such changes are mainly due to advances in technology and communication between countries. During the past 20 years, improvement in information technology has been identified as the main reason for the reductions in the cost of cross-border service links, which increase the economic incentive for international outsourcing. ${ }^{1}$ Recent studies have investigated this phenomenon with a focus on social welfare, wage disparity and unemployment. Theoretical researches on outsourcing predominantly build on traditional trade models. Basically, three approaches embodying flexible wages and full employment have been followed.

1. One-sector two-factor models. Feenstra and Hanson (1996 a, b, 1999) underpin outsourcing as a factor-biased technology change. They conclude that outsourcing of unskilled-labor intensive fragments to unskilled-labor abundant countries would increase the demand for skilled labor at both countries, and hence results in a decrease of relative wages of unskilled-labor in the outsourcing sending country. Similarly, Bhagwati, Panagariya and Srinivasan (2004) show that outsourcing labor abroad would increase social welfare as a whole, but in the absence of a method of transfer, would benefit the owners of capital while

\footnotetext{
${ }^{1}$ See Harris (2001) and Jones and Kierzkowski (2001).
} 
making workers worse off. Deardorff (2005) assumes that the North has a Hicksneutral technological advantage over South in one production activity and that final good production takes the Cobb-Douglas function. He finds that if an unskilled-labor activity is outsourced at South and North continues to diversify, the wage of unskilled labor in the north will fall and the wage of skilled labor will increase. However, if factor endowments differ enough to lead to specialization, then it is possible for both factors in North to gain from this outsourcing.

2. Two-sector two-factor models. These models are mainly set up in the HeckscherOhlin framework. Arndt (1997), Deardorff (1998, 2001) and Kohler (2002) underscore the importance of sector-biased rather than factor-biased technology change. For example, if a labor intensive import competing industry in U.S. moves some of its fragments to Mexico, this acts like a technology improvement in the remaining fragments of this industry. As shown in these papers, for a small open economy with constant terms of trade, outsourcing of a labor (capital) intensive fragment leads to an increase (a decline) in the wages of the sending country depending upon the relative factor-intensity of the outsourced part. This is a well-known result from Heckscher-Ohlin model that labor gains from a technology improvement in the labor intensive sector.

3. Specific-factor models. Kohler (2001) analyses outsourcing using a specificfactor framework with two sectors and comes to different conclusions regarding the impact on national welfare and relative wages as compared to the results of traditional Heckscher-Ohlin models. In his model, capital is the sector specific 
factor while labor is a mobile factor. Domestic labor loses if a labor intensive fragment moves offshore and international outsourcing may cause a welfare loss if the cost of fragmentation includes a fixed element. Moreover Kohler highlighted a crucial distinction between outsourcing with and without foreign direct investment.

On the other hand, when the production of those intermediate inputs moves to foreign countries, a practical fear at the home country is that jobs will be destroyed and unemployment will rise. A number of recent studies have estimated the impacts on the US labor markets. Estimate by Forrester Research suggests that there will be job losses totaling 3.3 million white collar jobs by the year of 2015 , and the prediction by Deloitte Research shows that outsourcing will shift 2 million financial-sector jobs by the year 2009. ${ }^{2}$ Other estimates by Bardhan and Kroll (2003), that 11 percent of American jobs are potentially at risk of being off-shored, have drawn more attention from politicians and journalists. However, those authors does not clarify whether the prediction is that the US economy will have fewer jobs than it would otherwise have had because of outsourcing or that outsourcing will cause those workers to shift from original jobs they have had into different jobs.

While the relation between outsourcing and unemployment has been an important issue for politician and the public, not very much careful theoretical analysis about this relationship have been conducted. Mitra and Ranjan (2007) construct a two-sector model where unemployment is caused by search frictions and they find that wage increases and sectoral unemployment decreases, something can be explained by the productivity enhancing (cost reducing) effect of outsourcing. Their results are consistent with the

\footnotetext{
${ }^{2}$ See Drezner (2004).
} 
empirical findings of Amiti and Wei (2005a, b) for the US and the UK, which offer no support for the anxiety of "massive job losses" associated with outsourcing. In fact, using data on 78 sectors in the UK for the period 1992-2001, Amiti and Wei find a positive relationship between outsourcing and employment in many of their specifications. Likewise, Mann (2003) claims that subject to outsourcing, a stable or small rising employment trend in certain occupational categories such as architecture, engineering, IT, business suggests relatively little impact of outsourcing on employment, once adjustments have been made for the business cycle downturn. More evidence on job losses from other sources suggests that aggregate effect of outsourcing has so far been negligible for US, UK as well as other countries. ${ }^{3}$

The present study will keep to the traditional concerns, investigating the outsourcing impacts on welfare, wage disparity as well as unemployment. However, in contrast to the previous literatures, the approach here builds on a framework that involves two factors and two final goods with a pure intermediate good which exhibits an output-generated external increasing-returns-to-scale (IRS). By this we mean an externality that is internal to the industry but external to the individual firms. The two-sector equilibrium with pure intermediate goods was original analyzed by Batra and Casas (1973) and Schweinberger (1975) where all the industries exhibit constant-returns-to-scale (CRS). On the one hand, considerable research have been undertaken using variable-returns-to-scale (VRS) production technology in investigating the implications of free trade or political policy during the 1970s and 1980s, see Jones (1968), Kemp (1969), Choi and Yu (1984) and

\footnotetext{
${ }^{3}$ For the case of US, see Bhagwati, Panagariya and Srinivasan (2004); for the case of UK, see Gerd Rohde (2007) and for the case of other countries, see Rohde (2007) and OECD research (2006) which found no "systematic evidence" that net outward investment of service is associated with a significant decline in employment as a result of outsourcing.
} 
Panagariya $(1980,1981,1986)$.

As far as we know, this paper offers the first investigation of equilibrium properties in a model that embodies both intermediate goods and VRS, extensions that are justified by the following considerations. First, the introduction of intermediate goods permits fragmentation of the production process and makes outsourcing feasible. Second, the introduction of VRS is both consistent with historical and recent evidence regarding the presence of IRS in a variety of industries in the real world and relaxes the strong assumptions of the traditional model that have restricted the applicability of that research. ${ }^{4}$ Finally, support for the way that external effects are modeled here can be found in Porter (1990) who made a strong case for the existence of output generated external effects, especially in relatively skill-intensive industries.

This model provides a formal basis for outsourcing, offers an explanation for the recently observed phenomenon of skilled-labor outsourcing, and also contributes to the debate over why an increase in the skill intensive production should occur in the face of a rising skilled-labor wage rate. Our model demonstrates that outsourcing one intermediate input to a cheaper-cost country may (will) enlarge the domestic wage disparity against unskilled labor if the home country is large (small), which offers some support for the stylized fact that in recent decades there has been a decline in the relative wage of unskilled labor in the US factor markets. ${ }^{5}$

While arguably the most important development in recent decades in US factor markets is the decline in the relative wage of unskilled labor, by contrast, in European labor markets it is undoubtedly the rise and persistence of unemployment. For this reason,

\footnotetext{
${ }^{4}$ For historical survey on external economies, see Chipman (1965); for empirical studies on non-CRS, see Goldstein and Moses (1973) and Mansfield (1997: 191-192).

${ }^{5}$ See Feenstra and Hanson (1996 a, b); for recent empirical finding, see Geishecker and Gorg (2004).
} 
we extend our framework by adding a binding minimum-wage constraint in the unskilled-labor market in order to examine the possible effects of free trade and outsourcing on unemployment. In doing so, we build our approach on the classic minimum-wage model of Brecher $(1974 a, b)$. We find that outsourcing has a positive impact on employment, but at the same time it aggravates another distortion by further decreasing the production of the good with positive externality. Therefore a net loss may occur as the final outcome to the home country.

The paper is structured as follows. Chapter 2 sets up the basic model and introduces related assumptions. Chapter 3 analyzes some of the main technical properties of our framework for a closed economy. The implications of free trade and international outsourcing are examined in Chapter 4 and Chapter 5 respectively, where only the case of a normal output response to price in the final goods is considered. To this point, flexible wages and full employment have been assumed. In Chapter 6, in order to be able to explore the unemployment issue, the model is extended to embody a binding minimumwage constraint and related properties are addressed. Chapter 7 and Chapter 8 examine the implications of free trade and international outsourcing respectively with a focus on employment. A brief conclusion follows in Chapter 9. 


\section{The Basic Model and Assumptions}

Assume a perfectly competitive economy in which firms maximize profits, which are driven to zero in equilibrium. Two primary factors, skilled labor $S$ and unskilled labor $L$, are used in the production of two commodities $X, Y$ and one pure intermediate good $Z$, which is produced solely to serve as an input in the final production of good $X$. The production of good $Z$ by a representative firm in that industry is assumed to depend on the inputs employed by that firm and to be positively related to the industry output level. Technology in industry $Z$ therefore exhibits IRS which is an industry-specific output generated external effect, and this effect is external to the individual firm while internal to the industry. Perfectly inelastic factor supplies, full employment, flexible factor prices as well as perfect factor mobility between industries but perfect immobility between countries are also assumed. The production functions of these three goods are

$$
\begin{aligned}
& X=F^{X}\left(S_{T}, L_{T}, Z\right), \\
& Z=F^{Z}\left(S_{Z}, L_{Z}, Z\right), \\
& Y=F^{Y}\left(S_{Y}, L_{Y}\right) .
\end{aligned}
$$

Here, $F^{Y}(\cdot)$ is strictly quasi-concave, positively linear homogeneous with positive marginal products of each input and satisfies the Inada conditions. The notation $\left(S_{Y}, L_{Y}\right)$ represents the skilled and unskilled labor used in the production of good $Y$, whereas $\left(S_{T}, L_{T}\right)$ and $\left(S_{Z}, L_{Z}\right)$ reflect particular characteristics of the production processes $F^{X}(\cdot)$ and $F^{Z}(\cdot)$ respectively, which we now investigate in more detail.

Consider the production of good $Z$ first. Here we capture the desired external economies outlined above by rewriting (2) as 


$$
Z=g(Z) z\left(S_{Z}, L_{Z}\right)
$$

where $z(\cdot)$ possesses all the properties described for function $F^{Y}(\cdot)$, and $\left(S_{Z}, L_{Z}\right)$ is the skilled and unskilled labor used in the production of good $Z$. The economies of scale $g(Z)>1$ have $\frac{d g(Z)}{d Z}>0$ that implies a positive elasticity $\varepsilon$ of the external effect, which is given by $\frac{d g(Z)}{d Z} \frac{Z}{g(Z)}$ and is assumed to be a constant. We assume that $\varepsilon<1$ which ensures that a higher output of good $Z$ requires more factors than a lower production level of that good.

The specification of the production technology for good $X$, which allows for the possibility of outsourcing part of the production process, is necessarily more complicated. Define $T\left(S_{T}, L_{T}\right)$ as a physical measure of the value-adding process used with intermediate good $Z$ to produce final good $X$. Given constant-returns-to-scale (CRS) production technology $T\left(S_{T}, L_{T}\right)$ is also strictly quasi-concave with positive marginal products of each input and satisfies the Inada conditions. Let the unit price of $T$ be $V$, which, by cost minimization, is equal to $a_{T S} W_{S}+a_{T L} W_{L}$. Here $a_{T i}, i=S, L$ denotes the quantity of each type labor required to produce one unit of $T$ and $W_{i}, i=S, L$ denotes the wage rate for respective factor. We assume that the production of good $X$ is a costless assembly process of the two intermediate inputs $T$ and $Z$, and uses them in fixed proportions. Without loss of generality, it is assumed that each unit of good $X$ requires one unit of $T$ and $1 / a$ unit of $Z{ }^{6}$ Therefore, the production function of $X$ can

\footnotetext{
${ }^{6}$ To keep the analysis tractable, we follow the standard literature--e.g. Batra and Casas (1973) and Deardorff (1988)--in assuming Leontief production technology using $T$ and $Z$ to produce final good $X$.
} 
be written as

$$
X=\min \left[T(\cdot), \frac{Z(\cdot)}{a}\right] \text {, }
$$

where $a$ represents the fixed Leontief input coefficient and is given by

$$
a=Z / X
$$

Therefore, one unit of good $X$ generates a gross revenue $P_{X}$ and a net value-added $V \equiv P_{X}-a P_{Z}$, where $P_{X}$ and $P_{Z}$ are the unit prices of $X$ and $Z$ respectively.

Of the three production activities, as long as good $Y$ is assumed to be the least skill intensive, then the ranking of skill intensity of $T$ and $Z$ will not affect any results of the mathematical derivations below. ${ }^{7}$ However, taking into account Porter's (1990) justification for the existence of output generated external effects in relative skilled-labor intensive industries, the ranking of skill intensity of these goods is therefore assumed to be $k_{Z}>k_{T}>k_{Y}$, where $k_{i} \equiv S_{i} / L_{i} ; i=Z, T, Y$. It is also assumed that factor intensity reversal does not occur and that the endowment ratio lies between the skill intensity of industries $Z$ and $Y$.

CRS production technology and perfect competition require that the prices of goods $X$ and $Y$ are equal to the average (unit) cost as reflected in (6.1) and (6.2). The assumption that the IRS is external to individual firms allows us to maintain the assumption of perfect competition, so that good $Z$ is still priced according to unit cost, which is shown in Appendix $A 1 .^{8}$ The unit cost of each good reflects market price as in

\footnotetext{
${ }^{7}$ If industry $Y$ is assumed to be the most skilled-labor intensive, then the technical properties derived in Chapter 3 will be quite different. In the open economy situation, home will not outsource $T$ because now it costs less to produce at home.

${ }^{8}$ See Helpman (1985).
} 
$(6.1)-(6.3)$ :

$$
\begin{aligned}
& a_{T S} W_{S}+a_{T L} W_{L}+a P_{Z}=P_{X}, \\
& a_{Y S} W_{S}+a_{Y L} W_{L}=P_{Y}, \\
& a_{z S} W_{S}+a_{z L} W_{L}=P_{Z} g(Z),
\end{aligned}
$$

where $a_{i j}$ denotes the quantity of factor $j(=S, L)$ required to produce a unit of good $i(=z, T, Y)$. Using Lerner diagram to describe $(6.1)-(6.3)$, the only difference, in contrast to the standard CRS case would be that, instead of price $P_{Z}, P_{Z} g(Z)$ is the true price for the factor index $z\left(S_{Z}, L_{Z}\right)$ in industry $Z$. Thus, the dollar's-worth isoquants of $z, T$ and $Y$ correspond to output quantities $1 / P_{Z} g(Z), 1 / V$ and $1 / P_{Y}$ respectively as illustrated in Figure 1. Here $\omega$ denotes the wage ratio in terms of unskilled labor, which is $W_{S} / W_{L}$.

Full employment conditions are specified in (7.1) and (7.2) to complete the production side of the model.

$$
\begin{aligned}
& S_{T}+S_{Z}+S_{Y}=a_{T S} T+a_{z S} z+a_{Y S} Y=\bar{S}, \\
& L_{T}+L_{Z}+L_{Y}=a_{T L} T+a_{z L} z+a_{Y Z} Y=\bar{L} .
\end{aligned}
$$


Figure 1: Lerner Diagram: Modified for the Presence of an Externality

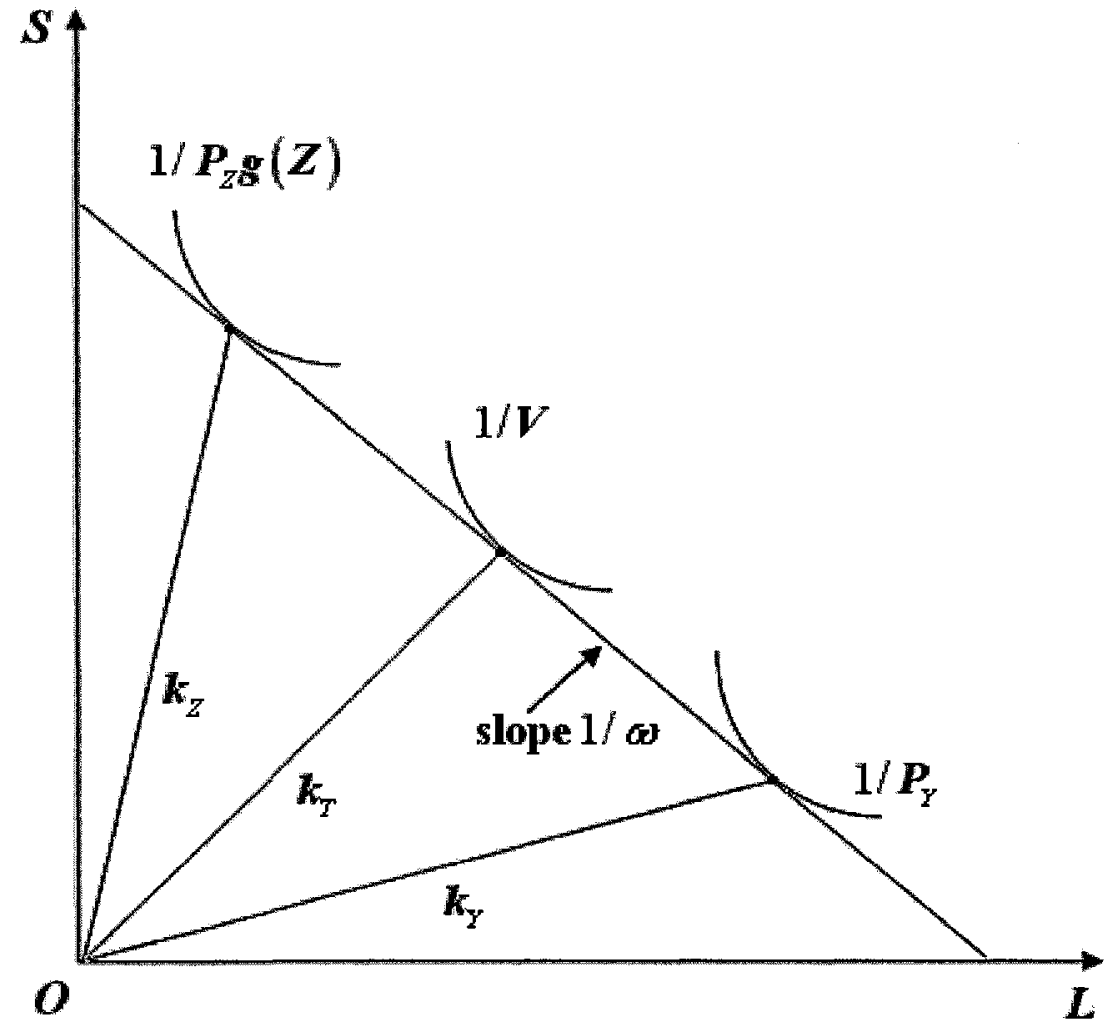




\section{Some Properties of the Model}

\subsection{The Slope of the Production-Possibility Frontier (PPF)}

It was first shown by Vanek (1963) that the slope of the net transformation curve equals minus the commodity-price ratio when some of the final products also serve as intermediate goods. Batra and Casas (1973) also show that this result holds when there is a pure intermediate good which exhibits CRS and is not identical with the final goods. However, in the present model with the pure intermediate good having an outputgenerated external effect, this would no longer be true. The non-tangency between the price line and the PPF due to VRS technologies associated with external economies of scale was originally addressed by Kemp (1964, Ch8; 1969, Ch8).

The locus of the PPF is determined by maximizing the output of one good subject to production technologies and endowments, while holding the output of the other good constant. Therefore, the optimization problem can be written as

$$
\begin{aligned}
\max _{L_{Y}, L_{T}, S_{Y}, S_{T}, Z} F^{Y}\left(S_{Y}, L_{Y}\right) \quad \text { subject to } \\
X=\bar{X} \\
X=T\left(S_{T}, L_{T}\right) \\
Z=a X \\
Z=g(Z) z\left(S_{Z}, L_{Z}\right), \\
S=S_{T}+S_{Z}+S_{Y}, \\
L=L_{T}+L_{Z}+L_{Y} .
\end{aligned}
$$

Constraints (8.2) and (8.3) restate the fixed-proportion relationships of the Leontief technology for production of good $X$ as described by (4). Equation (8.4) rewrite the production function of $\operatorname{good} Z$ as in $(2.1)$ and the last two equations are the full 
employment conditions for $S$ and $L$. Following this, the Lagrangian function is as follows

$$
\begin{aligned}
L= & F^{Y}\left(S_{Y}, L_{Y}\right)+\gamma\left[\bar{X}-T\left(S_{T}, L_{T}\right)\right] \\
& +\psi\left[Z-g(Z) z\left(S-S_{T}-S_{Y}, L-L_{T}-L_{Y}\right)\right]+\xi\left[Z-a T\left(S_{T}, L_{T}\right)\right] .
\end{aligned}
$$

It is shown in Appendix $A 2$ that the slope of the PPF can be derived from this maximization process and is given by

$$
\frac{d Y}{d X}=-\left(\frac{F_{L}^{Y}}{T_{L}}+\frac{F_{L}^{Y} a\left[1-g^{\prime}(Z) z\right]}{g(Z) z_{L}}\right) .
$$

Here $F_{L}^{Y}$ denotes the marginal product of unskilled labor in the production of good $Y$, while the remaining terms $T_{L}$ and $z_{L}$ are defined in the same manner and represent the partial derivatives of $T(\cdot)$ and $z(\cdot)$ with respect to $L$ respectively. Profit maximization requires equality between the value of the private marginal product and the return to that factor, which yields the following equations:

$$
\begin{aligned}
& V T_{L}=W_{L}, \\
& P_{Z} g(Z) z_{L}=W_{L}, \\
& P_{Y} F_{L}^{Y}=W_{L} .
\end{aligned}
$$

Substituting (10), (2.1) and (5) into (9), it is easily derived that

$$
\frac{d Y}{d X}=-\left(\frac{P_{X}}{P_{Y}}-a \varepsilon \frac{P_{Z}}{P_{Y}}\right)
$$

Given that $\varepsilon>0$, equation (11) indicates that the slope of the PPF at a particular point is less in absolute value than the associated price ratio, which implies that the price line should be steeper than the PPF if good $X$ is measured on the horizontal axis while good $Y$ is measured on the vertical axis. This reflects the fact that an expansion of a firm in 
industry $Z$ generates a positive externality on other firms in that industry, so that the private (firm-level) marginal product of each factor is smaller than the social (industrylevel) marginal product. From the viewpoint of socially optimal endowment allocations, this deviation leads to under-employment of factors in industry $Z$, as well as in industry $X$ because of the fixed-proportion relationship.

When the price line is tangent to the PPF, the curvature of the PPF can be inferred from the output response to price. That is to say, the PPF is locally strictly concave or convex to the origin as the output response to price is normal or perverse. However, whenever a non-tangency occurs, this argument does not necessarily hold any longer. We will revisit this curvature issue in section 3.5 .

\subsection{Basic Relationships}

Totally differentiating $(7.1),(7.2)$ and $(6.1)-(6.3)$, and making appropriate substitutions, we obtain the following equations which are central to the subsequent analysis: ${ }^{9}$

$$
\begin{aligned}
& {\left[\lambda_{T S}+\lambda_{Z S}(1-\varepsilon)\right] \hat{X}+\lambda_{Y S} \hat{Y}=\hat{S}+R_{S}\left(\hat{W}_{S}-\hat{W}_{L}\right),} \\
& {\left[\lambda_{T L}+\lambda_{Z L}(1-\varepsilon)\right] \hat{X}+\lambda_{Y L} \hat{Y}=\hat{L}-R_{L}\left(\hat{W}_{S}-\hat{W}_{L}\right),} \\
& \theta_{T S} \hat{W}_{S}+\theta_{T L} \hat{W}_{L}+\theta_{X Z} \hat{P}_{Z}=\hat{P}_{X}, \\
& \theta_{Y S} \hat{W}_{S}+\theta_{Y L} \hat{W}_{L}=\hat{P}_{Y}, \\
& \theta_{Z S} \hat{W}_{S}+\theta_{Z L} \hat{W}_{L}-\hat{P}_{Z}=\hat{z} \varepsilon /(1-\varepsilon) .
\end{aligned}
$$

Here, $R_{S} \equiv \lambda_{T S} \frac{P_{X} \theta_{T L} \sigma_{T}}{V}+\lambda_{Z S} \theta_{Z L} \sigma_{Z}+\lambda_{Y S} \theta_{Y L} \sigma_{Y}, R_{L} \equiv \lambda_{T L} \frac{P_{X} \theta_{T S} \sigma_{T}}{V}+\lambda_{Z L} \theta_{Z S} \sigma_{Z}+\lambda_{Y L} \theta_{Y S} \sigma_{Y}$ and $\sigma_{i}$ is the elasticity of substitution between skilled labor and unskilled labor in production

\footnotetext{
${ }^{9}$ See Appendix $A 3$ for the mathematical derivations of equations (12.1)-(12.5).
} 
$i(=Z, T, Y)$. The "hat" notation denotes the proportionate change of a variable, so that $\hat{X}=d X / X$ and $\hat{P}=d P / P$. Since $\omega$ is defined as the wage ratio in terms of unskilled labor, it follows that $\hat{\omega}=\hat{W}_{S}-\hat{W}_{L}$. The coefficient $R_{S}$ is the aggregate percentage saving in skilled labor with a one percent rise in the relative wage ratio at unchanged output levels, while $R_{L}$ in $(12.2)$ is defined similarly. When $\omega$ increases, $R_{S}$ measures the saving from the adjustment to a less skilled-labor intensive technique in both industries. Coefficient $\lambda_{i j}$ denotes the fraction of factor $j$ employed in industry $i$ while $\theta_{i j}$ refers to factor $j$ 's distributive share in industry $i .{ }^{10}$ Equations $(12.1)-(12.5)$ simply generalize Jones's (1968) algebra to allow for intermediate goods. Moreover, this system of equations would collapse to those equations in Jones (1965) if we set $\varepsilon=0$ and drop the intermediate good $Z$.

Note that the term on the right-hand side of (12.5) would disappear if there is no externality in industry $Z$ and taking $\varepsilon=0$ we can simply solve for $\hat{P}_{Z}$. By substitution of $\hat{P}_{Z}$ into $(12.3)$, equations $(12.3)$ and $(12.4)$ now constitute a system relating factor returns and commodity prices which indicates that factor returns are uniquely determined by commodity prices even in the presence of the intermediate good. This is well known as Samuelson's one-to-one correspondence. However, given that $\varepsilon>0$ in the present model, this simple relationship no longer holds. As $z$ would appear in (12.3), in addition to the effect of commodity prices, the wage rates are also dependent on the external effect and the output level of good $Z$. Similarly, the externality also influences the ${ }^{10}$ For example, $\lambda_{T S} \equiv \frac{a_{T S} T}{S}, \theta_{Z S} \equiv \frac{a_{Z S} W_{S}}{P_{Z} g(Z)}$. 
$\lambda$-weighted equations (12.1) and (12.2) through term $\varepsilon$. Therefore, the basic duality feature of CRS technologies is no longer assured.

We shall now take the analysis a further step by considering whether the StolperSamuelson and Rybczynski Theorems hold within our more general model.

\subsection{The Stolper-Samuelson Theorem}

Under CRS technologies the relationship between commodity prices and factor returns is summarized by the Stolper-Samuelson Theorem, which states that a rise in the price of a commodity raises the relative and absolute (real) return to the factor used more intensively in the production of that good while lowering the absolute reward of the other factor. However, this relationship does not necessarily hold in the present model. This is addressed in detail as follows.

First, substituting the fixed endowments condition $\hat{S}=\hat{L}=0$ into (12.1) and (12.2), we can derive

$$
\begin{aligned}
& \hat{X}=\frac{\mu_{X}}{|\lambda|}\left(\hat{W}_{S}-\hat{W}_{L}\right), \\
& \hat{Y}=-\frac{\mu_{Y}}{|\lambda|}\left(\hat{W}_{S}-\hat{W}_{L}\right) .
\end{aligned}
$$

Here $\mu_{X} \equiv R_{S} \lambda_{Y L}+R_{L} \lambda_{Y S}, \mu_{Y} \equiv R_{L}\left(\lambda_{T S}+\lambda_{Z S}(1-\varepsilon)\right)+R_{S}\left(\lambda_{T L}+\lambda_{Z L}(1-\varepsilon)\right)$ and both terms are positive. Coefficient $|\lambda|$, the determinant of $\lambda_{i j}$ in (12.1) and (12.2), is given by $\left(\lambda_{T S} \lambda_{Y L}-\lambda_{T L} \lambda_{Y S}\right)+(1-\varepsilon)\left(\lambda_{Z S} \lambda_{Y L}-\lambda_{Z L} \lambda_{Y S}\right)$. Recalling that the ranking of the skillintensity is assumed to be $k_{Z}>k_{T}>k_{Y}$, it is straightforward to show that $|\lambda|>0$. In addition, we can obtain the following equation derived from $\left(A 3.3^{\prime}\right)$ and $\left(A 3.4^{\prime}\right)$ in 
Appendix $A 3$ :

$$
\hat{z}=(1-\varepsilon) \hat{X}
$$

Using (14) we rewrite (13.1) as

$$
\frac{\varepsilon}{1-\varepsilon} \hat{z}=\frac{\varepsilon \mu_{X}}{|\lambda|}\left(\hat{W}_{S}-\hat{W}_{L}\right)
$$

Substituting (15) into (12.5) and solving for $\hat{P}_{Z}$ yields

$$
\hat{P}_{Z}=\left(\theta_{Z S}-\frac{\varepsilon \mu_{X}}{|\lambda|}\right) \hat{W}_{S}+\left(\theta_{Z L}+\frac{\varepsilon \mu_{X}}{|\lambda|}\right) \hat{W}_{L}
$$

Then substituting $\hat{P}_{Z}$ into (12.3), we can now rewrite (12.3) and (12.4) in the following manner:

$$
\begin{gathered}
\theta_{X S}^{\prime} \hat{W}_{S}+\theta_{X L}^{\prime} \hat{W}_{L}=\hat{P}_{X}, \\
\theta_{Y S}^{\prime} \hat{W}_{S}+\theta_{Y L}^{\prime} \hat{W}_{L}=\hat{P}_{Y} .
\end{gathered}
$$

Here we define $\boldsymbol{\theta}^{\prime}$ as the two-by-two matrix:

$$
\boldsymbol{\theta}^{\prime} \equiv\left(\begin{array}{cc}
\theta_{X S}^{\prime} & \theta_{X L}^{\prime} \\
\theta_{Y S}^{\prime} & \theta_{Y L}^{\prime}
\end{array}\right) \equiv\left(\begin{array}{c}
\theta_{T S}+\theta_{X Z}\left(\theta_{Z S}-\frac{\varepsilon \mu_{X}}{|\lambda|}\right) \\
\theta_{Y S}+\theta_{X Z}\left(\theta_{Z L}+\frac{\varepsilon \mu_{X}}{|\lambda|}\right) \\
\theta_{Y L}
\end{array}\right) .
$$

If every industry exhibits CRS, each $\theta_{i j}^{\prime}(i=X, Y ; j=S, L)$ is positive reflecting the positive effect of a one percent rise in factor $j$ 's price on the average cost (unit price) of producing commodity $i$. However, with the externality in industry $Z$, the situation is not so straightforward. From inspection of the elements of $\boldsymbol{\theta}^{\prime}$, we can see that in addition to the direct effect of a change in factor prices on the unit cost, there is an additional indirect effect due to the externality, captured by the term $\varepsilon \mu_{X} /|\lambda|$ in coefficients $\theta_{X S}^{\prime}$ and $\theta_{X L}^{\prime}$. 
Both coefficients are only related to good $X$, which uses the IRS intermediate good as a production component. This is because changes in factor prices induce a change in the skill-intensity of each industry which would affect the composition of outputs in a fullemployment model. However, due to the externality and in contrast to the standard CRS model, any change in output of good $Z(X)$ here has a further impact on unit cost.

Given that $\varepsilon \mu_{X} /|\lambda|$ is positive, the sign of $\theta_{X S}^{\prime}$ is therefore ambiguous whereas the signs of all other $\theta_{i j}^{\prime} s$ are clearly positive. In the event that $\theta_{X S}^{\prime}$ is negative, this would imply that the external effect is so great as to outweigh the direct effect of a change in $W_{S}$ on the unit cost of producing good $X$. Solving (17.1) and (17.2) for $\hat{W}_{S}$ and $\hat{W}_{L}$, we obtain

$$
\begin{aligned}
& \hat{W}_{S}=\frac{\theta_{Y L}^{\prime} \hat{P}_{X}-\theta_{X L}^{\prime} \hat{P}_{Y}}{\left|\theta^{\prime}\right|}, \\
& \hat{W}_{L}=\frac{-\theta_{Y S}^{\prime} \hat{P}_{X}+\theta_{X S}^{\prime} \hat{P}_{Y}}{\left|\theta^{\prime}\right|},
\end{aligned}
$$

where $\left|\theta^{\prime}\right|$ denotes the determinant of matrix $\boldsymbol{\theta}^{\prime}$ and is given by

$$
\left|\theta^{\prime}\right| \equiv\left(\theta_{T S} \theta_{Y L}-\theta_{T L} \theta_{Y S}\right)+\theta_{X Z}\left(\theta_{Z S} \theta_{Y L}-\theta_{Z L} \theta_{Y S}\right)-\theta_{X Z} \frac{\varepsilon \mu_{X}}{|\lambda|}
$$

Bearing in mind that factor shares must sum to unity, we may rearrange terms in (19) in the following alternative ways:

$$
\begin{aligned}
& \left|\theta^{\prime}\right|=\theta_{T S}+\theta_{X Z} \theta_{Z S}-\theta_{Y S}-\theta_{X Z} \frac{\varepsilon \mu_{X}}{|\lambda|}, \\
& \left|\theta^{\prime}\right|=\theta_{Y L}-\theta_{X Z} \theta_{Z L}-\theta_{T L}-\theta_{X Z} \frac{\varepsilon \mu_{X}}{|\lambda|} .
\end{aligned}
$$


With respect to (19) we already know that $\theta_{X Z} \frac{\varepsilon \mu_{X}}{|\lambda|}$ is positive and given the ranking of the skill-intensity, the first two terms $\left(\theta_{T S} \theta_{Y L}-\theta_{T L} \theta_{Y S}\right)$ and $\theta_{X Z}\left(\theta_{Z S} \theta_{Y L}-\theta_{Z L} \theta_{Y S}\right)$ are also positive. Because of the negative sign preceding the final term, the sign of $\left|\theta^{\prime}\right|$ is therefore ambiguous. Here, we exclude the case of $\left|\theta^{\prime}\right|=0$ which would result in both $\hat{W}_{S}$ and $\hat{W}_{L}$ being undefined in (18.1) and (18.2) respectively. By way of interest, the case $\left|\theta^{\prime}\right|=0$ would imply the situation where the effect of a percentage change in the wage ratio $\omega$ has no effect on the relative commodity price.

Define $P$ as the relative price of $\operatorname{good} X$ in terms of $\operatorname{good} Y$, therefore we have $\hat{P}=\hat{P}_{X}-\hat{P}_{Y}$. Using (19.1) and (19.2), we can derive the following equations from (18.1) and (18.2), which describe the change in the real return of each factor and the change in the wage ratio $\omega$ respectively as the commodity price ratio changes:

$$
\begin{aligned}
& \widehat{\left(\frac{W_{S}}{P_{X}}\right)}=\hat{W}_{S}-\hat{P}_{X}=\frac{\theta_{X L}^{\prime}}{\left|\theta^{\prime}\right|}\left(\hat{P}_{X}-\hat{P}_{Y}\right)=\frac{\theta_{X L}^{\prime}}{\left|\theta^{\prime}\right|} \hat{P}, \\
& \widehat{\left(\frac{W_{S}}{P_{Y}}\right)}=\hat{W}_{S}-\hat{P}_{Y}=\frac{\theta_{Y L}^{\prime}}{\left|\theta^{\prime}\right|}\left(\hat{P}_{X}-\hat{P}_{Y}\right)=\frac{\theta_{Y L}^{\prime}}{\left|\theta^{\prime}\right|} \hat{P}, \\
& \widehat{\left(\frac{W_{L}}{P_{X}}\right)}=\hat{W}_{L}-\hat{P}_{X}=-\frac{\theta_{X S}^{\prime}}{\left|\theta^{\prime}\right|}\left(\hat{P}_{X}-\hat{P}_{Y}\right)=-\frac{\theta_{X S}^{\prime}}{\left|\theta^{\prime}\right|} \hat{P}, \\
& \widehat{\left(\frac{W_{L}}{P_{Y}}\right)}=\hat{W}_{S}-\hat{P}_{Y}=-\frac{\theta_{Y S}^{\prime}}{\left|\theta^{\prime}\right|}\left(\hat{P}_{X}-\hat{P}_{Y}\right)=-\frac{\theta_{Y S}^{\prime}}{\left|\theta^{\prime}\right|} \hat{P}, \\
& \hat{\omega}=\hat{W}_{S}-\hat{W}_{L}=\frac{1}{\left|\theta^{\prime}\right|}\left(\hat{P}_{X}-\hat{P}_{Y}\right)=\frac{1}{\left|\theta^{\prime}\right|} \hat{P} .
\end{aligned}
$$

It is known from the discussion above that $\theta_{X L}^{\prime}, \theta_{Y S}^{\prime}$ and $\theta_{Y L}^{\prime}$ are positive whereas the 
signs of $\theta_{X S}^{\prime}$ and $\left|\theta^{\prime}\right|$ are uncertain. From inspection of the elements of $\boldsymbol{\theta}^{\prime}$, it is clear that $\theta_{X S}^{\prime}>\left|\theta^{\prime}\right|$, leading to the following possibilities.

Case 1: $\theta_{X S}^{\prime}>\left|\theta^{\prime}\right|>0$

If the commodity price ratio $P$ increases, both the real return (in terms of either good) and the relative return to skilled labor will increase, whereas the real return and relative return to unskilled labor will fall. The Stolper-Samuelson Theorem holds in this case.

Case 2: $\theta_{X S}^{\prime}>0>\left|\theta^{\prime}\right|$

In this case if the commodity price ratio $P$ increases, the real return to skilled labor and the relative wage $\omega$ will decline, whereas the real return to unskilled labor will rise. This implies that the Stolper-Samuelson Theorem is reversed.

Case 3: $0>\theta_{X S}^{\prime}>\left|\theta^{\prime}\right|$

In case 3 , with the exception of the term $\widehat{\left(\frac{W_{L}}{P_{X}}\right)}$, all other terms follow the conclusions obtained in case 2 . Here, the real return of one factor does not necessarily change in the same direction as the relative return of that factor whenever there is a change in the price ratio. For example, an increase in the commodity price ratio $P$ lowers the real return to unskilled labor in terms of good $X$ but raise the relative return in terms of skilled labor.

The above discussion implies that the condition $\left|\theta^{\prime}\right|>0$ is necessary and sufficient for validity of the Stolper-Samuelson Theorem. Insight into these possibilities may also 
be easily explained by reference to the Lerner diagram. Recall that $P_{X}=V+a P_{Z}$ and total differentiating this equation with respect to $\omega$ yields

$$
\frac{d P_{X}}{d \omega}=\frac{d V}{d \omega}+a \frac{d P_{Z}}{d \omega}
$$

The fact that an increase in wage ratio $\omega$ raises price $V\left(\frac{d V}{d \omega}>0\right)$ cannot ensure a positive $\frac{d P_{X}}{d \omega}$ because the sign of $\frac{d P_{Z}}{d \omega}$ is indeterminate due to the externality. To see why this indeterminacy arises, we use the following expression from Komiya (1967):

$$
\frac{d\left(P_{Z} g(Z)\right)}{d V}=\frac{f_{T}}{f_{Z}} \cdot \frac{\left(k_{Z}-k_{Y}\right)}{\left(k_{T}-k_{Y}\right)}
$$

where $f_{Z}(\cdot) \equiv z\left(1, \frac{S_{Z}}{L_{Z}}\right), f_{T}(\cdot) \equiv T\left(1, \frac{S_{T}}{L_{T}}\right)$. The right-hand side of $(22)$ is positive because good $Y$ has been assumed to be the least skilled-labor intensive. Rearranging terms we may rewrite $(22)$ as

$$
\frac{d P_{Z}}{d V}=\frac{1}{g(Z)}\left(\frac{f_{T}}{f_{Z}} \cdot \frac{\left(k_{Z}-k_{Y}\right)}{\left(k_{T}-k_{Y}\right)}-P_{Z} \frac{d g(Z)}{d Z} \frac{d Z}{d V}\right)
$$

The sign of $\frac{d Z}{d V}$, as with the sign of $\frac{d T}{d V}$, is positive due to the Leontief production technology. ${ }^{11}$ The term $P_{Z} \frac{d g(Z)}{d Z} \frac{d Z}{d V}$ incorporating the external effect is also positive and therefore acts in opposition to the original effect on $P_{Z}$ identified by Komiya of a

\footnotetext{
${ }^{11}$ See Appendix $A 4$ for the mathematical proof. The intuition for this is straightforward. Given the CRS production technology the output of $T$ is positively related to the price $V$. The output of good $Z$ must also change whenever $T$ changes because of the fixed proportion relationship.
} 
change in factor prices. The sign of $\frac{d P_{Z}}{d V}$ is therefore ambiguous depending on which term in the bracket dominates. Simple manipulation of (21) yields

$$
\frac{d P_{X}}{d \omega}=\frac{d V}{d \omega}\left(1+a \frac{d P_{Z}}{d V}\right)
$$

which indicates that the sign of $\frac{d P_{X}}{d \omega}$ is uncertain given that $\frac{d V}{d \omega}$ is positive and the sign of $\frac{d P_{Z}}{d V}$ is ambiguous.

\subsection{The Rybczynski Theorem}

In the standard trade model, the effects of a change in factor supply on commodity outputs at constant factor prices are the same as the effects at constant commodity prices, where the latter case is referred to as the Rybczynski Theorem. This equivalence is because Samuelson's one-to-one correspondence principle holds with CRS technologies. However, as shown in the previous section, the Stolper-Samuelson Theorem may now fail and a particular commodity price ratio may be associated with more than one factor price ratio. In this situation, the choice of which price ratio is held constant does matter.

Before we proceed to examine the validity of the Rybczynski Theorem in the present model, it is of interest to explore the different responses to a change in factor supply when different price set is assumed to be constant. As a preliminary step, we consider the effects of a change in the endowments at constant factor prices. Setting $\hat{W}_{S}=\hat{W}_{L}=0$, we can rewrite (12.1) and (12.2) as 


$$
\begin{aligned}
& \lambda_{X S} \hat{X}+\lambda_{Y S} \hat{Y}=\hat{S}, \\
& \lambda_{X L} \hat{X}+\lambda_{Y L} \hat{Y}=\hat{L} .
\end{aligned}
$$

Here, we define $\lambda$ as the two-by-two matrix:

$$
\lambda \equiv\left(\begin{array}{cc}
\lambda_{X S} & \lambda_{Y S} \\
\lambda_{X L} & \lambda_{Y L}
\end{array}\right) \equiv\left(\begin{array}{cc}
\lambda_{T S}+\lambda_{Z S}(1-\varepsilon) & \lambda_{Y S} \\
\lambda_{T L}+\lambda_{Z L}(1-\varepsilon) & \lambda_{Y L}
\end{array}\right) .
$$

It has already been shown that the determinant $|\lambda|$ is positive and given that $0<\varepsilon<1$, each coefficient $\lambda_{i j}(i=X, Y ; j=S, L)$ must also be positive. This implies that no factor is "inferior" at constant factor prices because an expansion of any good requires an increasing demand for both factors. Solving $\left(12.1^{\prime}\right)$ and $\left(12.2^{\prime}\right)$ for $\hat{X}$ and $\hat{Y}$, we obtain

$$
\begin{aligned}
& \hat{X}=\frac{\lambda_{Y S} \hat{S}-\lambda_{Y S} \hat{L}}{|\lambda|} . \\
& \hat{Y}=\frac{\left[\lambda_{T S}+\lambda_{Z S}(1-\varepsilon)\right] \hat{L}-\left[\lambda_{T L}+\lambda_{Z L}(1-\varepsilon)\right] \hat{S}}{|\lambda|} .
\end{aligned}
$$

Equations (23.1) and (23.2) clearly demonstrates that the effects on commodity outputs of a change in factor supply at constant factor prices are normal as in the traditional trade model. It follows that an increase in the supply of skilled labor raises the output of good $X$ which intensively uses skilled labor, but decreases the output of good $Y$.

The Rybczynski Theorem states that, given constant commodity prices, an increase in the supply of a factor results in an expansion of the industry which uses that factor more intensively and a contraction of the other industry. In contrast to the above case we will now show how the externality generates different results for this situation where the commodity prices are held constant. Setting $\hat{P}_{X}=\hat{P}_{Y}=0$ and using (16), we rewrite 
(12.3) and (12.4) as

$$
\begin{aligned}
& \left(\theta_{T S}+\theta_{X Z} \theta_{Z S}\right) \hat{W}_{S}+\left(\theta_{T L}+\theta_{X Z} \theta_{Z L}\right) \hat{W}_{L}=\theta_{X Z} \varepsilon \hat{X}, \\
& \theta_{Y S} \hat{W}_{S}+\theta_{Y L} \hat{W}_{L}=0 .
\end{aligned}
$$

Solving for $\hat{W}_{S}$ and $\hat{W}_{L}$, we obtain:

$$
\hat{W}_{S}-\hat{W}_{L}=\theta_{X Z} \frac{\varepsilon \hat{X}}{|\theta|}
$$

where the determinant $|\theta|$ is positive and is defined as

$$
|\theta| \equiv\left(\theta_{T S} \theta_{Y L}-\theta_{T L} \theta_{Y S}\right)+\theta_{X Z}\left(\theta_{Z S} \theta_{Y L}-\theta_{Z L} \theta_{Y S}\right)
$$

By inspection of (19) and (26), we have the following relationship:

$$
|\theta|=\left|\theta^{\prime}\right|+\theta_{X Z} \frac{\varepsilon \mu_{X}}{|\lambda|}
$$

Substituting (25) into (12.1) and (12.2) yields:

$$
\begin{aligned}
& \lambda_{X S}^{\prime} \hat{X}+\lambda_{Y S}^{\prime} \hat{Y}=\hat{S}, \\
& \lambda_{X L}^{\prime} \hat{X}+\lambda_{Y L}^{\prime} \hat{Y}=\hat{L} .
\end{aligned}
$$

Here, we define $\lambda^{\prime}$ as the two-by-two matrix:

$$
\lambda^{\prime} \equiv\left(\begin{array}{ll}
\lambda_{X S}^{\prime} & \lambda_{Y S}^{\prime} \\
\lambda_{X L}^{\prime} & \lambda_{Y L}^{\prime}
\end{array}\right) \equiv\left(\begin{array}{ll}
\lambda_{T S}+\lambda_{Z S}(1-\varepsilon)-R_{S} \frac{\theta_{X Z} \varepsilon}{|\theta|} & \lambda_{Y S} \\
\lambda_{T L}+\lambda_{Z L}(1-\varepsilon)+R_{L} \frac{\theta_{X Z} \varepsilon}{|\theta|} & \lambda_{Y L}
\end{array}\right) .
$$

Each coefficient $\lambda_{i j}^{\prime}(i=X, Y ; j=S, L)$ represents the change in demand for factor $j$ due to an expansion in industry $i$ at the constant commodity prices. Due to the externality, holding commodity prices constant here does not necessarily ensure the factor prices to be constant. Any output change of good $X$ has a direct impact on factor prices through 
the external effect, which leads to changes in the skill-intensity of each industry and the composition of outputs. In the absence of any other effects, a change in the composition of outputs will in turn affect the factor returns. In order to maintain constant commodity prices, there must in general be a compensating change in factor returns to offset the initial external effect of output change on commodity prices.

Inspecting matrix $\lambda^{\prime}$, it is straightforward that $\lambda_{X L}^{\prime}, \lambda_{Y S}^{\prime}$ and $\lambda_{Y L}^{\prime}$ are positive which have the normal explanations as in the standard model, whereas the sign of $\lambda_{X S}^{\prime}$ is uncertain. In the event that $\lambda_{X S}^{\prime}$ is negative, this would imply that the external effect of an increase in output of $X(Z)$ on unit cost is so strong as to require that the change in factor returns releases even more skilled labor in industry $X$ in order to keep constant commodity prices. The consequence is that an expansion of good $X$ needs less skilled labor, intensively used in that industry. Solving (27.1) and (27.2) for $\hat{X}$ and $\hat{Y}$, we obtain

$$
\begin{aligned}
& \hat{X}=\frac{\lambda_{Y}^{\prime} \hat{S}-\lambda_{Y S}^{\prime} \hat{L}}{\left|\lambda^{\prime}\right|}, \\
& \hat{Y}=\frac{\lambda_{X S}^{\prime} \hat{L}-\lambda_{X L}^{\prime} \hat{S}}{\left|\lambda^{\prime}\right|},
\end{aligned}
$$

where $\left|\lambda^{\prime}\right|$ denotes the determinant of matrix $\lambda^{\prime}$ and is given as follows:

$$
\begin{aligned}
& \left|\lambda^{\prime}\right| \equiv\left(\lambda_{T S} \lambda_{Y L}-\lambda_{T L} \lambda_{Y S}\right)+(1-\varepsilon)\left(\lambda_{Z S} \lambda_{Y L}-\lambda_{Z L} \lambda_{Y S}\right)-\theta_{X Z} \frac{\varepsilon \mu_{X}}{|\theta|} \\
& \left|\lambda^{\prime}\right|=|\lambda|-\theta_{X Z} \frac{\varepsilon \mu_{X}}{|\theta|}
\end{aligned}
$$

Using (26.1), we may rewrite $\left|\lambda^{\prime}\right|$ more compactly as: 


$$
\left|\lambda^{\prime}\right|=\frac{|\lambda|\left|\theta^{\prime}\right|}{|\theta|}
$$

Recall that both $|\lambda|$ and $|\theta|$ are positive, the sign of $\left|\lambda^{\prime}\right|$ will be determined by the sign of $\left|\theta^{\prime}\right|$. The value of the determinant $\left|\lambda^{\prime}\right|$ must be non-zero since the case of $\left|\theta^{\prime}\right|=0$ was excluded in the previous section. Therefore, in contrast to the standard model, the validity of the Rybczynski Theorem here depends on the signs of $\lambda_{X S}^{\prime}$ and $\left|\lambda^{\prime}\right|$. From inspection of the elements of $\lambda^{\prime}$ it is clear that $\lambda_{X S}^{\prime}>\left|\lambda^{\prime}\right|$, which leads to the following possibilities.

Case 1: $\left|\theta^{\prime}\right|>0 \Rightarrow\left|\lambda^{\prime}\right|>0$ and $\left|\lambda_{X S}^{\prime}\right|>0$

Equations (28.1) and (28.2) demonstrate that an increase in the supply of skilled labor while holding the supply of the other factor fixed $(\hat{S}>0, \hat{L}=0)$ leads to an expansion in industry $X$ and a contraction in industry $Y$. On the other hand, if there is an increase in the supply of unskilled labor $(\hat{S}=0, \hat{L}>0)$, then the reverse results will occur. In this case, the Rybczynski Theorem holds.

Case 2: $\left|\theta^{\prime}\right|<0 \Rightarrow\left|\lambda^{\prime}\right|<0$ and $\left|\lambda_{x S}^{\prime}\right|>0$

In this case, there will be an expansion in industry $Y$ and a contraction in industry $X$ if there is an increase in the supply of skilled labor $(\hat{S}>0, \hat{L}=0)$. An increase in the supply of unskilled labor $(\hat{S}=0, \hat{L}>0)$ would raise the output of good $X$ and decrease the output of good $Y$. This implies that the Rybczynski Theorem is reversed.

Case 3: $\left|\theta^{\prime}\right|<0 \Rightarrow\left|\lambda^{\prime}\right|<0$ and $\left|\lambda_{X S}^{\prime}\right|<0$ 
The change in factor supplies has asymmetric impacts on the production of each good in this case. An increase in the supply of skilled labor $(\hat{S}>0, \hat{L}=0)$ yields a reversed Rybczynski effect as in case 2 , where the output of good $X$ declines and the output of good $Y$ increases. However, an increase in the supply of unskilled labor $(\hat{S}=0, \hat{L}>0)$ leads to an expansion in both industries $X$ and $Y$ where the Rybczynski theorem holds for good $Y$ but fails for good $X$.

The above discussion shows that a positive sign of $\left|\lambda^{\prime}\right|$, which requires that $\left|\theta^{\prime}\right|>0$, is necessary and sufficient for validity of the Rybczynski Theorem. Which of the above cases occurs depends mainly on the strength of the external effect, the proportion coefficient $a$ and the skill- intensity in each industry.

\subsection{The Output Response to Price and the Curvature of the PPF}

In this section we will first show that the output response to price of the final goods is normal if and only if the condition $\left|\theta^{\prime}\right|>0$ is satisfied. Second, we will show that a normal output response to price of the final goods is only a sufficient condition for concavity of the PPF.

Taking good $Y$ as numeraire to set $P_{Y}=1$ and $\hat{P}_{Y}=0$, then $P_{X}$ and $P_{Z}$ equal the relative prices of goods $X$ and $Z$ in terms of good $Y$ respectively. Following this, we can rewrite (18.1) and (18.2) as follows: 


$$
\begin{aligned}
& \hat{W}_{S}=\frac{\theta_{Y L}^{\prime} \hat{P}_{X}}{\left|\theta^{\prime}\right|}, \\
& \hat{W}_{L}=-\frac{\theta_{Y S}^{\prime} \hat{P}_{X}}{\left|\theta^{\prime}\right|} .
\end{aligned}
$$

Substituting $\hat{W}_{S}$ and $\hat{W}_{L}$ into (13.1) and rearranging terms, we have

$$
\begin{aligned}
& \hat{P}_{X}=\frac{|\lambda|\left|\theta^{\prime}\right|}{\mu_{X}} \hat{X}, \\
& \hat{P}_{X}=\frac{1}{\mu_{X}}\left(|\lambda||\theta|-\theta_{X Z} \varepsilon \mu_{X}\right) \hat{X},
\end{aligned}
$$

where $\left(30^{\prime}\right)$ is obtained by simply substituting $(26.1)$ into $(30)$. Given all the positive coefficients, it is straightforward to see from the above two equations that $\left|\theta^{\prime}\right|>0$ is equivalent to $|\lambda||\theta|-\theta_{X Z} \varepsilon \mu_{X}>0$. Both are equally valid conditions to yield a normal output response to price for the final goods.

Similarly, the output-price relationship for the intermediate good $Z$ can be derived by substituting $\left(18.1^{\prime}\right),\left(18.2^{\prime}\right)$ and $(30)$ into $(16)$ :

$$
\hat{P}_{z}=\frac{1}{\mu_{X}}\left[\left|\lambda \| \theta^{*}\right|-\varepsilon \mu_{X}\right] \hat{X}
$$

where $\left|\theta^{*}\right| \equiv\left(\theta_{Z S} \theta_{Y L}-\theta_{Z L} \theta_{Y S}\right)>0$ and the sign of the overall coefficient in (31) is therefore ambiguous. In addition, the condition $\left|\theta^{\prime}\right|>0$ ensuring a normal output response to price for the final goods does not imply a normal output response to price for the intermediate good.

Now, recall that (11) describing the slope of the PPF is given by 


$$
\frac{d Y}{d X}=-\left(P_{X}-a \varepsilon P_{Z}\right)
$$

Normally, the sign of the derivative of $\frac{d Y}{d X}$ with respect to $X$ is used to determine the curvature of the PPF. Differentiating (11) with respect to $X$ and recalling the assumption that $\varepsilon$ is constant, we shall obtain

$$
\frac{d^{2} Y}{d X^{2}}=-\left(\frac{d P_{X}}{d X}-\varepsilon a \frac{d P_{Z}}{d X}\right) \cdot 12
$$

Clearly, the sign of $\frac{d^{2} Y}{d X^{2}}$ is determined by the signs and magnitudes of $\frac{d P_{X}}{d X}$ and $\frac{d P_{Z}}{d X}$ respectively which can be derived by simply rearranging the terms in $\left(30^{\prime}\right)$ and $(31):{ }^{13}$

$$
\begin{aligned}
& \frac{d P_{X}}{d X}=\frac{1}{\mu_{X}}(|\lambda||\tilde{\theta}|) \frac{P_{X}}{X}+\frac{1}{\mu_{X}}\left(|\lambda|\left|\theta^{*}\right|-\varepsilon \mu_{X}\right) \frac{a P_{Z}}{X}, \\
& \frac{d P_{Z}}{d X}=\frac{1}{\mu_{X}}\left(|\lambda|\left|\theta^{*}\right|-\varepsilon \mu_{X}\right) \frac{P_{Z}}{X},
\end{aligned}
$$

where $|\tilde{\theta}| \equiv \theta_{T S} \theta_{Y L}-\theta_{T L} \theta_{Y S}>0$.

We are now going to show that a normal output response to price of the final goods is only a sufficient and not a necessary condition for concavity of the PPF in the present model. Here, no restriction is placed on the sign of (31). Substituting (33.1) and (33.2) into (32), we obtain the key equation for the discussion here:

${ }^{12}$ A constant $\varepsilon$ implies $\frac{d \varepsilon}{d X}=0$ which, as shown in Appendix $A 5$, is satisfied if the external effect takes an exponential form.

${ }^{13}$ It is clear that the two signs are crucially dependent on many parameters, such as the external effect, the elasticity of substitution and the skill-intensity in each industry. We shall explore later in Appendix $B$ the consequences of some special cases where these parameters are taking extreme values. Here however, our focus is on the general situation. 


$$
\frac{d^{2} Y}{d X^{2}}=-\left[\frac{1}{\mu_{X}}(|\lambda||\tilde{\theta}|) \frac{P_{X}}{X}+(1-\varepsilon) \frac{1}{\mu_{X}}\left(|\lambda|\left|\theta^{*}\right|-\varepsilon \mu_{X}\right) \frac{a P_{Z}}{X}\right]
$$

It is clearly noticed that the only differences between (33.1) and (34) are in the overall sign and the presence in $(34)$ of the term $(1-\varepsilon)$ which is less than 1 . Therefore, if the sign of $\frac{d P_{X}}{d X}$ in (33.1) is positive (a normal output response to price), then the sign of $\frac{d^{2} Y}{d X^{2}}$ in (34) must be negative (the overall sign of the terms in the square bracket is positive) and the PPF will be concave. However, because the possibly negative component in $(34)$ is smaller (due to the presence of $(1-\varepsilon)$ ) than that in $(33.1)$, concavity (a positive overall sign of the terms in the square bracket in (34)) may occur even if the sign of $\frac{d P_{X}}{d X}$ in (33.1) is negative. ${ }^{14}$ To put this in another way, when the output response to price of the final good is perverse, we cannot unambiguously determine whether the PPF is concave or convex.

The results above are partly consistent with the conclusion drawn by Herberg and Kemp (1969). These authors show that a sufficiently strong IRS or a weak IRS is not a sufficient condition for the PPF to be convex or concave. Also, a normal (perverse) output response to price is not a necessary condition for concavity (convexity). In our model we conclude that the condition $\left|\theta^{\prime}\right|>0$, necessary and sufficient for validity of

\footnotetext{
${ }^{14}$ From inspection of equations (33.1) and (34), we know that this situation can only arise when the following inequality is satisfied:
}

$$
-(1-\varepsilon)\left(|\lambda|\left|\theta^{*}\right|-\varepsilon \mu_{X}\right) \frac{a P_{Z}}{X}<\frac{1}{\mu_{X}}(|\lambda||\tilde{\theta}|) \frac{P_{X}}{X}<-\frac{1}{\mu_{X}}\left(|\lambda|\left|\theta^{*}\right|-\varepsilon \mu_{X}\right) \frac{a P_{Z}}{X} .
$$


both the Stolper-Samuelson and Rybczynski theorems, would yield a normal output response to price, which again is also the sufficient condition for concavity of the PPF..$^{15}$ However the reverse conclusion does not necessarily hold.

\subsection{Multiple Production Equilibria}

The analysis undertaken so far has demonstrated first, that the PPF may lose concavity due to the economies of scale and second, that the PPF is strictly convex to the origin in the neighborhood of $X=0$ and is strictly concave in the neighborhood of $Y=0 .{ }^{16}$ As previously shown by Kemp (1969) and Panagariya (1981), where a PPF has these properties, there may be more than one production equilibrium consistent with a given price ratio. In Figure 2 we have characterized the three situations, first where a price ratio $P_{1}$ is associated with two incompletely specialized and one completely specialized production equilibria, second where a price ratio $P_{2}$ is consistent with two completely specialized production points and third where a price ratio $P_{3}$ is associated with an unique production equilibrium involving complete specialization in good $Y .{ }^{17}$ It is also known from this previous literature that in the three equilibria case associated with $P_{1}$, the equilibrium $E_{2}$ is unstable while both $E_{1}$ and $E_{3}$ are stable.

As we extend our analysis to an open economy framework, in order to maintain the focus on the implications of outsourcing in the presence of externality, we shall not consider the complication of multiple production equilibria but limit our attention to the

\footnotetext{
${ }^{15}$ Under the condition $\left|\theta^{\prime}\right|>0$ the PPF is concave with the exception in the neighborhood of $Y=0$. As mentioned in footnote 14, this special case is discussed in Appendix $B$.

${ }^{16}$ See Appendix $B$ for a formal proof.

${ }^{17}$ See Bhagwati, Panagariya and Srinivasan (1998, Chapter 11), and Kemp (1969, Chapter 8).
} 
Figure 2: Multiple Production Equilibria

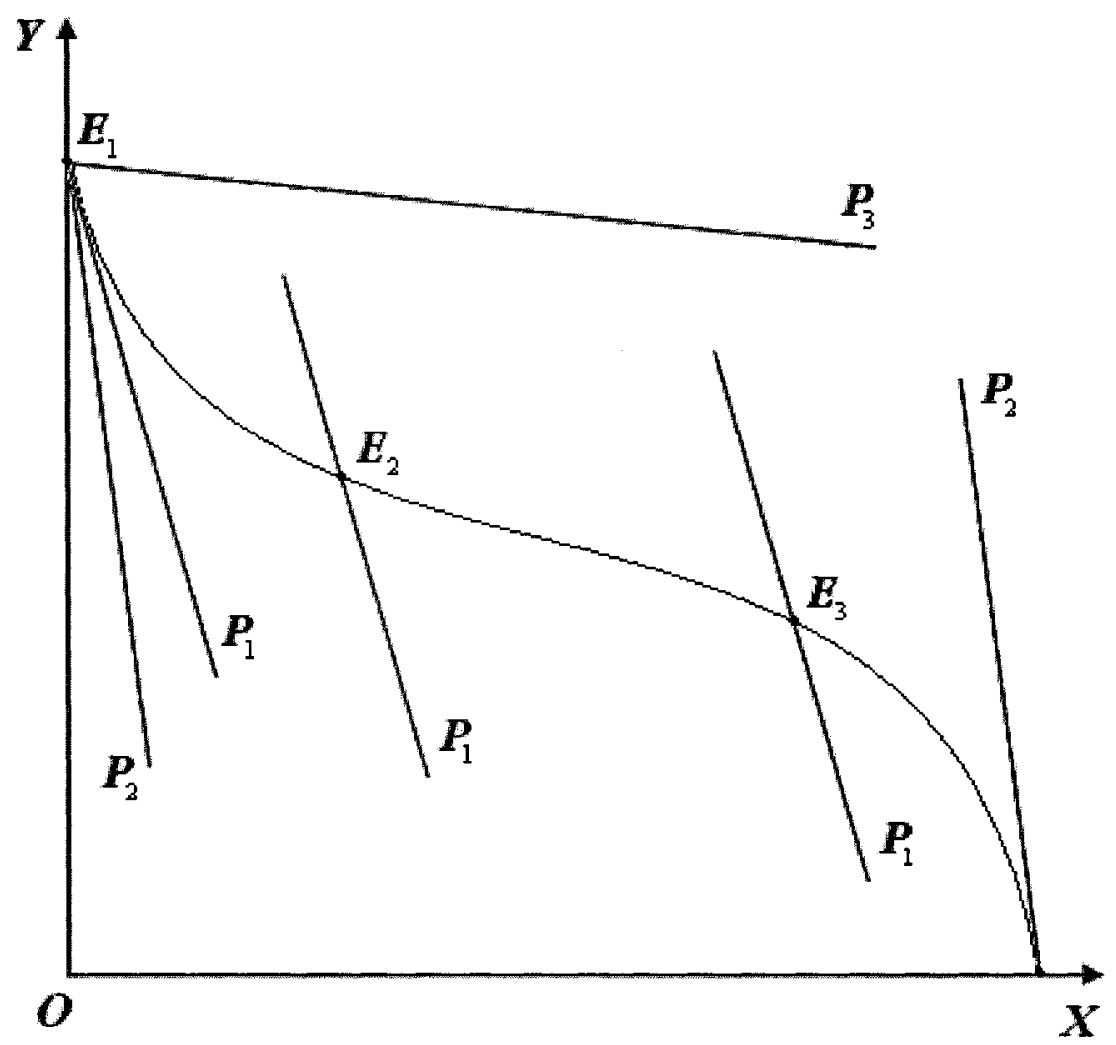


situation where the final good's output response to price is normal. This would require that $\left|\theta^{\prime}\right|>0$ which is also sufficient to ensure that we are operating on the concave portion of the PPF. 


\section{Free Trade in Final Goods}

\section{1: The Absence of Factor-Price Equalization}

Where it is necessary to distinguish between home and foreign variables, we shall denote the foreign variables by an asterisk $(*)$. For simplicity, we often use the names Home and Foreign to denote the home and foreign countries, respectively. Now assume that the two countries have the same endowments ${ }^{18}$ and three comparable industries producing the same goods, but there is no an output-generated externality in industry $Z^{*}$ at Foreign. ${ }^{19}$ This is consistent with Porter's (1990) observation that clusters which generate industry-specific externalities are often located only in certain countries. Without any difference in technology $\left(g(Z)=g^{*}\left(Z^{*}\right)>1\right)$ cross countries, an endowment difference alone could also lead to a factor-return differential and an incentive for outsourcing (as discussed in Footnotes 18 and 19). However, for simplicity and without loss of generality, we shall limit our analysis to the current specification which is sufficient for our purpose to drive un-equalized factor returns cross countries.

${ }^{18}$ In the present model with $g(Z)>g^{*}\left(Z^{*}\right)=1$ for any given $Z=Z^{*}$ and with the externality being skill biased, an endowment difference would reinforce the effect of the technology difference in each of the following two cases: (1). $S / L>S^{*} / L^{*}$ with $S>S^{*}$; and (2). $S / L=S^{*} / L^{*}>1$. This reinforcement would lead to an even more pronounced difference in factor returns and unit costs of the intermediate inputs under free trade. Only when Home is assumed to have more unskilled labor, will the effect of the endowment difference on factor returns tend to offset the effect of the technology difference.

${ }^{19}$ This special case of $g^{*}\left(Z^{*}\right)=1$ is sufficient for our present purposes of investigating outsourcing driven by un-equalized factor returns which is brought about by technology difference. By way of interest, if we relax the assumption $g^{*}\left(Z^{*}\right)=1$ within the current framework, as long as $g(Z)>g^{*}\left(Z^{*}\right)$ for any given $Z=Z^{*}$ our results in this section will be unchanged qualitatively. Conversely, if $g(Z)<g^{*}\left(Z^{*}\right)$, then the home country will have a lower $V$ in free trade and the outsourcing direction will be reversed in the subsequent section. However, if $g(Z)=g^{*}\left(Z^{*}\right)>1$ for any given $Z=Z^{*}$, an international factor-return differential (like the one in the present framework) would arise from the endowment difference considered in Footnote 18. 
It is also assumed throughout that both commodities $X$ and $Y$ are normal goods. Which good is exported in free trade depends as usual on the autarky price ratio relative to the foreign price ratio, both ratios being determined by the production technologies, the endowments as well as the demand sides. A specific solution cannot be obtained unless these factors are specified.

The normalization $P_{Y}=1$ will be retained for simplicity and, as indicated above, the assumption $\left|\theta^{\prime}\right|>0$ is adopted in order to ensure that we are operating on the concave portion of the PPF. We shall also assume the intermediate good $Z$ to be non-tradable, which can be justified in at least three ways. First, due to the technology difference across countries, free trade in both final goods as well as the intermediate good $Z$ is not consistent with the situation where both countries remain diversified in the production of all three goods. Second, in order to protect the technology advantage embodied in the production externality, the home country might decide not to export good $Z$ directly except as a component of the final good $X$. Third, $Z$ can be interpreted as headquarter services of skilled labor in in-house activities (e.g., in Silicon Valley) at Home, while $T$ is the unskilled component outsourced to Foreign.

In our model, if both countries have the same wage ratio $\omega$, the relative price $P_{X}$ will be lower at Home. Equivalently, if both countries have the same price ratio $P_{X}$, the domestic $\omega$ will be higher. To see this, choose an arbitrary wage ratio $\omega=\omega^{*}$, so that in a Lerner diagram (like Figure 1) the three dollar's-worth isoquants of $z, T$ and $Y$ must be tangent to the same isocost line in both countries. The isoquants of $T$ and $Y$ have the standard interpretations associated with CRS technologies, which indicates that both 
countries have the same prices $V$ and $P_{Y}$. The only difference is that the isoquant of intermediate $\operatorname{good} Z$ is $1 / P_{Z} g(Z)$ at Home with $g(Z)>1$ and is $1 / P_{Z}^{*}$ abroad with $g\left(Z^{*}\right)=1 .{ }^{20}$ This would simply imply that $P_{Z}<P_{Z}^{*}$. Recall that $P_{X}=V+a P_{Z}$, so that, given the same $V$ in both countries, the domestic price $P_{X}$ must be lower than the foreign price. Since this argument holds for every single value of $\omega$, the relationship between $\omega$ and $P_{X}$ can be described by a continuous curve for each country as shown in Figure 3, where the commodity price ratio $P_{X}$ is measured on the horizontal axis and the wage ratio $\omega$ is measured on the vertical axis.

Here, we can see that at any given $\omega$ the domestic price ratio is lower than the foreign one. This is because changes in factor prices, in addition to having a direct effect on the commodity prices, would also affect the composition of outputs in this fullemployment model. However, due to the externality and in contrast to the foreign country with CRS technologies, any change in output of good $Z(X)$ at Home has a further impact on unit cost and acts in opposition to the original effect. Compared with the other country, a higher (lower) commodity price ratio needs not entail a higher (lower) relative return to the factor which is intensively used in that commodity. For example, the wage ratio $\omega$, corresponding to the price ratio $P_{X}$, is higher than $\omega^{* 1}$ which is associated with an even higher price ratio $P_{X}^{* 1}$ abroad. In addition, it is also clear from Figure 3 that in

\footnotetext{
${ }^{20}$ In the previous discussion, the form of the external effect has been assumed to be $g(Z)=Z^{\varepsilon}$. It is known that $g(Z)<1$ if and only if $0<Z<1$ given that $0<\varepsilon<1$. Here, without loss of generality and to ensure that $g(Z)>1$, we simply assume that home will produce more than one unit if she decides to produce that good.
} 
Figure 3: The Comparison between Domestic and Foreign Wage Ratios

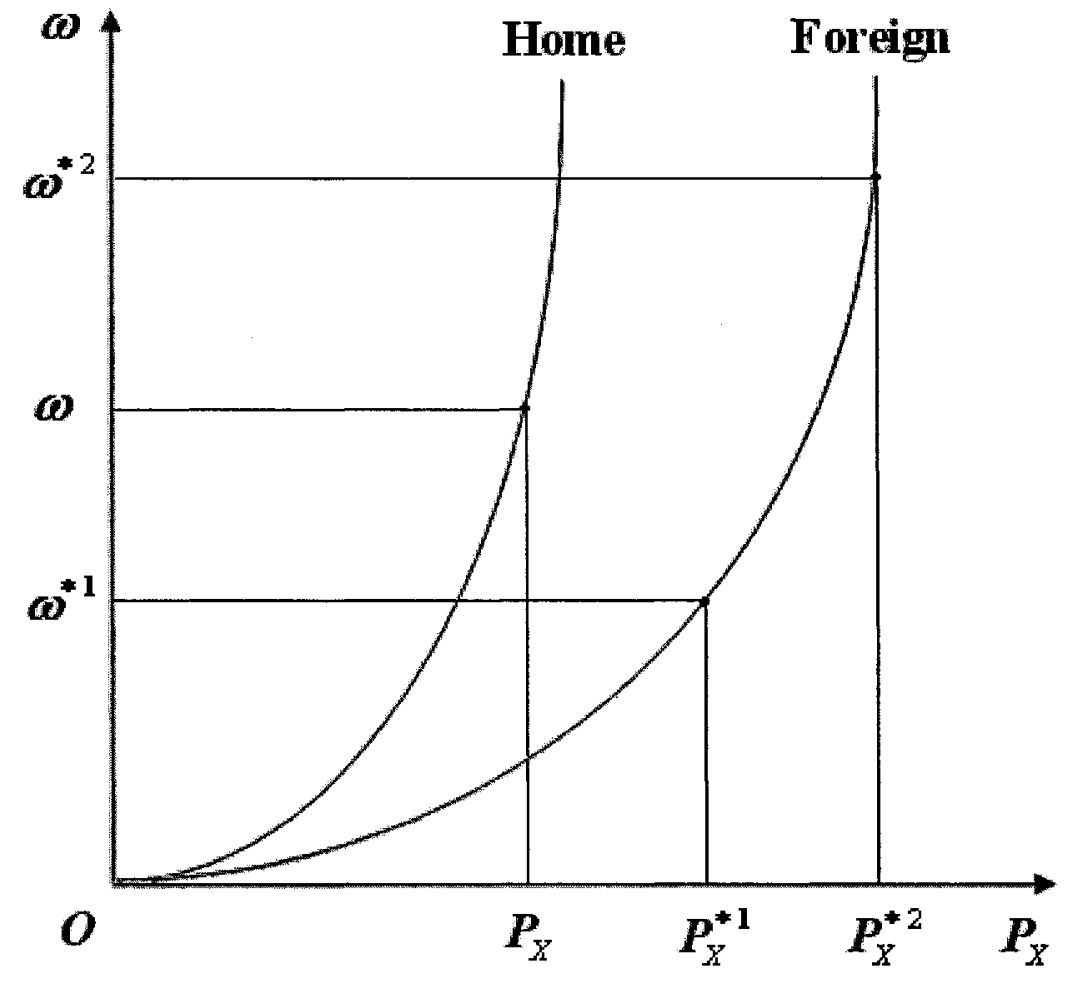


free trade we have $\omega>\omega^{*}$ given the same world commodity prices.

Due to the technology difference across countries, the equalization of the commodity prices in free trade does not ensure that the prices of the two production fragments, $V$ and $V^{*}, P_{Z}$ and $P_{Z}^{*}$, will be the same. The absence of factor-return equalization $\omega>\omega^{*}$ implies that all the dollar's-worth isoquants of the foreign country are tangent to a steeper factor price line as illustrated in Figure 4. Here, all the dollar's-worth isoquants associated with CRS production technologies, such as $1 / V, 1 / V^{*}$ and $1 / P_{Y}$, have the standard interpretations implying that $V>V^{*}$. The complication is again associated with the intermediate good $Z$ where the external effect $g(Z)$ is greater than 1 at Home, but equal to 1 abroad. Although the isoquant $1 / P_{Z} g(Z)$ is closer to the origin than $1 / P_{Z}^{*}$, this does not imply that $P_{Z}$ is greater than $P_{Z}^{*}$ because of the presence of $g(Z)$. In fact if $P_{Z} \geq P_{Z}^{*}$, we must have $P_{X}>P_{X}^{*}$ given that $V>V^{*}$, which contradicts the outcome of free trade. Therefore, the domestic $P_{Z}$ must be lower than the foreign price $P_{Z}^{*}$. In addition, this is an alternative way to see why cannot the intermediate good $Z$ be traded simultaneously with the two final goods while both countries diversify in all the production.

In summary, technology difference drives a factor return differential between the two countries under free trade such that the home country has a higher $\omega$, a lower $P_{Z}$ due to the economies of scale and a higher $V$ because of the intensive use of the more expensive factor at Home. The differences in factor returns and hence the induced deviations in the unit costs of the intermediate inputs give Home an incentive to outsource which is our focus in the next chapter. 
Figure 4: The Comparison between Domestic and

Foreign Intermediate Inputs Prices

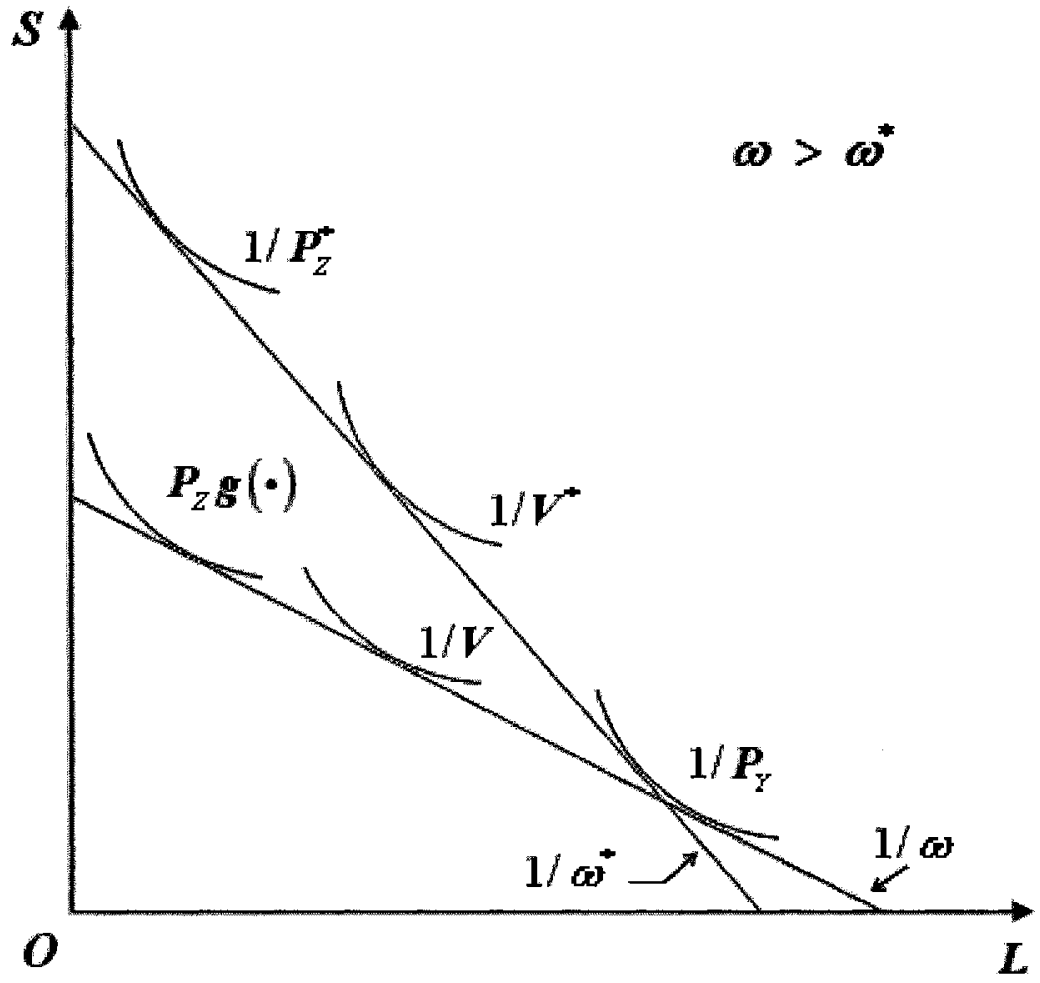




\section{2: Comparative Statics}

To examine the welfare effects of free trade, we assume that the demand side, represented by a strictly quasi-concave social utility function with positive marginal utilities, is dependent only on the consumptions of the two final goods and ignore any differences between the preference of skilled labor and unskilled labor:

$$
U=U\left(X^{D}, Y^{D}\right)
$$

where $X^{D}$ and $Y^{D}$ are the consumed quantities of each good. The budget constraint, reflecting that the total value of production is equal to the national expenditure, holds for both autarky and free trade:

$$
P_{X} X+Y=P_{X} X^{D}+Y^{D}
$$

Totally differentiating (35), we obtain

$$
d U=U_{X} d X^{D}+U_{Y} d Y^{D}
$$

Here, $U_{X}$ and $U_{Y}$ are the partial derivatives of the utility function with respect to $X^{D}$ and $Y^{D}$ respectively, and therefore represent the positive marginal utilities of each good. Since good $Y$ is considered as the numeraire, $U_{Y}$ also has the interpretation of marginal utility of income. The maximization of social utility requires equality between the marginal rate of substitution and the good price ratio, which is given by $\frac{U_{X}}{U_{Y}}=P_{X}$. Using this condition, we rewrite (37) as

$$
\frac{d U}{U_{Y}}=P_{X} d X^{D}+d Y^{D}
$$

Then, totally differentiating (36) yields 


$$
\left(X-X^{D}\right) d P_{X}+P_{X} d X+d Y=P_{X} d X^{D}+d Y^{D}
$$

As shown above, with $P_{Y}=1$ the slope of the PPF is given by

$$
d Y=-\left(P_{X}-\varepsilon a P_{Z}\right) d X
$$

Now, substituting $(38)$ and $\left(11^{\prime}\right)$ into $\left(37^{\prime}\right)$ to obtain a measure of the welfare change:

$$
\frac{d U}{U_{Y}}=\left(X-X^{D}\right) d P_{X}+a \varepsilon P_{Z} d X
$$

Recall that given the positive externality, there is a wedge between the social marginal product and the private marginal product (marginal cost), which leads to underproduction of good $Z(X)$. Thus, the second expression of the two terms on the right-hand side of (39) reflects the benefit (hurt) associated with an increase (a decrease) in the output of good $X$ where the social marginal benefit exceeds the marginal cost by $a \varepsilon P_{Z}$. The first expression simply indicates the terms-of-trade effect which is clearly positive. It is known that for the initial infinitesimal move from autarky to free trade, the welfare change measured by (39) is evaluated at autarky. Therefore, we can drop the term $\left(X-X^{D}\right)$ which is equal to zero and hence rewrite (39) in the following simplified form:

$$
\frac{d U}{U_{Y}}=a \varepsilon P_{Z} d X
$$

Equation (40) shows that the social welfare will be initially enhanced if Home exports good $X$ as evaluated at autarky. Conversely, importing good $X$ associated with a decline in the domestic production of good $X$ will, at least initially, make the home country worse off relative to autarky. 
The above statement is consistent with the well known standard trade theory regarding the situation where there is a non-tangency between the price line and the PPF. It says that if trade could increase the production of the goods which are under-produced in autarky, then opening to trade will improve the home country's welfare; if trade decreases the production of those goods, then free trade will have an ambiguous welfare effect but will at least initially decrease the welfare. For example, Kemp (1969) and Choi and Yu (1984) show that free trade may be inferior to no trade in the presence of VRS. Their conclusion is based on the assumption that the under-produced good in autarky would be imported when the economy is open to trade.

Both (39) and (40) can also be applied to the case of a small open economy and a similar conclusion will be obtained. Here, we retain the term $d P_{X}$ because we are considering a movement from autarky to free trade where the price faced by Home does change.

What is the impact of free trade on the wage ratio $\omega$ ? The percentage change in the wage ratio due to a percentage change in the commodity price ratio has been derived as $\hat{\omega}=\hat{P}_{X} /\left|\theta^{\prime}\right|$. It follows, given the normal output response to price $\left(\left|\theta^{\prime}\right|>0\right)$, that free trade associated with exporting good $X\left(d P_{X}>0\right)$ must enlarge the wage disparity against unskilled labor relative to autarky, whereas importing good $X\left(d P_{X}<0\right)$ should have an opposite effect. This is simply an application of the Stolper-Samuelson theorem which, as shown previously, retains its validity in the present model providing that $\left|\theta^{\prime}\right|>0$ 


\section{International Outsourcing ${ }^{21}$}

\subsection{Introduction}

Since the production process of good $X$ has separate and distinct elements, it is possible to outsource one of those elements to the place where the unit cost of producing that part is cheaper. It has been demonstrated in the previous chapter that $V>V^{*}$ under free trade because of the intensive use of the more expensive factor at Home, so that the home country would like to have $T$ produced offshore to enjoy the lower production cost abroad. Hence, fragment $T$ will be imported back and integrated with the domestically produced good $Z$ into the production process for final good $X .{ }^{22}$ For the analysis in this chapter, the following assumptions are made:

- There is no transportation cost or any other additional cost of outsourcing, but trade needs to be balanced.

- We assume for simplicity that outsourcing is complete which leads to no domestic production of $T$ anymore, though this need not necessarily be so. This situation can be ensured by an even stronger assumption that the domestic price $V$ is always higher than the foreign price $V^{*}$, which implies that the domestic user cost of $T$ is decreasing when Home moves from free trade to outsourcing. ${ }^{23}$

- No extra factor is required to transform the fragments $T$ and $Z$ into the final good $X$, and this costless assembly process is assumed to be attached to industry $Z$ at Home.

\footnotetext{
${ }^{21}$ From here on, we shall use the term free trade only to refer to the situation of trading in final goods and without any outsourcing activity.

${ }^{22}$ Outsourcing fragment can be either physical components or services. In our framework, $T$ is neither the most nor the least skilled-labor-intensive good. A possible example is a call center for technical assistance with computers, which is more skill intensive than the manufacturing sector $(Y)$ but less skill intensive than the headquarter office $(Z)$.

${ }^{23}$ Further discussion regarding the assumption of complete outsourcing is provided in Appendix $A 6$.
} 
Before examining the implications of outsourcing, we first simply derive some properties of the $\mathrm{PPF}^{\mathrm{ZY}}$ which denotes the PPF between goods $Z$ and $Y$, while for the subsequent discussion we will use the notation $\mathrm{PPF}^{\mathrm{XY}}$ to represent the PPF between the final goods $X$ and $Y$. This scenario, where complete outsourcing leaves the home country only needing to produce goods $Z$ and $Y$, is similar to the cases investigated in many papers between 1965 and 1985, involving VRS for the two-factor two-sector models. ${ }^{24}$ As shown in Appendix $A 7$, the slope of the $\mathrm{PPF}^{\mathrm{ZY}}$ is given by

$$
\frac{d Y}{d Z}=-\frac{P_{Z}}{P_{Y}}(1-\varepsilon)
$$

Retaining the assumption $\frac{d \varepsilon}{d Z}=0$ and setting $P_{Y}=1$, the curvature of the $\mathrm{PPF}^{\mathrm{ZY}}$ indicated by the derivative of (41) is therefore given by

$$
\frac{d^{2} Y}{d Z^{2}}=-\frac{d P_{Z}}{d Z}(1-\varepsilon)
$$

which implies that the $\mathrm{PPF}^{\mathrm{ZY}}$ is concave or convex dependent only upon whether the output response to price of good $Z$ is normal or perverse. We have (43) derived in Appendix $A 8$ to describe this output-price relationship

$$
\hat{P}_{Z}=\frac{1}{\mu_{z}}\left[\left|\lambda_{Z} \| \theta^{*}\right|-\varepsilon \mu_{Z}\right] \hat{Z}
$$

where $U_{S} \equiv \lambda_{Y S} \theta_{Y L} \sigma_{Y}+\lambda_{Z S} \theta_{Z L} \sigma_{Z}, U_{L} \equiv \lambda_{Y L} \theta_{Y S} \sigma_{Y}+\lambda_{Z L} \theta_{Z S} \sigma_{Z},\left|\lambda_{z}\right| \equiv\left(\lambda_{Z S} \lambda_{Y L}-\lambda_{Z Z} \lambda_{Y S}\right)(1-\varepsilon)$, $\mu_{Z} \equiv U_{S} \lambda_{Y L}+U_{L} \lambda_{Y S}$ and $\left|\theta^{*}\right| \equiv\left(\theta_{Z S} \theta_{Y L}-\theta_{Z L} \theta_{Y S}\right)$. Given that all those individual terms are positive, the sign of the overall coefficient in (43) is ambiguous, implying that the $\mathrm{PPF}^{\mathrm{ZY}}$

\footnotetext{
${ }^{24}$ See Jones (1968), Kemp (1969), Kemp and Takashi (1970) and Panagariya (1980).
} 
can be either concave or convex. ${ }^{25}$ Since no restriction has been placed on the output response to price of good $Z$, some worries may arise regarding non-unique production equilibrium. However, such worries would be unjustified since the production of the intermediate good $Z$ is constrained by the output level of good $X$ according to the Leontief production technology. Given the earlier assumption $\left|\theta^{\prime}\right|>0$ ensuring concavity of the $\mathrm{PPF}^{\mathrm{XY}}$, the output level of $X$ is uniquely determined by the world price.

While it is possible that the home country either exports or imports good $X$ at the outsourcing equilibrium, we will limit our attention to the case of home exporting $X$. The main arguments underlying both cases are similar and the discussion can be readily extended from one case to the other. We will consider Home as a large country first and then simplify the analysis to the case of a small open economy.

\subsection{The Effect on Supply and Demand at Constant Terms of Trade}

This section investigates how outsourcing will influence the supply and demand for each good in both countries at constant terms of trade. Given the full-employment conditions, outsourcing requires the factors released from industry $T$ to be reallocated between industries $Z$ and $Y$. It follows, due to the externality, that any change in production composition will in turn affect wage ratio. We will show that this process leads to an increase in the domestic output of good $Z$ at constant world commodity-price ratio $P_{X}^{*}$, whereas the impact on the domestic output of good $Y$ is uncertain. In addition, outsourcing also raises wage ratio $\omega$ and hence national income, an outcome sustained

\footnotetext{
${ }^{25}$ Appendix $A 8$ also discusses the curvature in the neighborhoods of the two end points, which shows that the $\mathrm{PPF}^{\mathrm{ZY}}$ is strictly convex in the neighborhood of $Z=0$ and is strictly concave as the output of good $Y$ approaches to zero.
} 
by both the external effect and the cost saving in $V .{ }^{26}$ Consequently, the demands for both goods increase at constant $P_{X}^{*}$.

\subsubsection{Domestic Production}

To derive these results, we introduce a new parameter $\varphi$ to represent the level of outsourcing activity. Suppose, for the sake of exposition, that the adjustment from free trade to complete outsourcing is not instantaneous. ${ }^{27}$ Thus, as $\varphi$ rises, it represents an increasing volume of $T$ imports from the foreign country. Recall that, due to the externality, holding constant commodity prices does not ensure constant factor prices in the present model. For this reason, it is helpful to consider a two-part decomposition of the production effect of any marginal increase in $\varphi$ at constant commodity-price ratio: the effect at constant wage ratio $\omega$, and then the effect when $\omega$ adjusts to restore the commodity-price ratio to its initial value.

\section{Decomposition: Part 1}

To keep this section relatively self-contained, we first briefly derive the key results by simple algebra, and then use an Edgeworth box diagram to illustrate the discussion. To begin, rewrite the full-employment conditions specified in (7.1) and (7.2) as follows

$$
\begin{aligned}
& \bar{S}=L_{Z} k_{Z}+L_{T} k_{T}+L_{Y} k_{Y}, \\
& \bar{L}=L_{Z}+L_{T}+L_{Y} .
\end{aligned}
$$

It follows after simple manipulation that

\footnotetext{
${ }^{26}$ If there is no externality and no cost saving brought about by outsourcing, there would be no incentive to outsource. National income as well as the initial free trade equilibrium would not be affected (after paying for $T$ ), since outsourcing in this scenario acts only as a pure movement of the production locations.

${ }^{27}$ We can think of the rise in $\varphi$ as representing a relaxation of a quota on imports of $T$.
} 


$$
\begin{aligned}
& \bar{S}=\frac{Z}{g(Z) f_{Z}\left(k_{Z}\right)} k_{Z}+\frac{T}{f_{T}\left(k_{T}\right)} k_{T}+\frac{Y}{f_{Y}\left(k_{Y}\right)} k_{Y}, \\
& \bar{L}=\frac{Z}{g(Z) f_{Z}\left(k_{Z}\right)}+\frac{T}{f_{T}\left(k_{T}\right)}+\frac{Y}{f_{Y}\left(k_{Y}\right)},
\end{aligned}
$$

since CRS technology of $z, T$ and $Y$ functions implies that $f_{Z}(\cdot) \equiv z\left(1, \frac{S_{Z}}{L_{Z}}\right)=\frac{Z}{g(Z) L_{Z}}$, $f_{T}(\cdot) \equiv T\left(1, \frac{S_{T}}{L_{T}}\right)=\frac{T}{L_{T}}$ and $f_{Y}(\cdot) \equiv Y\left(1, \frac{S_{Y}}{L_{Y}}\right)=\frac{Y}{L_{Y}}$. On the other hand, in the presence of outsourcing the fixed-proportion relationship between $Z$ and $T$ becomes

$$
Z=a(T+\varphi)
$$

Since skill intensity $k_{i}$ depends only on wage ratio $\omega$, we can derive the expressions for $Z, T$ and $Y$ in terms of $\varphi, \omega, \bar{S}$ and $\bar{L}$ by simultaneously solving (44.1), (44.2) and (45). For example, to solve for $Z$, first rearrange (44.2) to obtain

$$
Y=f_{Y}\left(\bar{L}-\frac{Z}{g(Z) f_{Z}}-\frac{T}{f_{T}}\right)
$$

where for simplicity we have omitted the argument of each function $f_{i}, i=z, T, Y$. Next, from (45) we have

$$
T=\frac{1}{a} Z-\varphi
$$

Finally, substituting both (46) and (45.1) into (44.1) yields

$$
\frac{Z}{g(Z)}\left(\frac{k_{Z}(\omega)-k_{Y}(\omega)}{f_{Z}\left(k_{Z}(\omega)\right)}\right)+\frac{Z}{a}\left(\frac{k_{T}(\omega)-k_{Y}(\omega)}{f_{T}\left(k_{T}(\omega)\right)}\right)=\bar{S}-k_{Y}(\omega) \bar{L}+\varphi\left(\frac{k_{T}(\omega)-k_{Y}(\omega)}{f_{T}\left(k_{T}(\omega)\right)}\right) .
$$

From this equation, we can solve for $Z$ as a function of $\varphi, \omega, \bar{S}$ and $\bar{L}$. Following 
this, we rewrite the production of $Z$ as

$$
Z=Z(\varphi, \omega, \bar{S}, \bar{L})
$$

and the production functions of other goods can be rewritten similarly. ${ }^{28}$ Here, $\varphi$ determines the outsourcing volume (and hence, as shown below, the domestic production of $T$ ) and therefore the residual amounts of endowments available for $Z$ and $Y$; while $\omega$ determines the skill intensities and hence indicates the allocation of endowments between each industry.

Substituting (48) into (47) and then differentiating (47) with respect to $\varphi$, we obtain

$$
\left(\frac{k_{Z}-k_{Y}}{f_{Z}\left(k_{Z}\right)}\right) \frac{1-\varepsilon}{g(Z)} \frac{\partial Z}{\partial \varphi}+\left(\frac{k_{T}-k_{Y}}{f_{T}\left(k_{T}\right)}\right) \frac{1}{a} \frac{\partial Z}{\partial \varphi}=\left(\frac{k_{T}-k_{Y}}{f_{T}\left(k_{T}\right)}\right) .
$$

Solving for $\frac{\partial Z}{\partial \varphi}$ yields

$$
\frac{\partial Z}{\partial \varphi}=\frac{a b_{2}}{a b_{1}+b_{2}}
$$

where $b_{1} \equiv \frac{k_{Z}-k_{Y}}{f_{Z}\left(k_{Z}\right)} \frac{1-\varepsilon}{g(Z)}>0, b_{2} \equiv \frac{k_{T}-k_{Y}}{f_{T}\left(k_{T}\right)}>0$ and, as will be recalled, $0<a<1$. Thus, it is clear that $1>\frac{\partial Z}{\partial \varphi}>0$. In addition, equation (45.1) implies

$$
\frac{\partial T}{\partial \varphi}=\frac{1}{a} \frac{\partial Z}{\partial \varphi}-1
$$

from which we can obtain $\frac{\partial T}{\partial \varphi}$ by substitution of the above expression for $\frac{\partial Z}{\partial \varphi}$. It follows that

${ }^{28}$ For convenience, I use the same symbol here to stand for both the variable and its related function. 


$$
\frac{\partial T}{\partial \varphi}=-\frac{a b_{1}}{a b_{1}+b_{2}}
$$

and $0>\frac{\partial T}{\partial \varphi}>-1$. Similarly, differentiating (46) with respect to $\varphi$ and using the preceding expressions for $\frac{\partial Z}{\partial \varphi}$ and $\frac{\partial T}{\partial \varphi}$, we can derive the relationship between $Y$ and $\varphi$, which is given by

$$
\frac{\partial Y}{\partial \varphi}=\frac{a b_{3}}{a b_{1}+b_{2}}
$$

where $b_{3} \equiv \frac{f_{Y}\left(k_{Y}\right)\left(k_{Z}-k_{T}\right)}{f_{T}\left(k_{T}\right) f_{Z}\left(k_{Z}\right)} \frac{1-\varepsilon}{g(Z)}>0$. It is straightforward to see that $\frac{\partial Y}{\partial \varphi}$ is positive.

Bear in mind that all these partial derivatives $\left(\frac{\partial Z}{\partial \varphi}, \frac{\partial T}{\partial \varphi}\right.$ and $\left.\frac{\partial Y}{\partial \varphi}\right)$ indicate the output effects of outsourcing at constant $\omega$.

We now use an Edgeworth box diagram to illustrate the above results. In Figure 5, unskilled labor is measured along the horizontal axis $O A\left(O^{\prime} B\right)$, and skilled labor is measured along the vertical axis $O B\left(O^{\prime} A\right)$. Reflecting the skill-intensity ranking $k_{Z}>k_{T}>k_{Y}, O a$ and $a b$ represent the initial production of $Z$ and $T$, respectively. The factors represented by $O^{\prime} b$ are used in industry $Y$, and everything else represented by $O b$ is used in producing $X$ (via $Z$ and $T$ ). Thus, $O b$ and $O^{\prime} b$ shall denote the output level of goods $X$ and $Y$, respectively, when no outsourcing takes place. ${ }^{29}$

\footnotetext{
${ }^{29}$ Note that even though the Leontief production technology requires one unit of $T$ to produce each unit of $X$, this does not necessarily imply that the length of $O b$ and $a b$ must be equal. It is possible with CRS technologies to use distances for a given skill-intensity as measures of output, although even for a single good, distances for different skill-intensities would have different mappings to output. Leaving this difficulty aside, comparisons of distances for different goods (with different skill-intensities) are further complicated because they may involve different mappings between distance and output.
} 
Figure 5: The Effect of Outsourcing on

Domestic Production at Constant Factor Prices

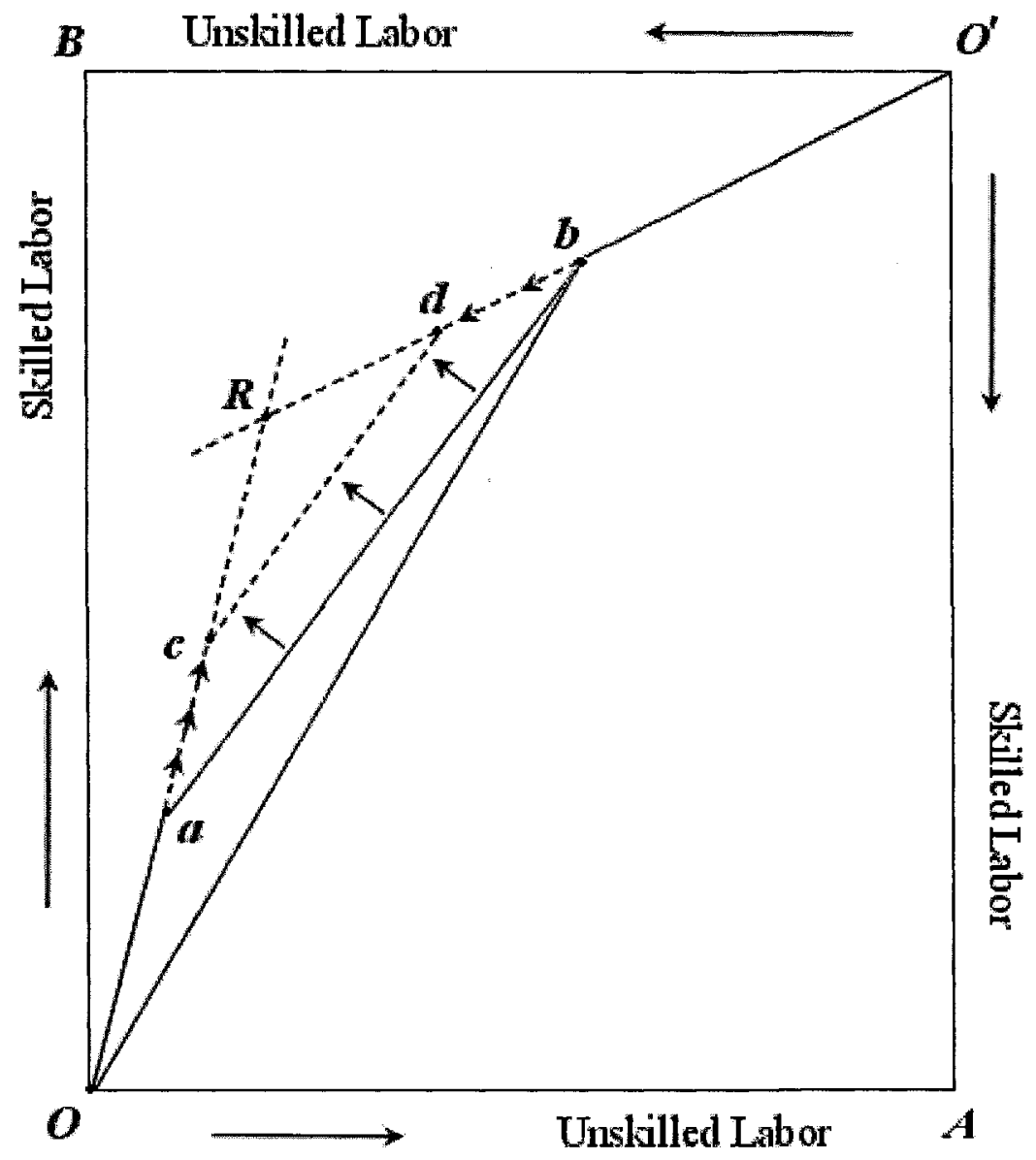


As stated, holding $\omega$ constant keeps skill intensities $k_{Z}, k_{T}$ and $k_{Y}$ constant. Thus, as $\varphi$ starts increasing from zero, the outputs of goods $Z$ and $Y$ will increase following the arrow direction as the domestic production of $T$ decreases (recalling that $\frac{\partial T}{\partial \varphi}<0$ ) from $a b$ to $c d$. As $\varphi$ continues to increase, this movement will eventually stop at $R$ where all the resources released from $T$ have been completely reallocated between industries $Z$ and $Y$ at constant $\omega$.

\section{Decomposition: Part 2}

Having indentified the impacts of outsourcing on the production of each good at constant $\omega$, we now examine the output effects when $\omega$ adjusts in order to restore the terms of trade to their initial value. During this non-instantaneous movement, when $\varphi$ starts to increase from zero, Home will retain some production of $T$ while facing two prices at the same time, a domestic price $V$ and a lower foreign price $V^{*}$. Here, we first use a Lerner diagram to illustrate the changes in $V$ and $P_{Z} g(Z)$, and hence identify the effect of outsourcing on $\omega$ at constant $P_{X}^{*}$. We then explain how the change in $\omega$ will reallocate factors between each industry, and thus determine the associated change in output composition.

As is clear from the discussion in part 1, there is an expansion in industry $Z$ at the original $\omega$ when $\varphi$ starts to increase. Initially holding $P_{Z}$ constant, the increase in $g(Z)$ causes the isocost line to rotate (as illustrated in Figure 6) leading to a higher wage ratio $\omega$ as well as a higher price $V \cdot{ }^{30}$ As $V$ rises, it follows that $P_{Z}$ must fall to maintain

\footnotetext{
${ }^{30}$ It may seem surprising at first sight that a relaxation of a quota on imports of $T$ leads to an even higher
} 
Figure 6: The Effect of Outsourcing on the

\section{Domestic Wage Ratio at Constant Terms of Trade}

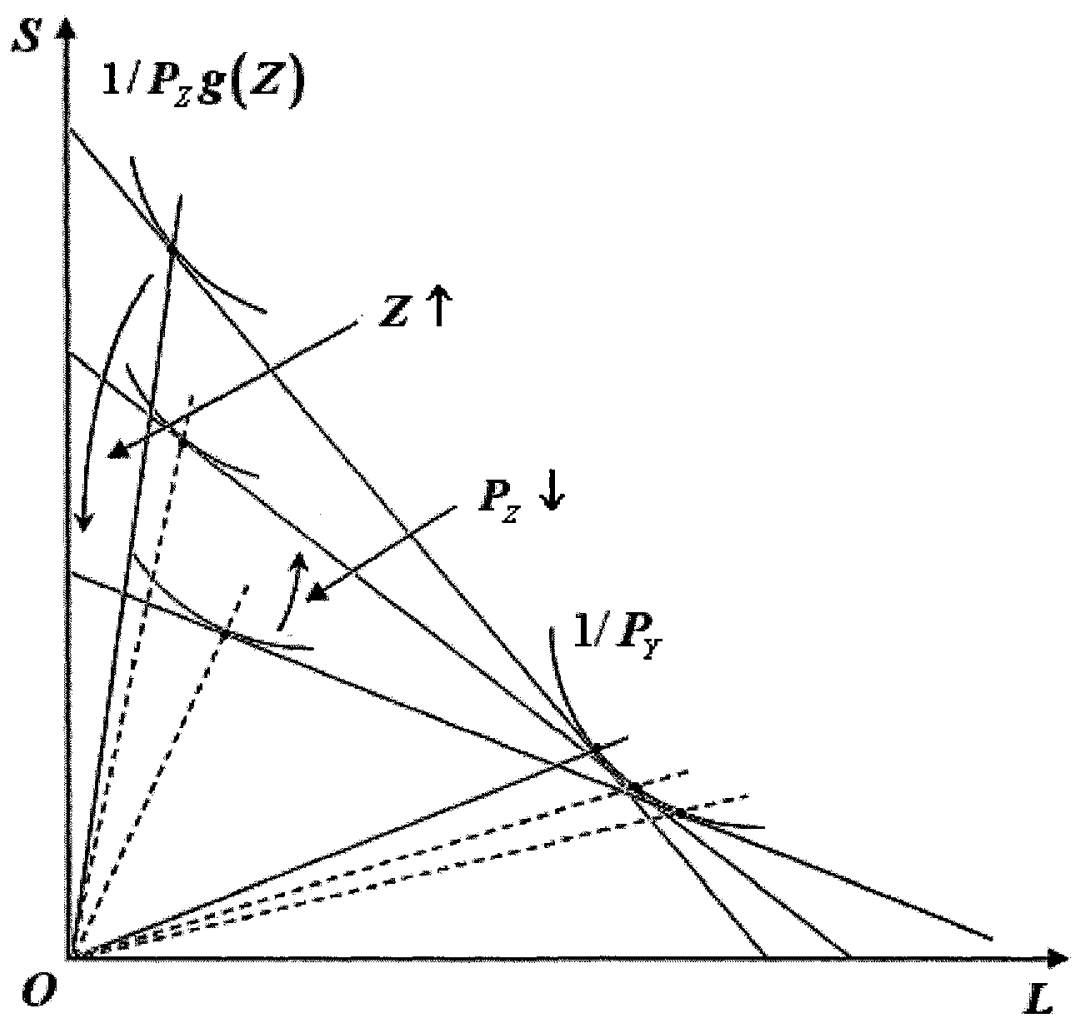

domestic price $V$. However, this result arises simply because the externality raises wage ratio at constant terms of trade, and hence must cause a rise in the unit cost $(V)$ of producing $T$. 
$P_{X}^{*}$ constant (given that $P_{X}^{*}=a P_{Z}+V$ ), which will in turn induces a decline in $\omega$. However, the effect of the drop in $P_{z}$ on $\omega$ only partially offsets the initial effect of the increase in $g(Z)$. To see this, suppose that the decrease in $P_{Z}$ just brings the isocost line back to the original position. In this situation, since there is no change in ( $\omega$ and) $V$, the lower $P_{Z}$ is inconsistent with the given commodity-price ratio $\bar{P}_{X}^{*}\left(=a P_{Z}+V\right)$. Using similar logic, it is straightforward to note that this inconsistency will continue to arise if the effect from the decrease in $P_{Z}$ is even stronger.

To formalize the above argument, we now demonstrate algebraically that an increase in $\varphi$ will raise $\omega$ at constant terms of trade. As the Lerner diagram indicates, both $P_{Z} g(Z)$ and $V$ are positively related with $\omega$, so that we can define $P_{Z} g(Z)=h(\omega)$ where $\frac{d h(\cdot)}{d \omega}>0 .{ }^{31}$ In addition, $P_{X}^{*}=a P_{Z}+V(\omega)$ implies that $P_{Z}$ can be written as a function $P_{Z}\left(\omega, P_{X}^{*}\right)$, where $\frac{\partial P_{Z}(\cdot)}{\partial \omega}<0$ and $\frac{\partial P_{Z}}{\partial P_{X}^{*}}>0$. Taken together, we obtain

$$
g(Z)=\frac{h(\omega)}{P_{Z}\left(\omega, P_{X}^{*}\right)}
$$

from which we can solve for $Z$ as follows

$$
Z=\tilde{Z}\left(\omega, P_{X}^{*}\right) \equiv \tilde{g}\left(\frac{h(\omega)}{P_{Z}\left(\omega, P_{X}^{*}\right)}\right)
$$

\footnotetext{
${ }^{31}$ Here, $h(\omega) \equiv \frac{f_{Y}^{\prime}\left(k_{Y}(\omega)\right)}{f_{Z}^{\prime}\left(k_{Z}(\omega)\right)}$ where $f_{i}^{\prime}(\bullet)$ represents the marginal product of skilled labor in industry $i(=z, Y)$, and therefore $\frac{1}{h^{\prime}(\omega)}$ is equivalent to a standard Stolper-Samuelson derivative.
} 
where $\tilde{g}(\cdot)$ is the inverse function of $g(\cdot)$; and $\frac{\partial \tilde{Z}}{\partial \omega}=\tilde{g}^{\prime}(\cdot)\left(\frac{1}{P_{Z}} \frac{d h(\cdot)}{d \omega}-\frac{h}{P_{Z}^{2}} \frac{\partial P_{Z}}{\partial \omega}\right)>0$ since $\tilde{g}^{\prime}(\cdot)>0, \frac{d h(\cdot)}{d \omega}>0$ and $\frac{\partial P_{Z}}{\partial \omega}<0$.

Note that $Z$ from (48) and (49) must be equal. We therefore have

$$
Z(\varphi, \omega, \bar{S}, \bar{L})=\tilde{Z}\left(\omega, P_{X}^{*}\right)
$$

Totally differentiating (50) at constant $P_{X}^{*}$ yields

$$
\frac{\partial Z}{\partial \varphi} d \varphi+\frac{\partial Z}{\partial \omega} d \omega=\frac{\partial \tilde{Z}}{\partial \omega} d \omega
$$

Then the solution we are seeking is given by

$$
\left.\frac{d \omega}{d \varphi}\right|_{\vec{P}_{X}^{*}}=\frac{\frac{\partial Z}{\partial \varphi}}{\left(\frac{\partial \tilde{Z}}{\partial \omega}-\frac{\partial Z}{\partial \omega}\right)},
$$

where $\frac{\partial Z}{\partial \varphi}>0$ and $\frac{\partial \tilde{Z}}{\partial \omega}>0$ as demonstrated above. Moreover, full employment implies that $\frac{\partial Z}{\partial \omega}>0$ because good $Z$ is the most skilled-labor intensive, which could be easily shown by using the endowment identity. A simple proof for this positive relationship follows shortly below.

Note that although both $\frac{\partial Z}{\partial \omega}$ and $\frac{\partial \tilde{Z}}{\partial \omega}$ are positive, an unambiguous sign of $\left(\frac{\partial \tilde{Z}}{\partial \omega}-\frac{\partial Z}{\partial \omega}\right)$ can still be obtained. The difference between $\frac{\partial Z}{\partial \omega}$ and $\frac{\partial \tilde{Z}}{\partial \omega}$ is that the latter is obtained at constant $P_{X}^{*}$ whereas the former is not. As explained above, in order to hold 
$P_{X}^{*}$ constant any increase in $\omega$ requires a decrease in $P_{Z}$, which would rotate the isocost line, partially counteracting the original increase in $\omega$. In this case, $Z$ must increase further (through $g(Z)$ ) to offset the negative effect from the drop in $P_{Z}$ to maintain the initial increase of $\omega$. Therefore, for any given increase in $\omega$, the expansion must be higher for $\tilde{Z}\left(\omega, P_{X}^{*}\right)$ than for $Z(\varphi, \omega, \bar{S}, \bar{L})$, which implies that $\left(\frac{\partial \tilde{Z}}{\partial \omega}-\frac{\partial Z}{\partial \omega}\right)>0$.

Therefore, each marginal increase in $\varphi$ causes a higher wage ratio and hence, falling skill intensities which will result in a reallocation of endowments between industries. ${ }^{32}$ To see this, recall that the full-employment identity is given by

$$
\frac{\bar{S}}{\bar{L}} \equiv k_{z} \frac{L_{Z}}{\bar{L}}+k_{T} \frac{L_{T}}{\bar{L}}+k_{Y} \frac{L_{Y}}{\bar{L}} \cdot 33
$$

Given the fixed endowment ratio, with falling $k_{Z}, k_{T}$ and $k_{Y}$ there must be an increase in the weight assigned to the relatively more skilled labor intensive good(s). Due to the fixed-proportion relationship between $Z$ and $T+\varphi, L_{Z}$ and $L_{T}$ have to increase (given the level of $\varphi$ ), while $L_{Y}$ must fall. ${ }^{34}$ But with $k_{Y}$ also falling, $S_{Y}$ should fall accordingly.

${ }^{32}$ The above argument does not apply to the last marginal increase in $\varphi$ before reaching complete outsourcing where there is no domestic production of $T$ and the home country only faces a foreign price $V^{*}$. In this situation, there is an expansion in $Z$ due to the same logic and an increase in $P_{Z}$ because of the lower $V^{*}$ given that $P_{X}^{*}=a P_{Z}+V^{*}$. Therefore, the corresponding increase in $P_{Z} g(Z)$ will flatten the isocost line leading to a higher $\omega$. Although the change in $P_{Z}$ is opposite to the discussion above, the overall impact of $\varphi$ on $\omega$ is qualitatively the same.

${ }^{33}$ As indicated above, each increase of $\varphi$ is associated with a decrease of the domestic production of $T$ as the economy moves from free trade to outsourcing, so that each different level of $T$ is reflected by the presence of $L_{T}$ in the identity during this non-instantaneous movement. It is clear that $L_{T}=0$ at complete outsourcing, and therefore we can drop the second expression on the right-hand side when $T=0$.

${ }^{34}$ To make it simpler to follow, by substitution of (44.2) and (45.1) we can rewrite the identity as

$$
\frac{\bar{S}}{\bar{L}} \equiv \frac{\left(k_{Z}-k_{Y}\right)}{f_{Z} L} \frac{Z}{g(Z)}+\frac{\left(k_{T}-k_{Y}\right)}{f_{T} L}\left(\frac{Z}{a}-\varphi\right)+k_{Y}
$$


Industry $Y$ therefore loses both factors and must experience a decline in its output, while industry $Z$ gains both factors and its output must expand. ${ }^{35}$

In summary, outsourcing raises the output of good $Z$ at constant terms of trade since the impacts in both parts of the decomposition move in the same direction. However, the direction of the net change in the output of good $Y$ is ambiguous, since industry $Y$ expands in the first part of the decomposition but contracts in the second part. Returning to $(50)$ we can solve for $\omega$ in terms of $\varphi$ and $P_{X}^{*}$ as $\omega\left(\varphi, P_{X}^{*}\right)$. Rewriting the production function of good $Y$ in the same manner as (48) and then substituting in $\omega\left(\varphi, P_{X}^{*}\right)$, we have

$$
Y=Y\left(\varphi, \omega\left(\varphi, P_{X}^{*}\right), \bar{S}, \bar{L}\right)
$$

Totally differentiating this equation with respect to $\varphi$ at constant price $\bar{P}_{X}^{*}$ yields

$$
\left.\frac{d Y}{d \varphi}\right|_{\bar{P}_{X}^{*}}=\beta_{1}+\beta_{2}
$$

where $\beta_{1} \equiv \frac{\partial Y}{\partial \varphi}>0$ and $\beta_{2} \equiv \frac{\partial Y}{\partial \omega} \frac{\partial \omega}{\partial \varphi}<0$, since $\frac{\partial Y}{\partial \omega}<0$ and $\frac{\partial \omega}{\partial \varphi}>0$ as shown above.

Of course, the movement from free trade to complete outsourcing is not infinitesimal, but is associated with a finite change of $\varphi$, which can be regarded as the sum (integral) of all the infinitesimal moves. With regard to $\left.\frac{d Y}{d \varphi}\right|_{\bar{P}_{X}^{*}}$ above, because the sign of this As is clear here, given that $\frac{\left(k_{Z}-k_{Y}\right)}{f_{Z} L}>0$ and $\frac{\left(k_{T}-k_{Y}\right)}{f_{T} L}>0$ as well as $d\left(\frac{Z}{g(Z)}\right)>0$, with a falling $k_{Y}$ there must be an increase in $Z$ at any specific level of $\varphi$. ${ }^{35}$ This demonstration shows $\frac{\partial Z}{\partial \omega}>0, \frac{\partial T}{\partial \omega}>0$ and $\frac{\partial Y}{\partial \omega}<0$. 
derivative is ambiguous, the sign of the integral over these infinitesimal changes must be also ambiguous.

\subsubsection{Domestic Consumption}

Having considered the production side at Home, we shall now turn to the domestic demand side. Let $I$ denote national income, which is given by

$$
I(\omega, \bar{S}, \bar{L})=W_{S} \bar{S}+W_{L} \bar{L}
$$

Totally differentiating (51) yields

$$
\begin{aligned}
\frac{\partial I}{\partial \omega} & =\frac{\bar{S} d W_{S}+\bar{L} d W_{L}}{d \omega}, \\
& =\bar{S} \frac{d W_{L}}{d \omega}\left(-\frac{a_{Y L}}{a_{Y_{S}}}+\frac{\bar{L}}{\bar{S}}\right)>0,
\end{aligned}
$$

where the second line of $(52)$ is obtained by using the condition $a_{Y S} d W_{S}+a_{Y L} d W_{L}=0 . .^{36}$

As demonstrated, outsourcing causes an increase in $\omega(d \omega>0)$ and a decline in $W_{L}$ $\left(d W_{L}<0\right)$ at constant terms of trade, while the earlier assumption that $k_{Z}>\frac{\bar{S}}{L}>k_{Y}$ ensures that $-\frac{a_{Y L}}{a_{Y_{s}}}+\frac{\bar{L}}{\bar{S}}<0$. Taken these conditions together, (52) therefore indicates that $d I>0$.

According to (35) and (36), domestic demand $Y^{D}$ can be defined as a function of the commodity-price ratio and national income. Using (51), we therefore have

\footnotetext{
${ }^{36}$ Recall the fact that each firm minimizes unit cost, taking factor prices as fixed. Therefore, the minimumunit-cost condition, which equates the marginal rate of technical substitution (among the two factors) and the ratio of factor prices, implies $W_{S} d a_{T S}+W_{L} d a_{T L}=0$. Totally differentiating (6.2) $a_{Y S} W_{S}+a_{Y L} W_{L}=P_{Y}$ and using the resulting condition, we obtain $a_{Y S} d W_{S}+a_{Y L} d W_{L}=0$, given that good $Y$ is the numeraire $\left(\hat{P}_{Y}=0\right)$.
} 


$$
Y^{D}=Y^{D}\left[P_{X}^{*}, I\left(\omega\left(\varphi, P_{X}^{*}\right), \bar{S}, \bar{L}\right)\right]
$$

Take the derivative of $Y^{D}$ with respect to $\varphi$ at constant $P_{X}^{*}$ to obtain

$$
\left.\frac{d Y^{D}}{d \varphi}\right|_{\bar{P}_{X}^{*}}=\alpha
$$

where $\alpha \equiv \frac{\partial Y^{D}}{\partial I} \frac{\partial I}{\partial \omega} \frac{\partial \omega}{\partial \varphi}>0$ since $\frac{\partial Y^{D}}{\partial I}>0, \frac{\partial I}{\partial \omega}>0$ and $\frac{\partial \omega}{\partial \varphi}>0$.

\subsubsection{Foreign Production and Consumption}

The above discussion can be readily modified for the foreign country where there is no externality and $T^{*}$ is the exportable good. ${ }^{37}$ Considering this modification, we first rewrite $(44.1),(44.2)$ and $(45)$ here as

$$
\begin{aligned}
\bar{S}^{*} & =\frac{Z^{*}}{f_{Z}^{*}\left(k_{Z}^{*}\right)} k_{Z}^{*}+\frac{T^{*}}{f_{T}^{*}\left(k_{T}^{*}\right)} k_{T}^{*}+\frac{Y^{*}}{f_{Y}^{*}\left(k_{Y}^{*}\right)} k_{Y}^{*}, \\
\bar{L}^{*} & =\frac{Z^{*}}{f_{Z}^{*}\left(k_{Z}^{*}\right)}+\frac{T^{*}}{f_{T}^{*}\left(k_{T}^{*}\right)}+\frac{Y^{*}}{f_{Y}^{*}\left(k_{Y}^{*}\right)}, \\
Z^{*} & =a\left(T^{*}-\varphi\right),
\end{aligned}
$$

where $a^{*}=a$ given the earlier assumption that both economies have the same production technologies in producing $X$. It is clear that we can obtain the expressions for $Z^{*}, T^{*}$ and $Y^{*}$ in terms of $\varphi, \omega^{*}, \bar{S}^{*}$ and $\bar{L}^{*}$ by simultaneously solving these three equations. Now, using the same logic as for Home, we can derive the following properties:

\footnotetext{
${ }^{37}$ This is not a really restrictive assumption, but we just assume that the foreign country remain diversified in production of all three goods.
} 


$$
\begin{aligned}
& \frac{\partial Z^{*}}{\partial \varphi}=-\frac{a b_{2}^{*}}{a b_{1}^{*}+b_{2}^{*}}, \\
& \frac{\partial T^{*}}{\partial \varphi}=\frac{a b_{1}^{*}}{a b_{1}^{*}+b_{2}^{*}}, \\
& \frac{\partial Y^{*}}{\partial \varphi}=-\frac{a b_{3}}{a b_{1}^{*}+b_{2}^{*}},
\end{aligned}
$$

where $b_{1} \equiv \frac{k_{Z}^{*}-k_{Y}^{*}}{f_{Z}^{*}\left(k_{Z}^{*}\right)}>0, b_{2} \equiv \frac{k_{T}^{*}-k_{Y}^{*}}{f_{T}^{*}\left(k_{T}^{*}\right)}>0$ and $b_{3} \equiv \frac{f_{Y}^{*}\left(k_{Y}^{*}\right)\left(k_{Z}^{*}-k_{T}^{*}\right)}{f_{T}^{*}\left(k_{T}^{*}\right) f_{Z}^{*}\left(k_{Z}^{*}\right)}>0$. Given $0<a<1$, it is straightforward to see that $-1<\frac{\partial Z^{*}}{\partial \varphi}<0,1>\frac{\partial T^{*}}{\partial \varphi}>0$ and $\frac{\partial Y^{*}}{\partial \varphi}<0$.

Recall that all the industries abroad exhibit CRS technologies, and hence the Samuelson one-to-one correspondence holds. Thus, holding the terms of trade constant will maintain both the wage ratio $\omega^{*}$ and skill intensity $k_{i}^{*}\left(i=Z^{*}, T^{*}, Y^{*}\right)$ constant. Therefore, (53) shows that the domestic outsourcing activity will lead to an increase in the production of $T^{*}$ and a consequent reduction in the outputs of goods $Z^{*}$ and $Y^{*}$, at constant terms of trade. This is illustrated in Figure 7 where $T^{*}$ expands from $a b$ to $c d$ as $\varphi$ increases, while $Z^{*}$ and $Y^{*}$ contract following the arrows along $O a$ and $O^{\prime} b$ respectively. (Figure 5 and Figure 7 haven been labeled similarly to make comparison of them self-explanatory.)

Since $\omega^{*}$ depends only on $P_{X}^{*}$, we can rewrite the production function of $Y^{*}$ as

$$
Y^{*}=Y^{*}\left(\varphi, \omega^{*}\left(P_{X}^{*}\right), \bar{S}, \bar{L}\right)
$$

Taking the derivative of $Y^{*}$ with respect to $\varphi$ at constant commodity prices, we have

$$
\left.\frac{d Y^{*}}{d \varphi}\right|_{\bar{P}_{X}^{*}}=\beta_{1}^{*}
$$


Figure 7: The effect of Outsourcing on

Foreign Production at Constant Terms of Trade

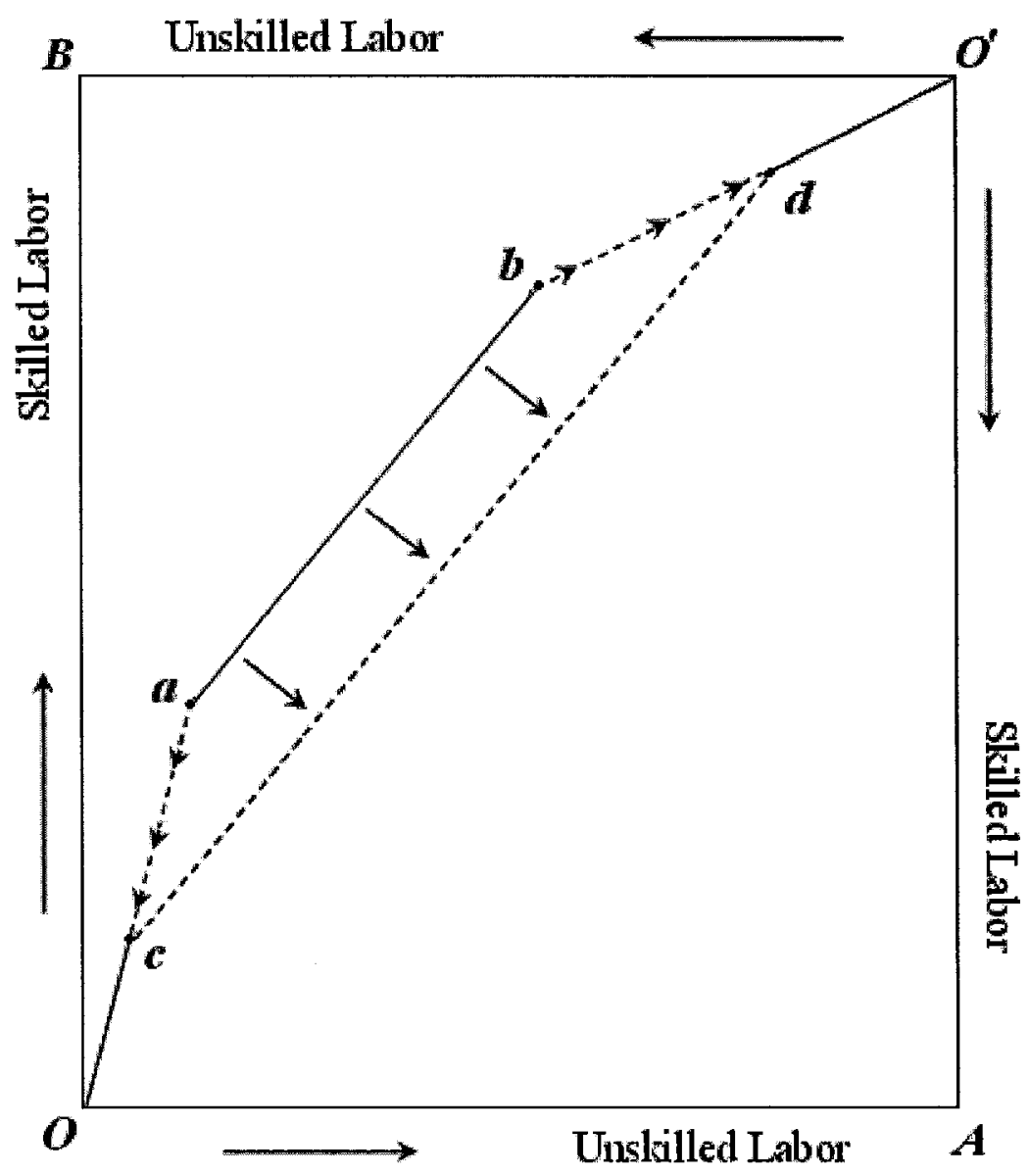


where $\beta_{1}^{*} \equiv \frac{\partial Y^{*}}{\partial \varphi}<0$. As for national income given by $I^{*}\left(\omega^{*}\left(P_{X}^{*}\right), \bar{S}^{*}, \bar{L}^{*}\right)$, it will not be affected in this case, and hence the demands for both commodities remain unchanged.

So far we have identified the impacts of outsourcing on the supply and demand for each good in both countries. Before proceeding to the next section, some further clarification is useful. First, it does not matter whether the home country chooses good $X$ or $Y$ as the payment for the import $T$, because world markets will eventually clear and determine the trade pattern for the final goods. Second, in contrast to free trade, where the budget constraint embodies equality between the value of total production and national expenditure, we now have to take account of the payment for the outsourced part as follows:

$$
P_{X}^{*}\left(X-X^{D}\right)+\left(Y-Y^{D}\right)=V T^{O}
$$

where $T^{O}$ denotes the import volume of $T$.

\subsection{The Effect on Terms of Trade}

Influencing both demands and supplies, outsourcing may cause a trade imbalance at the initial terms of trade. Therefore, an adjustment in commodity prices is required in order to clear world markets and restore equilibrium. As stated earlier, we will limit our attention to the case of Home exporting $X$, although the analysis can be readily extended to the other case where good $X$ is the home importable.

Define $E_{D}^{w} \equiv M-E^{*}$, which is the world excess demand for good $Y$, where $M$ and $E^{*}$ represent domestic import and foreign export, respectively. Initially, $E_{D}^{w}$ is equal to 
zero in free trade. Using all the production and demand functions of good $Y$ defined for both countries in the previous section, we therefore have

$$
\begin{aligned}
E_{D}^{w}= & Y^{D}\left[P_{X}^{*}, I\left(\omega\left(\varphi, P_{X}^{*}\right), \bar{S}, \bar{L}\right)\right]-Y\left[\varphi, \omega\left(\varphi, P_{X}^{*}\right), \bar{S}, \bar{L}\right] \\
& -Y^{*}\left[\varphi, \omega^{*}\left(P_{X}^{*}\right), \bar{S}^{*}, \bar{L}^{*}\right]+Y^{D^{*}}\left[P_{X}^{*}, I^{*}\left(\omega^{*}\left(P_{X}^{*}\right), \bar{S}^{*}, \bar{L}^{*}\right)\right],
\end{aligned}
$$

Totally differentiate $E_{D}^{w}$ with respect to $\varphi$ at constant price $P_{X}^{*}$ to obtain

$$
d E_{D}^{w}=\frac{\partial Y^{D}}{\partial I} \frac{\partial I}{\partial \omega} \frac{\partial \omega}{\partial \varphi} d \varphi-\frac{\partial Y}{\partial \varphi} d \varphi-\frac{\partial Y}{\partial \omega} \frac{\partial \omega}{\partial \varphi} d \varphi-\frac{\partial Y^{*}}{\partial \varphi} d \varphi
$$

where we have used the fact that outsourcing has no impact on foreign demand at constant terms of trade. By substitution of all the coefficients defined above, we rewrite $d E_{D}^{w}$ more compactly as

$$
d E_{D}^{w}=\left(\alpha-\beta_{1}-\beta_{2}-\beta_{1}^{*}\right) d \varphi
$$

This change in excess demand brought out by outsourcing at the original price ratio $P_{X}^{*}$ must of course be balanced by a matching change in the excess supply of good $Y$, resulting from an adjustment in the terms of trade. Define the world excess supply of $\operatorname{good} Y$ as $E_{S}^{w} \equiv E^{*}-M$. Totally differentiating $E_{S}^{w}$ with respect to $P_{X}^{*}$ at constant $\varphi$ and evaluating the differential at $\varphi=0$, it follows after simple manipulation that

$$
d E_{S}^{w}=\frac{M}{P_{X}^{*}}\left(1-e^{*}-e\right) d P_{X}^{*}
$$

where $e$ and $e^{*}$ are the price elasticities of domestic and foreign import demand, respectively. ${ }^{38}$ To derive the required change in the terms of trade for clearing world

${ }^{38}$ Specifically, $e \equiv \frac{\hat{M}}{\hat{P}_{X}^{*}}$ and $e^{*}=e_{S}^{*}+1$, where $e_{S}^{*} \equiv-\frac{\hat{E}^{*}}{\hat{P}_{X}^{*}}$ denoting the price elasticity of foreign export supply. 
markets and restoring equilibrium, we set $d E_{D}^{w}=d E_{S}^{w}$. Using (54) and (55), we obtain:

$$
\frac{d P_{X}^{*}}{d \varphi}=\frac{M}{P_{X}^{*}} \frac{\left(\beta_{1}+\beta_{2}+\beta_{1}^{*}-\alpha\right)}{\left(e^{*}+e-1\right)}
$$

The well-known Walrasian market-stability condition implies $\left(e^{*}+e-1\right)>0$, so that the impact on the terms of trade will depend on the net effect of $\left(\beta_{1}+\beta_{2}+\beta_{1}^{*}-\alpha\right)$. According to the previous discussion, only $\beta_{1}$ is positive while the last three terms are negative, including the signs. We may therefore conclude:

$$
\frac{d P_{X}^{*}}{d \varphi} \gtreqless 0 \quad \text { iff } \quad \beta_{1} \gtreqless \alpha-\beta_{2}-\beta_{1}^{*}
$$

\subsection{The Effect on Social Welfare:}

To summarize, the implications of outsourcing contain three components which have been discussed in the previous sections respectively. The net effect on social welfare will therefore depend on the signs and magnitudes of these three parts:

1. The effect on the production of industry $Z$, which has been under-produced from the social viewpoint;

2. The cost saving in acquiring $T$ through outsourcing;

3. The terms-of-trade effect that may work either in favor of or against Home.

We shall now use comparative-static analysis to explore the overall effect on social welfare. Totally differentiating social utility function $U\left(X^{D}, Y^{D}\right)$ with respect to $\varphi$, we obtain: 


$$
\frac{d U}{d \varphi}=\frac{\partial U}{\partial Y^{D}}\left[P_{X}^{*} \frac{\partial X}{\partial \varphi}+\frac{\partial Y}{\partial \varphi}+\left(P_{X}^{*}\left(\frac{\partial Y}{\partial X}\right)^{-1}+1\right) \frac{\partial Y}{\partial P_{X}^{*}} \frac{d P_{X}^{*}}{d \varphi}-P_{X}^{*} \frac{d E}{d \varphi}+\frac{d M}{d \varphi}\right] .{ }^{39}
$$

Balanced trade requires the following condition:

$$
P_{X}^{*} E=M+V^{*} T^{O},
$$

where $E$ is home export of good $X$ while $M$ and $T^{o}$, as defined previously, denote domestic import of good $Y$ and the quantity of the outsourced part $T$ respectively. Totally differentiating (57) with respect to $\varphi$ yields

$$
\frac{d M}{d \varphi}=P_{X}^{*} \frac{d E}{d \varphi}+E \frac{d P_{X}^{*}}{d \varphi}-T^{o} \frac{d V^{*}}{d \varphi}-V^{*}
$$

where we have used the fact $\frac{d T^{o}}{d \varphi}=1$. Substituting (58) into (56), we obtain:

$$
\frac{d U}{d \varphi}=\frac{\partial U}{\partial Y^{D}}\left[P_{X}^{*} \frac{\partial X}{\partial \varphi}+\frac{\partial Y}{\partial \varphi}-T^{o} \frac{d V^{*}}{d \varphi}-V^{*}+\left(P_{X}^{*}\left(\frac{\partial Y}{\partial X}\right)^{-1}+1\right) \frac{\partial Y}{\partial P_{X}^{*}} \frac{d P_{X}^{*}}{d \varphi}+E \frac{d P_{X}^{*}}{d \varphi}\right]
$$

Here, the external effect is embodied in both the first and fifth terms in the square bracket

${ }^{39}$ The derivation of equation $(56)$ is given below:

$$
\begin{aligned}
\frac{d U}{d \varphi} & =\frac{\partial U}{\partial Y^{D}}\left(P_{X}^{*} \frac{d X^{D}}{d \varphi}+\frac{d Y^{D}}{d \varphi}\right), \\
& =\frac{\partial U}{\partial Y^{D}}\left(P_{X}^{*} \frac{d\left[X\left(\varphi, P_{X}^{*}(\varphi), \bar{S}, \bar{L}\right)-E\right]}{d \varphi}+\frac{d\left[Y\left(\varphi, P_{X}^{*}(\varphi), \bar{S}, \bar{L}\right)+M\right]}{d \varphi}\right), \\
& =\frac{\partial U}{\partial Y^{D}}\left(P_{X}^{*} \frac{\partial X}{\partial \varphi}+P_{X}^{*} \frac{\partial X}{\partial P_{X}^{*}} \frac{d P_{X}^{*}}{d \varphi}-P_{X}^{*} \frac{d E}{d \varphi}+\frac{\partial Y}{\partial \varphi}+\frac{\partial Y}{\partial P_{X}^{*}} \frac{d P_{X}^{*}}{d \varphi}+\frac{d M}{d \varphi}\right), \\
& =\frac{\partial U}{\partial Y^{D}}\left[P_{X}^{*} \frac{\partial X}{\partial \varphi}+\frac{\partial Y}{\partial \varphi}+\left(P_{X}^{*}\left(\frac{\partial Y}{\partial X}\right)^{-1}+1\right) \frac{\partial Y}{\partial P_{X}^{*}} \frac{d P_{X}^{*}}{d \varphi}-P_{X}^{*} \frac{d E}{d \varphi}+\frac{d M}{d \varphi}\right] .
\end{aligned}
$$

Here, the production functions of $X$ and $Y$ are written as $X\left(\varphi, P_{X}^{*}(\varphi), \bar{S}, \bar{L}\right)$ and $Y\left(\varphi, P_{X}^{*}(\varphi), \bar{S}, \bar{L}\right)$ respectively. In these functions $\varphi$ determines the outsourcing volume and therefore the residual amounts of endowments available for $Z(X)$ and $Y$, while $P_{X}^{*}$ determines the intersection point of the price line and the $\mathrm{PPF}^{\mathrm{XY}}$. 
of $(56.1)$, which denote the impacts of outsourcing on the production of good $X(Z)$ at constant terms of trade and when terms of trade are changed respectively. The term $-V^{*}$ reflects the fact that the home country has to pay for what she has outsourced abroad while the term $-T^{o} \frac{d V^{*}}{d \varphi}$ denotes the cost saving. ${ }^{40}$ Let $\Psi$ denote the first four terms in the square bracket, representing the positive effects (expansion in industry $X(Z)$ and cost saving in $V$ ) brought out by outsourcing at constant terms of trade. Following this, we can simplify $(56.1)$ to

$$
\frac{d U}{d \varphi}=\frac{\partial U}{\partial Y^{D}}\left\{\Psi+\left[P_{X}^{*}\left(\frac{\partial Y}{\partial X}\right)^{-1}+1\right] \frac{\partial Y}{\partial P_{X}^{*}} \frac{d P_{X}^{*}}{d \varphi}+E \frac{d P_{X}^{*}}{d \varphi}\right\}
$$

In the standard CRS model, the term in the square bracket is zero by profit maximization because the price ratio is always equal to the negative slope of the PPF. However, the demonstrated fact that the price line is steeper than the PPF in the present model implies $\left[P_{X}^{*}\left(\frac{\partial Y}{\partial X}\right)^{-1}+1\right]<0$ and it is known $\frac{\partial Y}{\partial P_{X}^{*}}<0$ by the normal output response to price. Therefore, with the presence of the positive externality, the term $\left[P_{X}^{*}\left(\frac{\partial Y}{\partial X}\right)^{-1}+1\right] \frac{\partial Y}{\partial P_{X}^{*}}$ would indicate the gain (loss) from the increase (decrease) in the production of $X(Z)$ as trading prices increases (decreases). The final term on the righthand side of (56.1) reflects the terms-of-trade effect. To simplify the expression, define

\footnotetext{
${ }^{40}$ There should be no confusion regarding the notation $V^{*}$. Here, we are considering the change of the domestic user cost of $T$ as outsourcing occurs. The fact $V>V^{*}$ implies that the user cost for the amount $T^{O}$ is falling and therefore the term $-T^{o} \frac{d V^{*}}{d \varphi}$ is positive indicating the cost saving caused by outsourcing.
} 


$$
\begin{aligned}
& \Omega \equiv\left[P_{X}^{*}\left(\frac{\partial Y}{\partial X}\right)^{-1}+1\right] \frac{\partial Y}{\partial P_{X}^{*}} \text { and rewrite }(56.2) \text { as } \\
& \qquad \frac{d U}{d \varphi}=\frac{\partial U}{\partial Y^{D}}\left(\Psi+(\Omega+E) \frac{d P_{X}^{*}}{d \varphi}\right) .
\end{aligned}
$$

The economic intuition behind (58) is as follows. Outsourcing definitely yields benefits to Home denoted by $\Psi$, which are measured by the expansion of industry $Z$ and the cost saving in $V$ at the constant price $P_{X}^{*}$. However, the ambiguous change (if any) in the world price will not only have the usual terms-of-trade effect through $E$ but also influence the production of good $X(Z)$ through $\Omega$. The overall effect on welfare is therefore uncertain. However, for the foreign country, any improvement (deterioration) in terms of trade will be a net gain (loss) since there is no externality issue. We may summarize the derived conclusions as follows:

\section{Proposition 1}

$A$ : if $\frac{d P_{X}^{*}}{d \varphi}>0$ which implies that terms of trade are improved in favor of Home and there is a further expansion in the production of good $Z$, then Home will be better off whereas Foreign will lose due to the deterioration in terms of trade.

$\boldsymbol{B}:$ If $\frac{d P_{X}^{*}}{d \varphi}=0$ which implies that terms of trade are not affected, in this case the home country will gain from the cost saving and expansion in industry $Z$ at the constant terms of trade while foreign welfare will be unaffected.

$C:$ If $\frac{d P_{X}^{*}}{d \varphi}<0$ which implies that terms of trade are deteriorated against Home and there would be a decline in the production of good $Z$ caused by this decrease in 
$P_{X}^{*}$. Following this, the net effect on domestic social welfare will be ambiguous whereas the foreign country will gain due to the improved terms of trade.

\section{Corollary 1:}

In order to raise both countries' welfare, the following inequality must be satisfied:

$$
-\frac{1}{\Omega+E}<\frac{d P_{X}^{*}}{d \varphi}<0
$$

The explanation for this condition is that the foreign country gains from the improvement in terms of trade while the home country loses in the trade respect, but the positive effect of outsourcing at the original terms of trade dominates the negative effect from this decline in $P_{X}^{*}$. The increased production efficiency due to outsourcing generates an expansion in the world PPF, which makes it possible for both countries to gain.

\subsection{The Effect on Wage Ratio}

Recall that wage ratio has been defined as a function $\omega\left(\varphi, P_{X}^{*}(\varphi)\right)$ in section 5.2. Therefore, the effect of outsourcing on wage ratio can be obtained by simply totally differentiating $\omega$ with respect to $\varphi$ as follows

$$
\frac{d \omega}{d \varphi}=\frac{\partial \omega}{\partial \varphi}+\frac{\partial \omega}{\partial P_{X}^{*}} \frac{d P_{X}^{*}}{d \varphi}
$$

It has been demonstrated that $\frac{\partial \omega}{\partial \varphi}$ (at constant terms of trade) is positive whereas the 
change in terms of trade $\frac{d P_{X}^{*}}{d \varphi}$ is uncertain. In addition, the earlier assumption of a normal output response to price, which is necessary and sufficient for validity of the StolperSamuelson Theorem, implies that $\frac{\partial \omega}{\partial P_{X}^{*}}$ is also positive. Therefore, the ambiguous change in $P_{X}^{*}$ will lead to an uncertain net effect on wage ratio $\omega$. This readily reveals the following possible outcomes:

\section{Proposition 2}

$A$ : If $\frac{d P_{X}^{*}}{d \varphi}>0$ which has a positive impact on $\omega$, then the overall effect of outsourcing will flatten the isocost line and enlarge the wage disparity against unskilled labor.

$\boldsymbol{B}:$ If $\frac{d P_{X}^{*}}{d \varphi}<0$ which has a negative impact on $\omega$, then the net effect of outsourcing on wage ratio will be ambiguous.

$C:$ If $\frac{d P_{X}^{*}}{d \varphi}=0$, then the positive effect $\frac{\partial \omega}{\partial \varphi}$ will flatten the isocost line and enlarge the wage differential relative to its free-trade level.

\subsection{Small Open Economy}

For a small open economy, the implications of outsourcing are more straightforward to address since a small country has no power to affect the terms of trade. Using $\frac{d P_{X}^{*}}{d \varphi}=0$, equation (59) simplifies to 


$$
\frac{d U}{d \varphi}=\frac{\partial U}{\partial Y^{D}} \Psi
$$

which confirms that domestic welfare is improved with the cost saving in $V$ and the expansion in industry $Z$ at the unchanged terms of trade. Moreover, equation (60) can also be simplified to

$$
\frac{d \omega}{d \varphi}=\frac{\partial \omega}{\partial \varphi}
$$

It follows that outsourcing will raise wage ratio $\omega$ in favor of skilled labor. This result is consistent with the stylized fact that in recent decades there has been a decline in the relative wage of unskilled labor in the US factor markets. In the present model, it can be easily explained. As long as the home country continues to produce the most skillintensive good, outsourcing acts like a technology improvement and therefore raises the demand for skilled labor given that the positive externality is skill-biased, which must depress the wage rate of unskilled labor.

Bearing in mind that the terms of trade are unchanged for a small country, a simple conclusion follows:

\section{Proposition 3}

$\boldsymbol{A}$ : Outsourcing will improve domestic social welfare through the cost saving and the expansion in the industry with economies of scale.

$B$ : If the home country remains incompletely specialized in industries $Z$ and $Y$, outsourcing will enlarge the wage disparity against unskilled labor. 


\section{The Minimum-Wage Economy}

\subsection{Introduction}

Arguably the most important development in recent decades in US factor markets is the decline in the relative wage of unskilled labor. By contrast, in European labor markets it is undoubtedly the rise and persistence of unemployment. Technology improvement, reductions in trade barriers and outsourcing to developing countries have been identified as the key reasons both for the rising wage disparity in US, where the wages are considered relatively flexible, and for unemployment in Europe where a variety of institutions make wages more rigid. The flexible-wage economy has been investigated in detail through the previous chapters where we have developed a possible explanation for the observed facts by showing that international outsourcing may (will) enlarge the wage disparity for a large (small) country. However, the question of labor market rigidity has not yet been addressed. Therefore, it would be interesting to modify the flexible-wage full-employment home country assumed so far to an economy with an explicit minimum wage imposed by certain institutions. We shall then examine whether free trade or outsourcing in this modified framework could be explained as the factor contributing to the rise in the domestic unemployment, which is a stylized fact in Europe.

In doing this we will build our model on the classic minimum-wage work by Brecher (1974a, b) and we will confirm that within such a framework, national factor market institutions can profoundly affect the patterns of output, employment and wages. The purpose of this chapter is to develop the minimum-wage model, derive the associated constrained transformation curve and discuss some related properties. ${ }^{41}$

\footnotetext{
${ }^{41}$ Following Brecher $(1974 \mathrm{a}, \mathrm{b})$ the term "transformation curve" will always be used in this case where the market equilibrium depends on factor market relationship and entrepreneurial behavior, in addition to
} 


\subsection{Analytical Relationships}

Recall that since $z(\cdot), T(\cdot)$ and $Y(\cdot)$ are homogenous of degree 1 , we can rewrite these production functions as follows:

$$
\begin{aligned}
& Z=g(Z) L_{Z} f_{Z}\left(k_{Z}\right), \\
& T=L_{T} f_{T}\left(k_{T}\right), \\
& Y=L_{Y} f_{Y}\left(k_{Y}\right)
\end{aligned}
$$

where $f_{Z}(\cdot) \equiv z\left(1, \frac{S_{Z}}{L_{Z}}\right), f_{T}(\cdot) \equiv T\left(1, \frac{S_{T}}{L_{T}}\right)$ and $f_{Y}(\cdot) \equiv Y\left(1, \frac{S_{Y}}{L_{Y}}\right)$.

Now suppose that the unskilled-labor market is subject to a wage floor, which is exogenously given in real terms. Let this minimum real wage be set by some institutional agreements (unions or law), and be specified in terms of good $Y$ at some fixed level denoted by $\bar{w}_{L} \cdot{ }^{42}$ Therefore, the minimum-wage constraint can be written as

$$
w_{L} \geq \bar{w}_{L}
$$

Assume that $\bar{w}_{L}$ has been specified to exceed the maximum $w_{L}$ consistent with full employment in the closed economy, so that some unskilled worker is unemployed. This implies that the constraint $(62)$ is binding with $w_{L}=\bar{w}_{L}$ and hence we have $\omega=\bar{\omega}$. Following our previous work, Home is endowed with the fixed factor supplies of skilled labor $(\bar{S})$ and unskilled labor $(\bar{L})$. Since the wage rate of skilled labor is perfectly

\footnotetext{
technology and endowments, to distinguish from the term PPF which is a purely technically schedule given the endowments.

${ }^{42}$ In Brecher (1974a, b) the validity of the Stolper-Samuelson theorem ensures no difference in the analysis whether the minimum real wage is specified in terms of good $Y$, good $X$ or constant utility. However, with the presence of an externality in industry $Z$, the Stolper-Samuelson theorem now may fail as shown in the previous chapters. When this failure occurs, given that good $Z$ is only the intermediate input of producing good $X$, specifying the real wage in terms of good $X$ or a constant-utility combination of both goods rather than good $Y$ would change both the model and outcomes. In this paper, we restrict our interest only to the case where the minimum real wage is defined in terms of good $Y$.
} 
flexible, factor $S$ must be always fully utilized. Thus, we have

$$
\begin{aligned}
& \bar{L} \geq L=L_{Z}+L_{T}+L_{Y}, \\
& \bar{S}=L_{Z} k_{Z}+L_{T} k_{T}+L_{Y} k_{Y} .
\end{aligned}
$$

Denote $\bar{k}_{i}, i=Z, T, Y$ as the skill-intensity corresponding to $\bar{\omega}$ in each industry and it is known that $\bar{k}_{Z}>\bar{k}_{T}>\bar{k}_{Y}$ by the earlier assumption. In addition, we retain the assumption throughout this paper that the home production remains incompletely specialized. By substituting $\bar{k}_{i}$ into $(61)$, we may solve for $L_{i}, i=Z, T, Y$ and then substitute both $L_{i}$ and $\bar{k}_{i}$ into $(64)$ to obtain

$$
\bar{S}=\frac{a X}{g(a X) f_{Z}\left(\bar{k}_{Z}\right)} \bar{k}_{Z}+\frac{X}{f_{T}\left(\bar{k}_{T}\right)} \bar{k}_{T}+\frac{Y}{f_{Y}\left(\bar{k}_{Y}\right)} \bar{k}_{Y},
$$

where the fixed-proportion condition $a X=a T=Z$ has been applied and the external effect $g(Z)$ has also been written as $g(a X)$. Solving $(65)$ for $Y$ yields

$$
Y=\frac{f_{Y}}{\bar{k}_{Y}} \bar{S}-\frac{a \bar{k}_{Z} f_{Y}}{g(a X) \bar{k}_{Y} f_{Z}} X-\frac{\bar{k}_{T} f_{Y}}{\bar{k}_{Y} f_{T}} X .
$$

Here, for simplicity we have omitted the argument of each function $f_{i}, i=Z, T, Y$.

Equation (66) describes the minimum-wage constrained transformation curve, which is a Rybczynski-type locus at the fixed wage ratio $\bar{\omega}$. The fact that it is only a Rybczynski-type locus and not a real Rybczynski line is for the following two reasons. First, as shown below, this constrained transformation curve is not a straight line as in the standard CRS case but is convex to the origin. Second, in contrast to the assumption of constant commodity prices for the Rybczynski Theorem, the commodity prices in the present framework do not remain constant as we move along this curve due to the 
externality. Taking the derivative of $(66)$ with respect to $X$ yields the slope of the curve:

$$
\frac{d Y}{d X}=-\frac{(1-\varepsilon) a}{g(a X)} \frac{\bar{k}_{Z} f_{Y}}{\bar{k}_{Y} f_{Z}}-\frac{\bar{k}_{T} f_{Y}}{\bar{k}_{Y} f_{T}}
$$

where $\varepsilon$, as defined before, is the elasticity of the positive externality which was assumed to be less than 1 . Since all individual terms on the right-hand side of $(67)$ are positive, the sign of $\frac{d Y}{d X}$ is therefore negative, which implies that this curve is downward sloping. In addition, given that $g(a X)=1$ and $\varepsilon=0$ in the CRS case, equation (67) also indicates that this curve is relatively flatter than the standard Rybczynski line. This means that, compared with the CRS case, giving up one unit of good $Y$ leads to a larger expansion in industry $X$ due to the externality in the present model.

Turning now to the curvature of the curve, we take the derivative of (67) to obtain

$$
\frac{d^{2} Y}{d X^{2}}=\frac{a \varepsilon(1-\varepsilon)}{g(a X) X} \frac{\bar{k}_{Z} f_{Y}}{\bar{k}_{Y} f_{Z}}
$$

The positive sign of $\frac{d^{2} Y}{d X^{2}}$ confirms the convexity of the constrained transformation curve, which is because the external effect $g(Z)$ undermines the linearity of the relationship between output levels and factors employed as described by the Rybczynski Theorem in the conventional CRS case. We may now derive the effect on employment of unskilled labor as the home country moves along the curve at the fixed wage ratio $\bar{\omega}$. Substituting $L_{i}, i=Z, T, Y$ into $(63)$, we have

$$
L=\frac{a X}{g(a X) f_{Z}\left(\bar{k}_{Z}\right)}+\frac{X}{f_{T}\left(\bar{k}_{T}\right)}+\frac{Y}{f_{Y}\left(\bar{k}_{Y}\right)}
$$


Totally differentiating (69) and combining with (67), it follows after simple manipulation that:

$$
\frac{d L}{d Y}=-\frac{1}{f_{Y}\left(\bar{k}_{Y}\right)} \frac{\frac{a(1-\varepsilon)}{f_{Z} g(Z)} \bar{k}_{Y}+\frac{1}{f_{T}} \bar{k}_{Y}}{\frac{a(1-\varepsilon)}{f_{Z} g(Z)} \bar{k}_{Z}+\frac{1}{f_{T}} \bar{k}_{T}}+\frac{1}{f_{Y}\left(\bar{k}_{Y}\right)}>0
$$

Given the ranking $\bar{k}_{Z}>\bar{k}_{T}>\bar{k}_{Y}$, the sign of $\frac{d L}{d Y}$ is positive. Alternatively, we can derive the effect on employment in terms of changes in output of good $X$ :

$$
\frac{d L}{d X}=\frac{a(1-\varepsilon)}{f_{Z} g(a X)}\left(1-\frac{\bar{k}_{Z}}{\bar{k}_{Y}}\right)+\frac{1}{f_{T}}\left(1-\frac{\bar{k}_{T}}{\bar{k}_{Y}}\right)<0 .
$$

Therefore, with a rising output level of good $Y$ employment of unskilled labor will increase, while if output of good $X$ goes up, employment of unskilled labor will decrease.

\subsection{The Constrained Transformation Curve}

In the CRS case of Brecher (1974a, b), given the level of the minimum wage, the Samuelson one-to-one correspondence leads to the immediate identification of the associated price ratio and hence the section of the original full-employment $\mathrm{PPF}^{\mathrm{XY}}$ which will not be affected by the minimum wage. However, since in the present model the Stolper-Samuelson Theorem may fail and one price ratio may be consistent with more than one production point on the $\mathrm{PPF}^{\mathrm{XY}}$, we shall avoid any of the difficulties associated with this ambiguity by conducting our analysis using the one-to-one link between real wage and output ratio directly. Recall (13.1) and (13.2) from Chapter 3: 


$$
\begin{aligned}
& \hat{X}=\frac{\mu_{X}}{|\lambda|} \hat{\omega}, \\
& \hat{Y}=-\frac{\mu_{Y}}{|\lambda|} \hat{\omega} .
\end{aligned}
$$

By simple mathematical manipulation we obtain

$$
\widehat{\left(\frac{X}{Y}\right)}=\frac{\mu_{X}+\mu_{Y}}{|\lambda|} \hat{\omega},
$$

where all the coefficients $\mu_{X}, \mu_{Y}$ and $|\lambda|$ are positive. Equation (72) indicates that wage ratio $\omega$ is positively related to output ratio $X / Y$ within the original flexible wages and full employment model. Similarly, the relation between $\omega$ and the real wage in terms of good $Y$ can also be obtained by solving (20.4) and (20.5) from Chapter 3:

$$
\begin{gathered}
\widehat{\left(\frac{W_{L}}{P_{Y}}\right)}=-\frac{\theta_{Y S}^{\prime}}{\left|\theta^{\prime}\right|} \hat{P}, \\
\hat{\omega}=\frac{1}{\left|\theta^{\prime}\right|} \hat{P},
\end{gathered}
$$

which give us

$$
\widehat{\left(\frac{W_{L}}{P_{Y}}\right)}=-\theta_{Y S}^{\prime} \hat{\omega},
$$

where $\theta_{Y S}^{\prime}>0$. Combining (72) and (73) we therefore have

$$
\widehat{\left(\frac{W_{L}}{P_{Y}}\right)}=-\frac{|\lambda| \theta_{Y S}^{\prime}}{\mu_{X}+\mu_{Y}} \widehat{\left(\frac{X}{Y}\right)} .
$$

Equation(74), avoiding the ambiguity associated with the commodity prices, indicates that the real wage in terms of good $Y$ would decline as output ratio $X / Y$ increases (moving downward along the original $\mathrm{PPF}^{\mathrm{XY}}$ ). So once the minimum wage $\bar{w}_{L}$ and the 
associated production point are determined, we can easily see that the segment to the left of this point is with an above-minimum wage while that to the right of this point is with a below-minimum wage. ${ }^{43}$

Now we illustrate the above findings in Figure 8 where $M_{2} R_{2} M_{1}$ represents the original flexible-wage full-employment $\mathrm{PPF}^{\mathrm{XY}}$ as described in the previous chapters. Here, we assume that the minimum wage is equal to the marginal product of unskilled labor at $R_{2}$. Thus the production equilibrium with an above-minimum wage occurs in the conventional full-employment manner on segment $M_{2} R_{2}$, whereas segment $R_{2} M_{1}$ with a below-minimum wage (the output ratio $X / Y$ is larger than the critical value at $R_{2}$ ) is replaced by the new transformation curve $R_{2} R_{1}$ indicated by $(66)$. In the present context where the main focus is on unemployment, the segment $M_{2} R_{2}$ is therefore not especially interesting since the minimum wage is not high enough to be a binding constraint there. Segment $R_{1} M_{1}$, corresponding to complete specialization in good $X$ will also not be discussed in the subsequent sections since we have assumed that the home country remains diversified. ${ }^{44}$ To concentrate on the case of interest involving unemployment, we can either

1. Assume that with the minimum wage related to the production at $R_{2}$, autarky occurs on the constrained transformation curve $R_{2} R_{1}$ and opening to trade or outsourcing does not have the force strong enough to move the production

\footnotetext{
${ }^{43}$ This simple relationship does not necessarily hold if the minimum-wage is specified in terms of good $X$.

${ }^{44}$ See Brecher (1974a, b) for the detailed discussion regarding the properties of this segment.
} 
Figure 8: The Effect of a Binding Minimum-Wage Constraint on the PPF

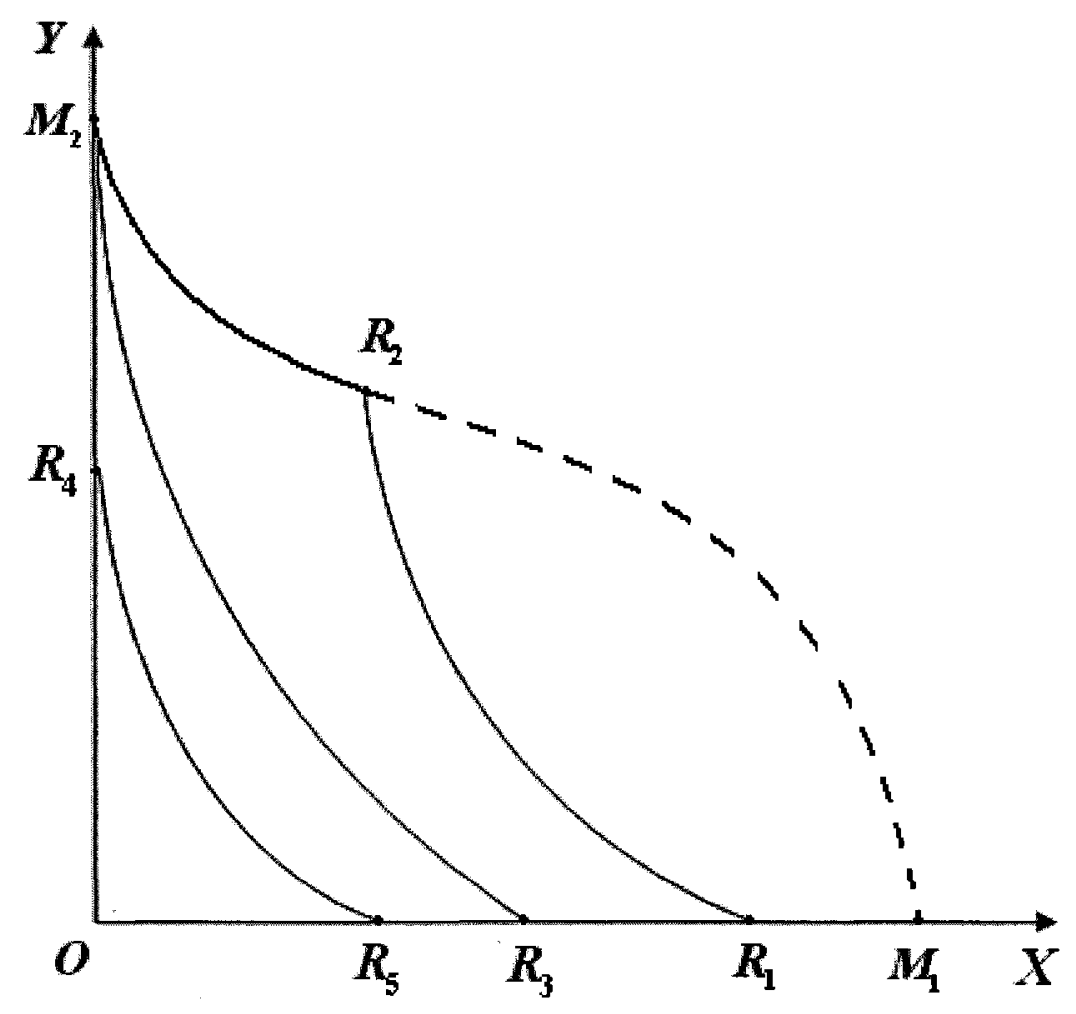


equilibrium upward beyond point $R_{2}$; or

2. Remove segment $M_{2} R_{2}$ by simply re-specifying the minimum wage at a sufficiently higher level and in this situation, the conventional $\mathrm{PPF}^{\mathrm{XY}}$ are fully constrained and becomes a uniformly convex curve such as $M_{2} R_{3}$.

If the minimum wage is even higher, the transformation curve will shift to the left again, to a position such as $R_{4} R_{5}$. Hence, moving along segment $M_{2} O$ (specialization in good $Y$ ) towards $O$ involves a successively increasing real wage in terms of good $Y$ and a greater level of unemployment. Without loss of generality, we simply take the first option for the following discussion by assuming that the home economy always operates on the constrained part $R_{2} R_{1}$ with a minimum wage equal to the marginal product of unskilled labor of industry $Y$ at $R_{2}$.

\subsection{The Perverse Output Response to Price}

As explained in chapter 2, the output-generated IRS which is external to individual firms allows us to preserve the assumption of perfect competition, so that each of the goods is still priced according to the unit cost, which is given by the following set of equations:

$$
\begin{gathered}
P_{Z}=\frac{\left(w_{L} L_{Z}+w_{S} S_{Z}\right)}{g(Z) L_{Z} f_{Z}}, \\
V=\frac{w_{L} L_{T}+w_{S} S_{T}}{L_{T} f_{T}}, \\
P_{Y}=\frac{w_{L} L_{Y}+w_{S} S_{Y}}{L_{Y} f_{Y}} .
\end{gathered}
$$

Recall that $P_{X}=a P_{Z}+V$ and define $P$ as the relative price of good $X$ in terms of $Y$. 
Using the above equations and the definitions of $\bar{k}_{i}, i=Z, T, Y$, we can obtain

$$
P=\frac{\left(1+\bar{\omega} \bar{k}_{Z}\right) a f_{Y}}{\left(1+\bar{\omega} \bar{k}_{Y}\right) g(a X) f_{Z}}+\frac{\left(1+\bar{\omega} \bar{k}_{T}\right) f_{Y}}{\left(1+\bar{\omega} \bar{k}_{Y}\right) f_{T}}
$$

In contrast to Brecher's case $(1974 \mathrm{a}, \mathrm{b})$ where there is only one relative price consistent with the diversified production on the constrained transformation curve (Rybczynski line), due to the external effect $g(a X)$ the relative price $P$ in the present framework does not remain constant while moving along $R_{2} R_{1}$ but actually decreases as the output level of good $X$ expands. The explanation for this perverse output response to price is as follows. Recall that, as illustrated by the Lerner diagram, fixing the wage ratio $\bar{\omega}$ is equivalent to holding the values of $P_{z} g(a X)$ and $V$ constant. If there is an increase in the production of good $X$ and hence in $g(a X)$, the price $P_{Z}$ must fall to maintain $P_{z} g(a X)$ constant. Therefore, the relative price $P$ must also decline. Totally differentiating (75), it follows after simple manipulation that:

$$
\frac{d X}{d P}=-\frac{X}{a \varepsilon P_{Z}}
$$

which confirms the perverse output response to price. While this may seem surprising at first sight, in fact, since the output-generated IRS is external to individual firms, there is nothing strange regarding the firms' behaviors. Firms always determine the production level according to the fixed factor rewards and thus have constant skill-intensity in each industry. The change in output of good $X(Z)$ only affects the price $P_{Z}\left(P_{Z}\right.$ and $Z$ are negatively related in order to keep the multiple product of $P_{Z} g(Z)$ constant) without any impact on individual firms' behavior. 
Another property of Brecher's case is that the price line is always flatter than the transformation curve (straight line) and the difference between the slopes of these two lines is constant. However in the current case, as shown below, the difference between $\frac{d Y}{d X}$ and $P$ is not constant while moving along the transformation curve $R_{2} R_{1}$. Recall that the slope of $R_{2} R_{1}$ and the price ratio are given by (67) and (75) respectively. Inspection of these two equations reveals that both terms are decreasing in magnitude as the production of $X(Z)$ increases. Subtracting (75) from the absolute value of $(67)$, we can obtain

$$
\left|\frac{d Y}{d X}\right|-P=\frac{a}{g(a X)} \frac{f_{Y}}{f_{Z}}\left(\frac{\bar{k}_{Z}-\bar{k}_{Y}}{\bar{k}_{Y}\left(1+\bar{\omega} \bar{k}_{Y}\right)}-\varepsilon \frac{\bar{k}_{Z}}{\bar{k}_{Y}}\right)+\frac{f_{Y}}{f_{T}}\left(\frac{\bar{k}_{T}-\bar{k}_{Y}}{\bar{k}_{Y}\left(1+\bar{\omega} \bar{k}_{Y}\right)}\right)
$$

The second bracketed expression on the right-hand side of (76) is clearly constant and positive, whereas the sign of the first expression is ambiguous due to the negative term $-\varepsilon \frac{\bar{k}_{Z}}{\bar{k}_{Y}}$. Therefore, the net sign of $(76)$ is also ambiguous. Note that if the first bracketed expression is non-zero, the first term will be diminishing in magnitude as the denominator $g(a X)$ increases, so that the difference $\left|\frac{d Y}{d X}\right|-P$ cannot hold constant. Defining $A \equiv\left(\frac{\bar{k}_{Z}-\bar{k}_{Y}}{\bar{k}_{Y}\left(1+\bar{\omega} \bar{k}_{Y}\right)}-\varepsilon \frac{\bar{k}_{Z}}{\bar{k}_{Y}}\right)$, we have the following possibilities regarding the sign and magnitude of this difference: 


\begin{tabular}{lll} 
sign & \multicolumn{1}{c}{ sign } & magnitude of the difference as $X$ increases \\
$A>0$, & $\left|\frac{d Y}{d X}\right|-P>0$, & diminishing; \\
$A=0$, & $\left|\frac{d Y}{d X}\right|-P>0$, & constant; \\
$A<0$, & $\left|\frac{d Y}{d X}\right|-P \geq 0$, & increasing; \\
$A<0$, & $\left|\frac{d Y}{d X}\right|-P<0$, & diminishing.
\end{tabular}

These four possibilities are listed in an order with $A$ decreasing. Interpretations of these possibilities are given below which are useful for the subsequent discussion of implications of free trade and outsourcing.

1. If $A>0$, then $\left|\frac{d Y}{d X}\right|-P$ must be positive for all the different output levels of $X$ and the difference in absolute value is diminishing (but never equal to zero) as $X$ increases.

2. If $A=0$, then $\left|\frac{d Y}{d X}\right|-P$ must be positive for all the different output levels of $X$ and the difference is constant as $X$ changes.

3. If $A<0$ and if $\left|\frac{d Y}{d X}\right|-P>0$ for all the different output levels of $X$, then the difference in absolute value is rising as $X$ increases.

4. If $A<0$ and if $\left|\frac{d Y}{d X}\right|-P<0$ for all the different output levels of $X$, then the difference in absolute value is diminishing as $X$ increases.

5. Taking points 3 and 4 together, if $A<0$, the difference $\left|\frac{d Y}{d X}\right|-P$ can be negative first, at some point becomes zero due to the negative term $A$ declining in magnitude as $X$ increases, and then is positive as $X$ continues to rise.

So what are the factors that cause the outcomes here to deviate away from those of 
Brecher's case where the price ratio is always smaller than the slope of the transformation curve by a constant difference? Recall that in Chapter 2 we have shown that the price line cuts the $\mathrm{PPF}^{\mathrm{XY}}$ from above due to the external effect. This reflects the fact that an expansion of a firm in industry $Z$ generates a positive externality on other firms in that industry, so that the private marginal product of each factor is smaller than the social marginal product. From the viewpoint of socially optimal endowment allocations, this deviation leads to underemployment of factors in industry $X(Z)$. However, in the present situation the commitment to the minimum real wage makes it socially more costly to have more good $X(Z)$ because any expansion in that industry has to cause more unemployment. If this were the only effect, it would imply that the price line should be flatter than the transformation curve, as shown in Brecher's case, to reflect the fact that industry $Y$ should be expanded from the social viewpoint in order to achieve a higher employment level.

Therefore, there is a two-edged effect from an increase of $X(Z)$, which on the one hand alleviates the distortion represented by the deviation between private and social marginal products, but on the other hand leads to a heavier burden of unemployment. It is clear that these two forces drive $P$ in opposite directions (relative to $\left|\frac{d Y}{d X}\right|$ ) and the net effect will determine the sign of $\left|\frac{d Y}{d X}\right|-P$.

To complete the specification of this minimum-wage model, we assume that the consumption preferences are homothetic, identical across countries and ignore any 
differences between the preferences of skilled labor and unskilled labor. The ratio of the quantities consumed of goods $X$ and $Y$ therefore depends only upon the price ratio $P$ :

$$
\frac{X^{D}}{Y^{D}}=\alpha(P), \quad \frac{d \alpha(P)}{d P}<0 .
$$

Since both the production and consumption of good $X$ relative to good $Y$ are negatively related to the relative price, we cannot rule out the possibility of multiple equilibria. Since we are interested in diversified and stable equilibria, assume that there is exactly one such equilibrium, and that the following condition holds at interior points along the entire constrained transformation curve $R_{2} R_{1}$ :

$$
\left|\frac{d(X / Y)}{d P}\right|<\left|\alpha^{\prime}(P)\right| .
$$

See Appendix $A 9$ for a more detailed discussion regarding the shape of the excess supply/demand curve, multiple equilibria and the necessary condition for stability of the equilibrium. Equation (78) ensures that an excess supply (demand) of good $X$ is induced as the price ratio deviates upward (downward) from the autarky equilibrium price $P^{A}$. 


\section{Free Trade and Unemployment}

\subsection{Excess Supply and Import Demand Curves}

It has been shown that in the present minimum-wage framework, the normal output response to price is reversed. We shall now explore whether this perverse feature will affect the beneficial free trade effects of the conventional CRS model when this economy becomes open. We assume that the foreign country retains flexible wages and denote $P^{* A}$ as the foreign autarkic price ratio. Other assumptions regarding the foreign production and consumption specified in Chapter 4 still hold for the current discussion.

Figure 9 reproduces the constrained transformation curve from Figure 8 and depicts the salient aspects of the equilibrium. ${ }^{45}$ In order to sustain the minimum wage $\bar{w}_{L}$ in autarky, the equilibrium price is $P^{A}$ and the consumption ratio of $X$ to $Y$ is given by $\alpha\left(P^{A}\right)$. For a higher relative price $P^{1}$, the production point is at $B$ on $R_{2} R_{1}$ and the indifference curve is tangent to the budget line at $B^{\prime}$ where the consumption ray given by $\alpha\left(P^{1}\right)$ goes through $B^{\prime}$. Thus a positive excess supply of good $X$ is represented by the horizontal distance between $B$ and $B^{\prime}$. Similarly for a lower relative price $P^{2}$, the production point is at $C$ and the corresponding consumption occurs at $C^{\prime}$ where the consumption ray $\alpha\left(P^{2}\right)$ goes through $C^{\prime}$. Hence, at the price $P_{2}$ there is an excess demand for good $X$ represented by the horizontal distance between $C$ and $C^{\prime}$.

It is helpful to present the above information by plotting the excess supply and import demand curves as illustrated in Figure 10. (Figure 9 and Figure 10 haven been

\footnotetext{
${ }^{45}$ In Figure 9 we draw all the price lines cutting the transformation curve from above, which is only one possible case (as discussed in Section 6.4). This scenario indicates that for the society, the benefit from an expansion in good $X(Z)$ dominates the cost of the associated decline in employment.
} 
Figure 9: The Constrained Transformation Curve with a Perverse Output Response to Price

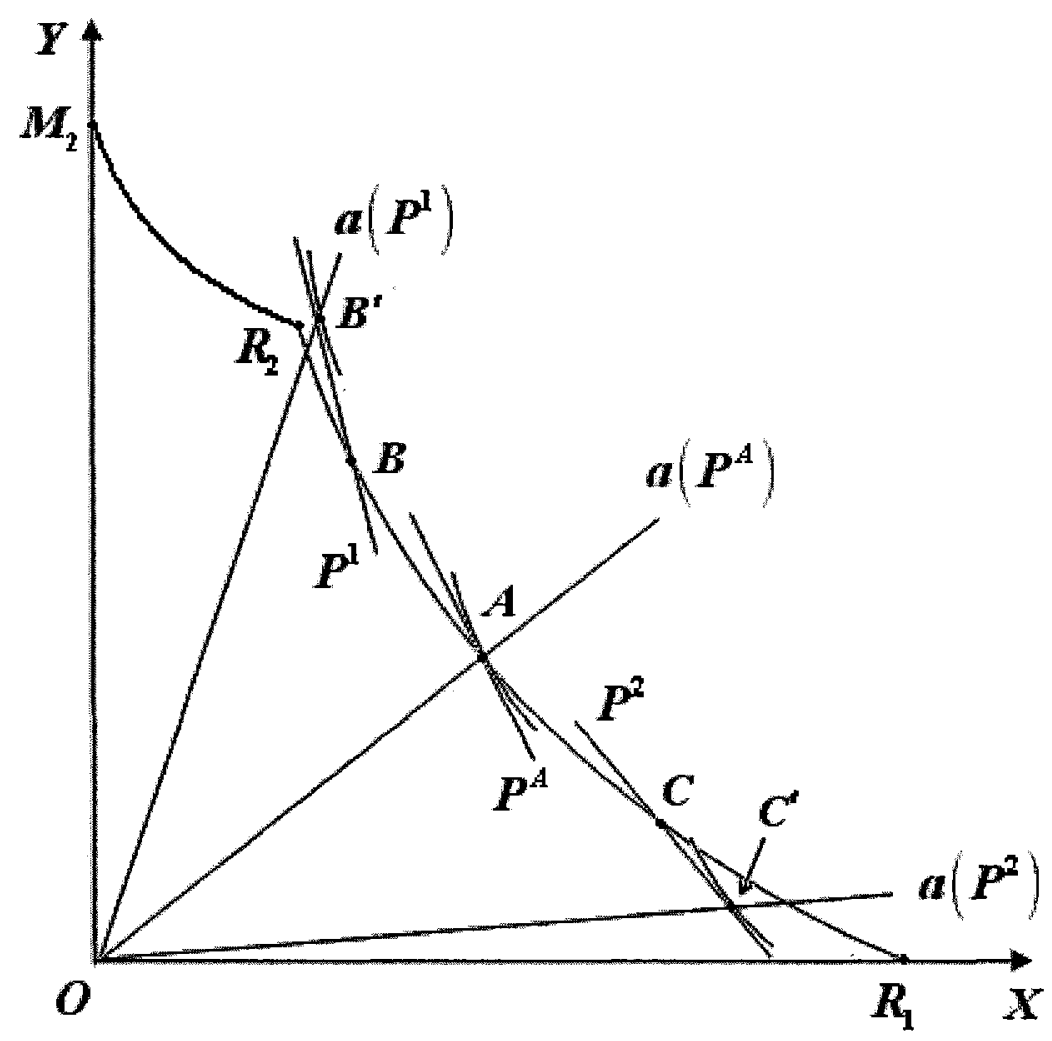


Figure 10: The Domestic Excess Supply and Foreign Import Demand Curves

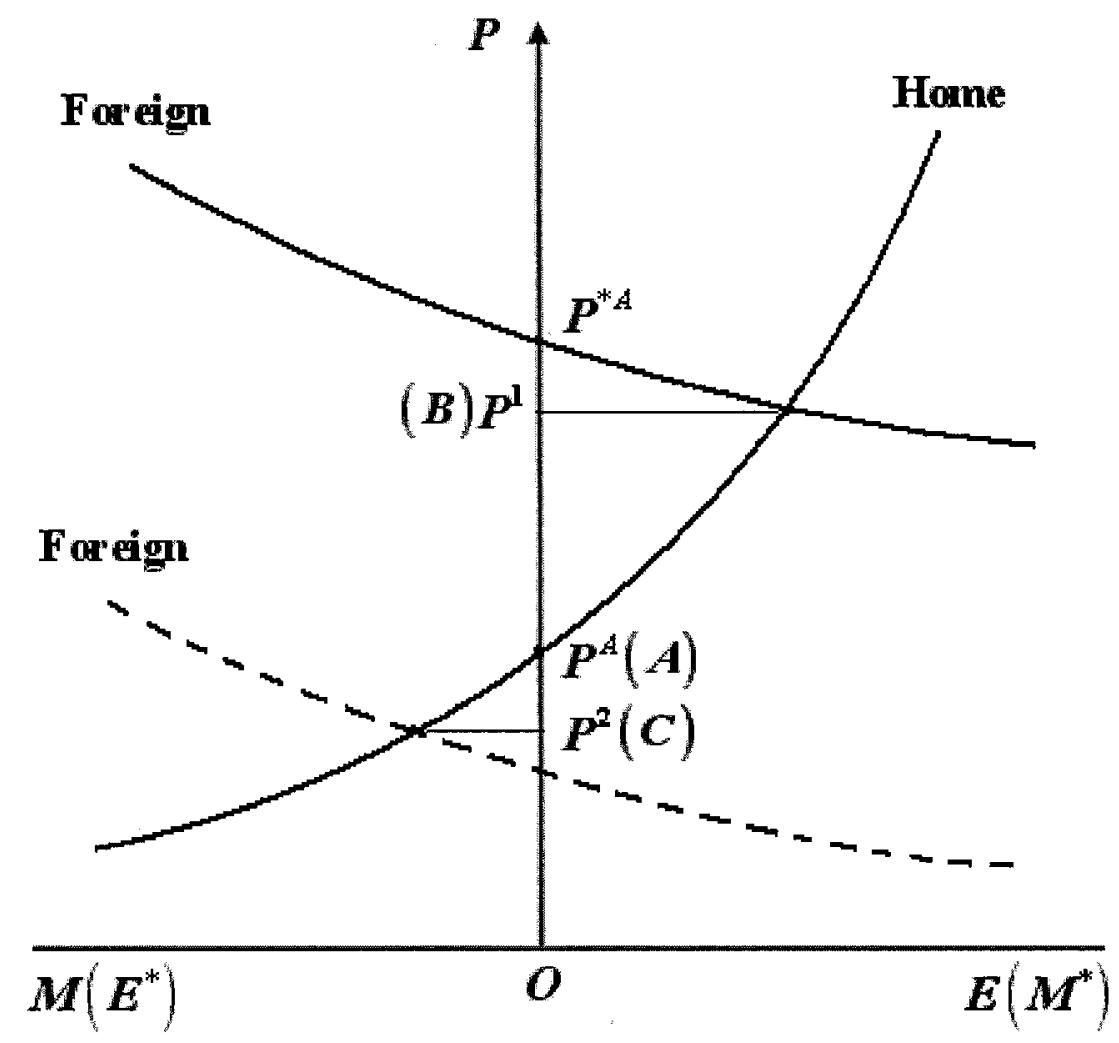


labeled similarly to make comparison of them self-explanatory. ${ }^{46}$ Here, the relative price $P_{A}$ and $P^{* A}$ represent the domestic autarky price and the foreign autarky price respectively. Two foreign import demand curves are depicted to show the possibilities of different trade patterns. The solid one is involved with a higher autarky price ratio (relative to Home) and therefore requires the import of good $X$ in free trade; the dashed curve is associated with a lower autarky price ratio (relative to Home) and therefore requires the export of good $X$ in free trade. It is clear that the equilibrium price in free trade is located within the range of the two autarky prices $\left[P^{A}, P^{* A}\right]$.

\subsection{Free Trade versus Autarky}

Now we consider the implications of free trade for this minimum-wage constrained economy. It has been demonstrated that the movement from autarky upward along $R_{2} R_{1}$ is involved with a contraction of good $X(Z)$, which is already under-produced, and an increased employment; whereas the movement from autarky downward along $R_{2} R_{1}$ is involved with an expansion in industry $X$ and a loss of employment. Therefore, in addition to the terms-of-trade effect, there is a trade-off between higher (lower) employment and higher (lower) production of good $X(Z)$, which should be expanded from the viewpoint of socially optimal allocation of resources. We may summarize the derived conclusion as follows:

1. The effect of terms of trade is always positive in either trade pattern.

\footnotetext{
${ }^{46}$ Davis (1998) did analyze the implications of a minimum-wage constrained economy trading with a flexible-wage economy, but without the complications of intermediate goods and economies of scale.
} 
2. Exporting good $X$ is associated with a contraction in the domestic production of $X$, which aggravates the distortion caused by the difference between the private and social marginal product but increases employment.

3. To maintain the minimum wage, importing good $X$ causes more unskilled labor to lose jobs in order to sustain the higher production of good $X$. This expansion to some extent alleviates the distortion of under-production of good $X(Z)$ but it comes at the cost of higher unemployment.

\subsection{Comparative Statics}

We have argued that whether free trade shall have a net beneficial impact depends on which effect(s) dominates. We will now derive the above results in a more formal and complete manner. Recall that (37) represents the social utility function which is strictly quasi-concave with positive marginal utilities and dependent only on the consumption levels of the two final goods:

$$
U=U\left(X^{D}, Y^{D}\right)
$$

The budget constraint, reflecting equality between the value of the production and the national expenditure, is given by $(38)$ :

$$
P_{X} X+Y=P_{X} X^{D}+Y^{D}
$$

Totally differentiating (37) and (38), it follows after simple manipulation that:

$$
d U=U_{Y}\left[\left(P\left(\frac{d Y}{d X}\right)^{-1}+1\right) \frac{d Y}{d P}+\left(X-X^{D}\right)\right] d P
$$


Here, $\frac{d Y}{d P}$ is positive due to the perverse output response to price. In contrast to the conventional CRS case, $d U$ is not necessarily equal to zero when (79) is evaluated at autarky. This is because of the ambiguous relationship between the price ratio and the slope of the transformation curve in the present model. In the event of $P=-\frac{d Y}{d X}$ which implies a tangency between price line and transformation curve, we would obtain the standard result that any infinitesimal change in $P$ has no effect on social welfare when $d U$ is evaluated at autarky. Otherwise when evaluated at autarky, $\frac{d U}{d P}$ will be either positive or negative depending on whether $P$ is smaller or greater than $-\frac{d Y}{d X}$.

As indicated by (79), we may think of the change in welfare as being made up of two parts: the net effect of changes in production and employment, and the terms-of-trade effect. To simplify the exposition, we define $B \equiv\left(P\left(\frac{d Y}{d X}\right)^{-1}+1\right) \frac{d Y}{d P}$. Given the positive term $\frac{d Y}{d P}$, the sign of $B$ therefore depends only on the relationship between the price ratio $P$ and the slope of the transformation curve $\frac{d Y}{d X}$. Specifically, we have

$$
\begin{array}{rll}
P=-\frac{d Y}{d X} & \Leftrightarrow & B=0, \\
P<-\frac{d Y}{d X} & \Leftrightarrow & B>0, \\
P>-\frac{d Y}{d X} \quad \Leftrightarrow & B<0 .
\end{array}
$$

Now rewrite (79) as follows: 


$$
\frac{d U}{U_{Y}}=B d P+\left(X-X^{D}\right) d P
$$

Note that the welfare outcome of free trade in general involves a finite movement along the transformation curve ${ }^{47}$ With regard to $(80)$, since the terms-of-trade effect $\left(X-X^{D}\right) d P$ is always positive in either trade pattern, we should focus our attention on the first part. If throughout this finite movement the sign of $B$ does not reverse (either $B \geq 0$ or $B \leq 0$ ), then the sign of the overall effect $B d P$ along this finite movement will be determined by the trade pattern (the sign of $d P$ ). However, if the sign of $B$ changes from positive to negative or vice versa as the home country moves from autarky to free trade, then the sign of the overall effect $B d P$ along this finite movement will be ambiguous. Bearing in mind that the terms-of-trade effect is always positive, we immediately obtain the following conclusions.

\section{Proposition 4}

$A$ : If $B \geq 0$ throughout the movement from autarky to free trade, the overall change in domestic welfare will be positive for the case of exporting good $X(d P>0)$ and ambiguous for the case of importing good $X(d P<0)$.

$B:$ If $B \leq 0$ throughout the movement from autarky to free trade, the overall change in domestic welfare will be positive for the case of importing good $X(d P<0)$ and ambiguous for the case of exporting good $X(d P>0)$.

$C:$ If the sign of $B$ changes from positive to negative or vice versa as the home

\footnotetext{
${ }^{47}$ As earlier mentioned in Section 5.2, a finite movement can be regarded as the sum (integral) of all the infinitesimal movements. If the sign of each infinitesimal movement does not change, this qualitative information will enable a conclusion to be reached regarding the sign of the associated integral. If the signs of the infinitesimal movements change, then the sign of the integral over these infinitesimal changes will be ambiguous.
} 
country moves from autarky to free trade, then the net welfare effect of free trade in either trade pattern will be ambiguous, though the terms-of-trade effect is always positive.

In contrast to the ambiguity at Home, in the foreign country where there is no externality or unemployment issue, social welfare is always improved by the gain from trade. 


\section{Implication of Outsourcing}

\subsection{Introduction}

The impact of growing trade with developing countries on labor markets in developed countries has been a source of great concern for many years. Although economists since Adam Smith have explained how free trade raises the wealth of nations and the material well-being of their citizen, many people remain skeptical. Their doubts are reinforced by politicians and commentators who point to jobs lost to more imports from low-wage countries due to globalization. The growing importance of the international procurement of intermediate inputs has added fuel to this fire. When the production of the intermediate goods moves to foreign countries, the fear at the home country is that jobs will be destroyed and unemployment will rise. A recent estimate by Forrester Research suggests that there will be job losses totaling 3.3 million white collar jobs by the year of 2015, and the prediction by Deloitte Research shows that outsourcing will shift 2 million financial-sector jobs by the year 2009. Other estimates by Bardhan and Kroll (2003), that 11 percent of American jobs are potentially at risk of being offshored, have drawn more attention from politicians and journalists. However, those authors do not clarify whether the prediction is that the US economy will have fewer jobs than it would otherwise have had because of outsourcing, or that outsourcing will cause those workers to shift into different jobs.

While the relation between outsourcing and unemployment has been an important issue for the public and politicians, not very much careful theoretical analysis about this relationship has been conducted. Mitra and Ranjan (2007) construct a two-sector model where unemployment is caused by search frictions, and they find that wage increases and 
sectoral unemployment decreases, something can be explained by the productivityenhancing (cost-reducing) effect of outsourcing. Their results are consistent with the empirical findings of Amiti and Wei $(2005 a, b)$ for the US and the UK, which offer no support for the anxiety of "massive job losses" associated with outsourcing. In fact, using data on 78 sectors in the UK for the period 1992-2001, Amiti and Wei find a positive relationship between employment and outsourcing in many of their specifications.

The purpose of this chapter is to examine the effect of outsourcing on unemployment that arises when there is a binding minimum-wage constraint. We find that outsourcing has a positive effect on employment, but at the same time it aggravates another distortion by further reducing the production of good $X(Z)$. Therefore, despite there being a cost saving and an increase in employment, the net impact of outsourcing on welfare is ambiguous. The main assumptions and ideas follow the discussion of international outsourcing in Chapter 5 , the only modification being that a minimum wage is now specified for this economy. For simplicity, we still take good $Y$ as numeraire and set $P_{Y}=1$.

\subsection{The Excess Supply and Import Demand Curves}

It was shown in Chapter 4 that $V>V^{*}$ and $P_{Z}<P_{Z}^{*}$ under free trade due to the

technology difference across countries where $g(Z)>1$ at Home and $g^{*}\left(Z^{*}\right)=1$ abroad. This difference in unit costs of the intermediate inputs gives the home country an incentive to outsource part $T$ to enjoy the lower production cost overseas. We will first examine how outsourcing would affect domestic export supply and foreign import demand at constant terms of trade. Once these effects have been determined, we are able 
to derive the change in the world price $P^{*}$ which would restore equality between world supply and demand.

Recall that at an arbitrary relative price, say the equilibrium price $P^{*}$ in free trade, when $T$ is completely outsourced to the foreign country at a lower price $V^{*}$, the domestic price $P_{Z}$ must rise in order to maintain $P^{*}$ constant given that $P^{*}=a P_{Z}+V^{*}$. The domestic wage ratio is fixed at $\bar{\omega}$ by the binding minimum wage, and as previously illustrated in the Lerner diagram this $\bar{\omega}$ determines the value of $P_{z} g(Z)$ given that $P_{Y}=1$. Therefore, with a rising $P_{Z}, g(Z)$ must decrease to keep the term $P_{Z} g(Z)$ constant and hence maintain the tangency between the dollar's-worth isoquant $1 / P_{z} g(Z)$ and the fixed isocost line. As a result, the production of good $Z$ decreases as will the supply of good $X$ due to the Leontief production technology.

This would imply not only that the factors released from the original domestic production of $T$ need to be completely absorbed by industry $Y$, but also that the factors released by the decrease in $Z$ will go to industry $Y$. Given the assumption that good $Y$ is the least skill-intensive, when the factors move from industries $T$ and $Z$ into industry $Y$, the required increased demand of unskilled labor can be met from the pool of unemployment. Therefore, unemployment is reduced without violating the minimum wage. A straightforward illustration of these changes is given in Figure 11 using the Edgeworth box framework, where unskilled labor is measured horizontally along $O A\left(O^{\prime} B\right)$ and skilled labor is measured vertically along $O B\left(O^{\prime} A\right)$.

Here, $O a, a b$ and $b c$, reflecting the ranking $\bar{k}_{Z}>\bar{k}_{T}>\bar{k}_{Y}$, represent the output levels of good $Z, T$ and $Y$ respectively at the free trade equilibrium, where everything 
Figure 11: The Effect of Outsourcing on Employment at Constant Terms of Trade

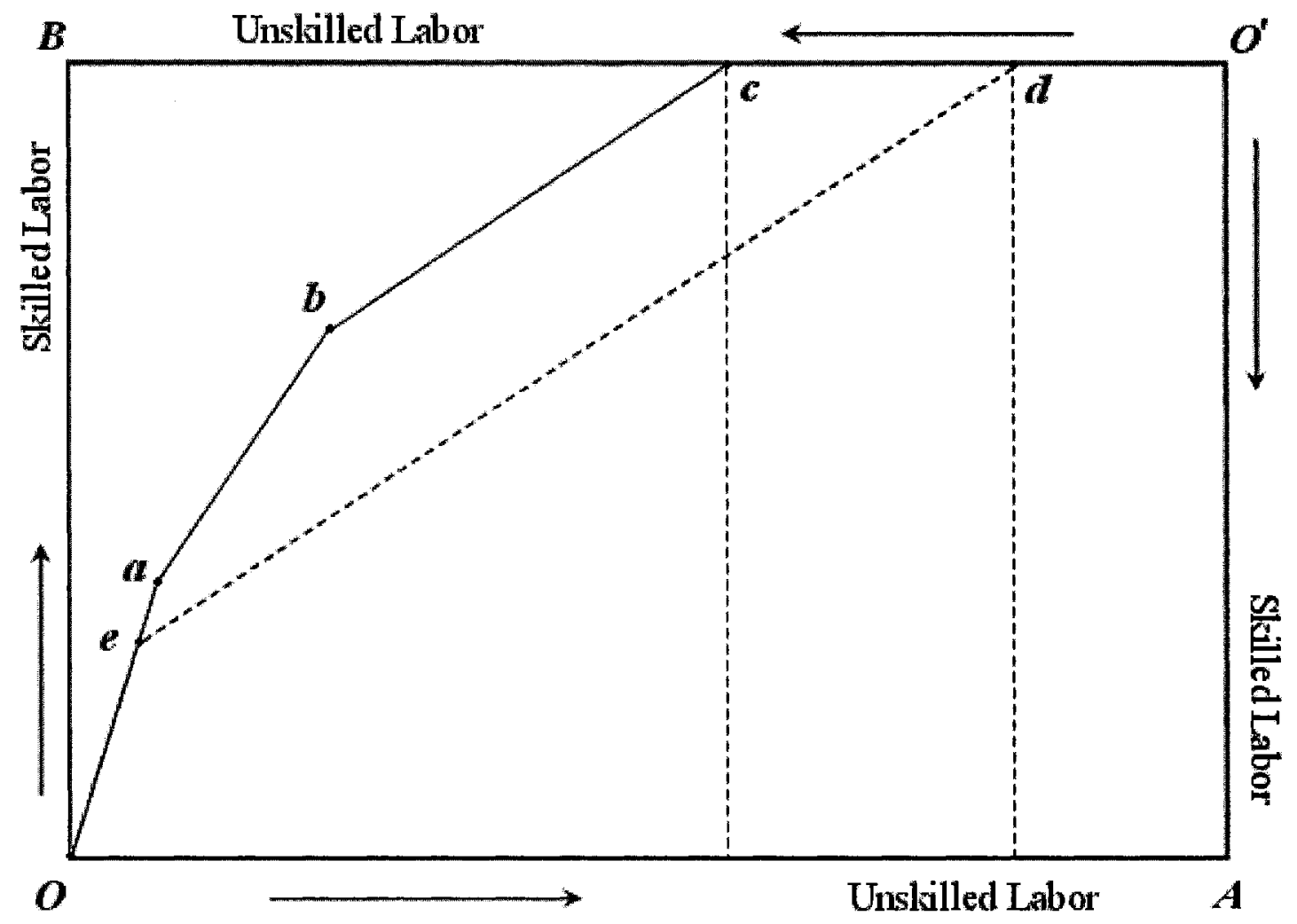


is domestically produced. The binding minimum-wage constraint causes unemployment of unskilled labor denoted by $c O^{\prime}$, which confirms that the constrained transformation curve $R_{1} R_{2}$ is below the conventional full-employment PPF. It is clear that the skillintensity in each industry is fixed by the minimum wage, and therefore any change to this equilibrium must be through changing employment of unskilled labor. The Edgeworth box diagram illustrates that when the production of $T$ is outsourced and when the output of $Z$ falls, industry $Y$ will expand from $b c$ to $e d$ while unemployment of unskilled labor decreases from $c O^{\prime}$ to $d O^{\prime}{ }^{48}$

We shall now turn to the domestic demand side. Here, national income $I$ needs to be modified from that used in Chapter 5 to take into account the existence of unemployment, so that we have

$$
I(\bar{\omega}, \bar{S}, L)=\bar{W}_{s} \bar{S}+\bar{W}_{L} L
$$

from which we can obtain $\frac{\partial I}{\partial L}=\bar{W}_{L}>0$ implying that national income is increasing as employment of unskilled labor $L$ rises at constant factor prices. It follows that the substitution effect is zero at unchanged relative price, and the positive income effect should raise the consumption of both normal goods. Therefore, the excess supply of good $X\left(E=X-X^{D}\right)$ at the given price $P^{*}$ is reduced since domestic supply decreases whereas domestic demand increases. ${ }^{49}$ In what follows, we will only consider the trade

\footnotetext{
${ }^{48}$ The Edgeworth box diagram here embodies the previous assumption that home always operates on the constrained transformation curve. Under these circumstances, $d$ must be to the left of $O^{\prime}$ to ensure that the minimum-wage constraint is binding and that unemployment exists.

${ }^{49}$ It is possible that the domestic excess supply could become negative following these changes in supply and demand at the constant good prices, whence the trade pattern will be reversed. This possibility will not
} 
pattern where the home country exports good $X$ at outsourcing although the analysis can be readily extended to the importing case.

Since the above arguments hold for every given relative price consistent with the constrained transformation curve, the opportunity to outsource will shift domestic excess supply curve to the left as illustrated in Figure 12. In Chapter 5 with flexible wages and full employment, complete outsourcing induces a fall in the real wage of unskilled labor with an expansion of the most skill intensive good at constant terms of trade. In this present minimum-wage framework, however, the incipient fall in the real wage is instead stanched via the decline in the production of $Z$, which is associated with a higher employment level, in order to maintain the commitment to the minimum wage. ${ }^{50}$

The discussion of the effects on the foreign country follows very similar lines to that presented in Chapter 5. Again, domestic outsourcing requires an expansion of the foreign production of $T$ and reductions in the supplies of both goods $X$ and $Y$ at the constant commodity prices. Foreign national income is not affected because the foreign country operates at full employment and the wage rates are held constant by Samuelson one-toone correspondence. Therefore, the foreign import demand for good $X$ must increase at that given price $P^{*}$ since supply decreases while demand remains constant. This will shift foreign import demand curve to the right as illustrated in Figure 12.

Figure 12 reproduces domestic excess supply curve and foreign import demand curve from Figure 11 (only for the case where Home exports good $X$ ) and depicts the shifts of the curves caused by outsourcing. The superscript " $F$ " and " $O$ " denote free trade and outsourcing respectively, so that $N^{F}$ is the free-trade equilibrium while $N^{O}$ is 
Figure 12: Shifts of the Domestic Excess Supply and Foreign Import Demand Curves

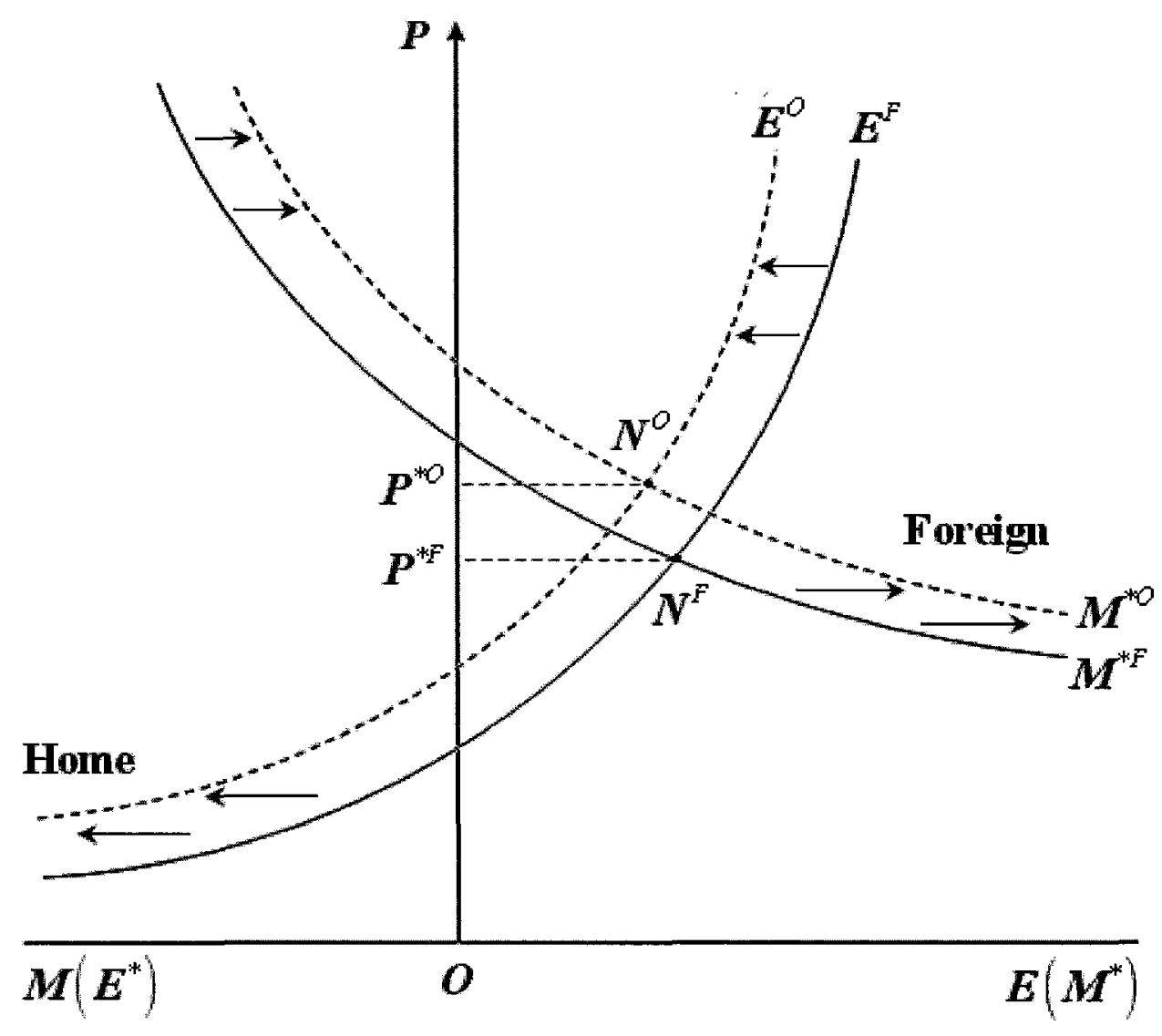


the outsourcing equilibrium. In addition, the domestic output response to price is still perverse with outsourcing, due to the external effect and minimum-wage constraint. The derivation of a precise formula for the output response to price is provided in Appendix $A 11$, where we also demonstrate that in the presence of complete outsourcing, employment of unskilled labor still increases as industry $Y$ expands and decreases as the production of good $Z(X)$ increases.

\subsection{The Implications of Outsourcing}

In this section we investigate the effects of outsourcing on social welfare with a special interest in the employment of unskilled labor when the equilibrium moves from $N^{F}$ to $N^{O}$ as illustrated in Figure 12. From this diagram, we observe that the relative price at outsourcing is clearly higher than that under free trade, while the change in the volume of trade is ambiguous depending on the shift of each curve.

As shown in the previous section, at constant terms of trade outsourcing induces a reduction in the domestic production of good $Z$ in order to maintain the minimum wage. In addition, the changes in excess supply and import demand brought on by outsourcing require the world commodity price to rise in order to clear the world market and restore the equilibrium. Given the perverse output response to price in the presence of complete outsourcing, this increase from $P^{* F}$ to $P^{* O}$ will reduce the domestic production of good $Z(X)$ further. Taken together, these two negative impacts on the production of good $X(Z)$ imply that the production equilibrium at outsourcing must lie somewhere to the left of the production point in free trade in Figure 13; where $R_{1} R_{2}$, reproducing the curve 
from Figure 9, is the transformation curve before outsourcing; and $R_{3} R_{4}$ represents the production possibilities when complete outsourcing occurs. ${ }^{51}$

The transformation curve $R_{3} R_{4}$ lying outside $R_{1} R_{2}$ simply reflects the fact that extra factors released from $T$ now are available for the two remaining industries with a higher employment level of unskilled labor. The movement from $N^{F}$ to $G$ at the constant price $P^{*}$ is associated with a decline in unemployment as the output of good $Z$ decreases, which was demonstrated by the Edgeworth box diagram in Figure 11. On the other hand, due to the perverse output response to price along $R_{3} R_{4}$, the movement from $G$ to $N^{O}$ is also associated with a decreasing output of good $Z$ and an increasing level of employment with the rising $P^{*}$.

As we have explained, any change in production induces a two-edged effect to the society, which either expands industry $X(Z)$ with economies of scale but causes more job loss, or lowers the output of $X(Z)$ but raises employment. In the present situation, there is a decline in the production of $X(Z)$ and hence a rise in employment. Thus, the net impact on welfare will be ambiguous depending on the relative magnitude of the two opposite effects (which can be indicated by the relationship between the price ratio $P^{*}$ and the associated slope of the transformation curve $\left|\frac{d Y}{d X}\right|$ ).

\footnotetext{
${ }^{51} \mathrm{Keep}$ in mind that the value of the production associated with $R_{3} R_{4}$ is higher than the national income which home can spend, because part of the production has to be used to pay for the imported fragment $T$. In other words, home cannot consume on the points along $R_{3} R_{4}$ but somewhere below $R_{3} R_{4}$. Since we are interested in the impact on employment, investigating the production side is sufficient for our present purposes, and we need not derive the actual consumption point here.
} 
Figure 13: Decomposition of the Effects of Outsourcing on Production and Employment

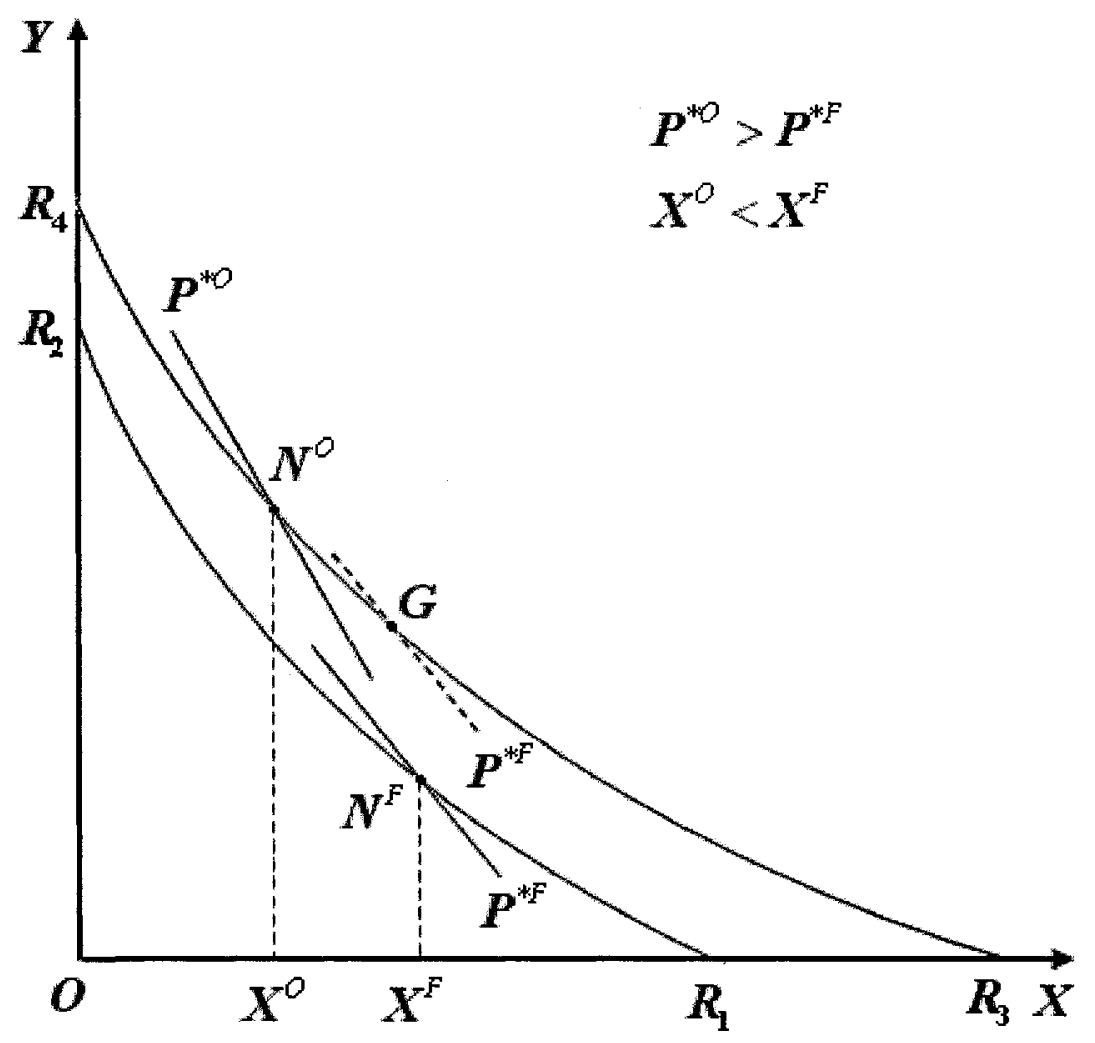


To summarize, outsourcing reduces unemployment relative to free trade, but this benefit is at the cost of a further contraction in industry $Z$ which is already underproduced from the social viewpoint. This outcome is independent of the trade pattern. On the other hand, the rising trading price implies that the terms-of-trade effect is positive if the home country exports good $X$ and is negative if the home country imports good $X$. Therefore, the overall effect of outsourcing on social welfare is ambiguous depending on which effect(s) dominates, even though there is always a cost saving. Of course, the deterioration (improvement) in the foreign terms of trade will result in a net loss (gain) to that country.

On this basis, one possible outcome could be that outsourcing makes both countries worse off compared with free trade. This result may seem surprising: that outsourcing an intermediate input to a cheaper-cost country while continuing the production in another industry where the home country has an externality-based comparative advantage would harm both economies. However, this type of immiserization is not rare, where some activities that are supposed to generate welfare improvement, actually lead to bad outcomes because of additional distortions. For example, it is well known in standard trade theory that if capital flows into a tariff-ridden economy where the importable good is capital-intensive, immiserization is inevitable if the capital flow is small and does not eliminate the trade of final goods. We shall now turn our attention to explaining why immiserization can occur in our model.

Given the cheaper outsourcing price $V^{*}$ of one intermediate input and the positive externality associated with another intermediate input in the remaining industry, it might appear that the final outcome of outsourcing should be "a higher output of the final good 
with a lower price". However, this is not the case here due to simultaneous presence of two distortions, the production externality and the binding minimum-wage constraint. Home's commitment to the minimum wage not only prevents the expansion of industry $Z$, but actually forces Home to reduce the production level further as outsourcing occurs. When this negative effect from the contraction of the industry which should have been expanded dominates the positive effect from the associated increase in employment, immiserization might well happen. ${ }^{52}$

One reason why the unfavorable outcome of outsourcing may occur is that the home country has been assumed to remain in diversified production. Recall segment $R_{1} M_{1}$ in Figure 8, which corresponds to complete specialization in good $X$. It is known from Brecher $(1974 \mathrm{a}, \mathrm{b})$ that moving along this segment towards $M_{1}$ is through a successively higher output of good $X$ and a greater level of employment, where the unemployed unskilled labor can bid the wage down in terms of good $X$ without violating the minimum wage defined in terms of good $Y$. If the outsourcing equilibrium occurs on this segment, then the trade-off between a higher production of $X$ and a higher employment level no longer exists because employment increases with the expansion in industry $X$. If the production point is close enough to $M_{1}$ (full employment), then the employment level may exceed that under free trade.

Since the effects of outsourcing on production and employment are independent of the trade pattern, the conclusion that outsourcing reduces unemployment at the cost of a

\footnotetext{
${ }^{52}$ As indicated previously, the terms of trade effect is negative when home imports good $X$, so that immiserization must occur in this case. On the other hand, the terms of trade are improved when home exports good $X$, then immiserization may still occur if the negative effect from the contraction of industry $Z(X)$ is strong enough.
} 
further deduction in the supply of good $X(Z)$ still holds when the home country imports $X$. The only difference compared with the case of exporting good $X$, would be that the increase in the equilibrium price is now a deterioration in domestic terms of trade but is an improvement to the foreign country. Therefore, the net outsourcing effect is still ambiguous for the home country, but is clearly a gain to the foreign country.

To close our discussion in this chapter, a summary of the impacts of outsourcing relative to free trade is provided in the following table.

Table 1: The Impacts of Outsourcing relative to Free Trade

\begin{tabular}{|c|c|c|c|c|c|}
\hline & \multicolumn{4}{|c|}{ Home } & Foreign \\
\hline & Terms of Trade & Employment & Output of $Z$ & Net Welfare & Net Welfare \\
\hline $\begin{array}{c}\text { Home } \\
\text { Exports } X\end{array}$ & improved & increased & contracted & ambiguous & loss \\
\hline $\begin{array}{c}\text { Home } \\
\text { Imports } X\end{array}$ & deteriorated & increased & contracted & ambiguous & gain \\
\hline
\end{tabular}




\section{Conclusion}

This thesis extends the traditional trade model in ways that appear to be justified by practical evidence. Our approach builds on a two-factor two-commodity framework with a pure intermediate good which exhibits external IRS. This model offers an explanation for the recently observed phenomenon of skilled-labor outsourcing and also contributes to the debate over why an increase in the skill-intensive production should occur in the face of a rising skilled-labor wage rate.

For the case with flexible wages and full employment we show that although there is always a cost saving, outsourcing can lead to either an improvement or a deterioration in terms of trade for the home country. This ambiguous change in the world commodity price ratio would also have an uncertain influence on the production of good $X(Z)$ which should be expanded from the social viewpoint. As a consequence, the net effect on social welfare is ambiguous and the impact on the wage ratio can also be either positive or negative depending upon the direction of the change in $P_{z} g(Z)$. However, the increased production efficiency due to outsourcing could generate an expansion in the world PPF, which would make it possible for both countries to gain. For a small open economy with unaffected terms of trade, the cost saving and the expansion of the industry with positive externality therefore yield a net welfare gain despite the falling wage of unskilled labor.

In order to examine the possible effects of free trade and outsourcing on unemployment, we then extend our framework by adding a binding minimum-wage constraint in the unskilled-labor market. In this case with simultaneous presence of two distortions, the production externality and the minimum wage, the output response to 
price becomes perverse along the constrained transformation curve associated with diversification. The two distortions also generate a trade-off between a higher output of good $X(Z)$ and a greater level of employment of unskilled labor. It follows that, in addition to positive terms-of-trade effect, free trade associated with exporting good $X$ leads to a decline in the production of that good and increased employment, whereas importing good $X$ leads to an expansion in that industry but causes the home country to suffer more unemployment. We then show that the introduction of international outsourcing, rather than threaten employment, actually enhances it. However, this benefit comes at the cost of aggravating another distortion by further decreasing the production of the good which is already being under-produced. In contrast to the implications under free trade, these impacts on production and employment are independent of trade pattern while the terms-of-trade effect may now be either positive or negative (depending upon the trade pattern). Again, due to the two distortions in this economy, outsourcing may yield a net loss to the home country as the final outcome.

This study demonstrates that concerns about welfare-reduction and job-loss effects of outsourcing may have been greatly exaggerated. This demonstration is consistent with recent empirical findings. 


\section{References}

1. Amiti, M and Wei, S. J., (2005a) "Fear of Service Outsourcing: Is It Justified?", Economic Policy, Vol. 20: 308-348.

2. Amiti, M and Wei, S. J., (2005b) "Service Off-shoring, Productivity, and Employment: Evidence from the United States", NBER Working Paper, No.11926.

3. Arndt, S. W., (1997), "Globalization and the Open Economy", North American Journal of Economics and Finance, Vol. 8(1): 71-79.

4. Bardhan, A. and Kroll, C., (2003), "The New Wave of Outsourcing", Fisher Center for Real Estate \& Urban Economics, Research Reports, No.1025.

5. Batra, R. and Casas, F. R., (1973), "Intermediate Products and the Pure Theory of International Trade: a Neo-Heckscher-Ohlin Framework", The American Economic Review, Vol. 63: 297-311.

6. Bhagwait, J. N., Panagariya, A. and Srinivasan, T. N., (2004), "The Muddles Over Outsourcing", Journal of Economic Perspective, Vol. 18: 93-114.

7. Brecher, R. A., (1974a), "Minimum Wage Rates and the Pure Theory of International Trade", Quarterly Journal of Economics, Vol. 88: 98-116.

8. Brecher, R. A., (1974b), "Optimal Commercial Policy for a Minimum-Wage Economy", Journal of International Economics, Vol. 4: 139-149.

9. Chipman, J. S., (1965), "A Survey of the Theory of International Trade: Part 2, The Neoclassical Theory", Econometrica: 685 - 760.

10. Davis, D. R., (1996), “Does European Unemployment Prop Up American Wages? National Labor Markets and Global Trade", The American Economic Review, Vol. 88: 478-494. 
11. Deardorff, A. V., (1998), "Fragmentation in Simple Trade Model", School of Public Policy, University of Michigan, Discussion Paper: No. 422.

12. Deardorff, A. V., (2001), "Fragmentation across Cones", Fragmentation: New Production Patterns in The World Economy by Arndt, S. W. and Kierzkowski, H., Oxford University Press: London.

13. Deardorff, A. V., (2005), "A Trade Theorist's Take on Skilled-Labor Outsourcing", International Review of Economics and Finance, Vol.14: 259-271.

14. Drezner, D., (2004), "The Outsourcing Bogeyman”, Foreign Affairs, May-June.

15. Feenstra, R. C. and Hanson, G., (1996a), "Globalization, Outsourcing, and Wage Inequality”, NBER Working Paper: No. W5424.

16. Feenstra, R. C. and Hanson, G., (1996b), "Foreign Investment, Outsourcing and Relative Wages", Political Economy of Trade Policy: Essay in Honor of Jagdish Bhagwait by Feenstra, R. C., Grossman, G. M. and Irwin, D. A., MIT Press.

17. Feenstra, R. C. and Hanson, G., (1999), "The Impact of Outsourcing and HighTechnology Capital on Wages: Estimates for the United States, 1979-1990", Quarterly Journal of Economics, Vol. 114: 907-940.

18. Harris, R., (2001), “A Communication Based Model of Global Production Fragmentation", Fragmentation: New Production Patterns in the World Economy by Arndt, S. W. and Kierzkowsk, H., Oxford University Press: London.

19. Helpman, E., (1985), "Market Structure and Foreign Trade: Increasing Returns, Imperfect Competition, and the International Economy", MIT press: Cambridge.

20. Herberg, H. and Kemp, M. C., (1969), "Some Implications of Variable Returns to Scale" Canadian Journal of Economics, Vol. 2: 403-415. 
21. Geishecker, I. and Gorg, H., (2004), "Winners and Losers: Fragmentation, Trade and Wages Revisited", IZA Discussion Paper: No.982.

22. Goldstein, G.S. and Moses, L.N., (1973), "A Survey of Urban Economics", Journal of Economic Literature, Vol. 11: 471-515.

23. Jones, R. W., (1965), “The Structure of Simple General Equilibrium Models”, Journal of Political Economy, Vol. 73: 557-572.

24. Jones, R. W., (1968), "Variable Returns to Scale in General Equilibrium Theory", International Economic Review, Vol. 9: 261-272.

25. Jones, R. W. and Kierzkowski, H., (2001), "Globalization and the Consequences of International Fragmentation", Money, Factor Mobility, and Trade: The Festschrift in Honor of Robert A. Mundell by Dornbusch, R., Calvo, G., and Obstfeld, M., MIT Press: Cambridge.

26. Kemp, M. C., (1964), "The Pure Theory of International Trade", Prentice-Hall, Englewood Cliffs.

27. Kemp, M. C., (1969), “The Pure Theory of International Trade and Investment", Prentice-Hall, Englewood Cliffs.

28. Kohler, W., (2001), “A Specific-Factors View on Outsourcing”, North American Journal of Economics and Finance, Vol.12: 31-53.

29. Kohler, W., (2002), “The Distributional Effect of International Fragmentation", University of Linz, Working Paper: No. 0201.

30. Komiya, R., (1967), "Non-Traded Goods and the Pure Theory of International Trade", International Economic Review, Vol. 8: 132-152.

31. Mann, C., (2003), "Globalization of IT Services and White Collar Jobs." Policy Brief 
PBO 3-11, Washington, D.C., Institute for International, Economics.

32. Mansfield, E., (1997), Applied Microeconomics, W. W. Nortton: New York.

33. Mitra, D. and Ranjan, P., (2007), "Off-shoring and Unemployment", NBER Working Paper: No. 13149 N.

34. OECD Report (2006), "The Share of Employment Potentially Affected by Offshoring - an Empirical Investigation", presented to the Working Party on the Information Economy.

35. Panagariya, A., (1980), "Variable Returns to Scale in General Equilibrium Theory Once Again", Journal of International Economics, Vol. 10: 499-526.

36. Panagariya, A., (1981), "Variable Returns to Scale in Production and Patterns of Specialization", The American Economic Review, Vol. 71: 221-330.

37. Panagariya, A., (1986), “Increasing Returns, Dynamic Stability and International Trade", Journal of International Economics, Vol. 20: 43-63.

38. Porter, M. E., (1990), "The Competitive Advantage of Nations", MacMillan: London.

39. Rohde, G., (2007), “Offshore Job Losses Exaggerated”, UNI Global Union.

40. Schweinberger, A. G., (1975), "Pure Traded Intermediate Products and the Heckscher-Ohlin Theorem", The American Economic Review, Vol. 65: 634-643.

41. Choi, J. Y. and Yu, E., (1984), "Gains from Trade under Variable Returns to Scale”, Southern Economic Journal, Vol. 50: 979-992. 


\section{Appendix A}

1. The Equality between Price and Unit Cost for the Good Embodying the Externality

Recall that (2.1) takes the special separable form, so that the function $z\left(S_{Z}, L_{Z}\right)$ can be considered as an index of factor input, which is used with a productivity measured by $g(Z)$ to yield the total output of $\operatorname{good} Z$. Denoting $P_{z}$ as the price of good $Z$ and letting $\tilde{C}_{z}\left(W_{S}, W_{L}\right)$ be the unit cost associated with $z\left(S_{Z}, L_{Z}\right)$, we have the following equation by competitive pricing:

$$
P_{z} g(Z)=\tilde{C}_{z}\left(W_{S}, W_{L}\right)
$$

Here, $P_{z} g(Z)$ is the unit return to the factor input index $z\left(S_{Z}, L_{Z}\right)$. On the other hand, the industry's total cost can be represented by the product of unit cost per factor input index $\left(\tilde{C}_{z}\left(W_{s}, W_{L}\right)\right)$ and total units of the index used in production $\left(\frac{Z}{g(Z)}\right)$. Therefore, the unit cost of good $Z$ should be equal to the total cost divided by the total output, which yields $\frac{\tilde{C}_{z}\left(W_{S}, W_{L}\right)}{g(Z)}$. It is clear that this term is also equal to the unit price $P_{Z}$ as indicated by $(A 1.1)$.

\section{The Slope of the PPF}

The Lagrangian function is set up as follows. Here we are interested in solving for the Lagrange multiplier $\gamma$ which represents the slope of the PPF.

$$
L=F^{Y}\left(S_{Y}, L_{Y}\right)+\gamma\left[\bar{X}-T\left(S_{T}, L_{T}\right)\right]+\psi\left[Z-g(Z) z\left(S-S_{T}-S_{Y}, L-L_{T}-L_{Y}\right)\right]+\xi\left[Z-a T\left(S_{T}, L_{T}\right)\right]
$$




$$
\text { F.O.C } \begin{aligned}
\frac{\partial L}{\partial S_{Y}} & =F_{S}^{Y}+\psi g(Z) z_{S}=0, \\
\frac{\partial L}{\partial L_{Y}} & =F_{L}^{Y}+\psi g(Z) z_{L}=0, \\
\frac{\partial L}{\partial S_{T}} & =-\gamma T_{S}+\psi g(Z) z_{S}-\xi a T_{S}=0, \\
\frac{\partial L}{\partial L_{T}} & =-\gamma T_{L}+\psi g(Z) z_{L}-\xi a T_{L}=0, \\
\frac{\partial L}{\partial Z} & =\psi\left[1-g^{\prime}(Z) z\right]+\xi=0,
\end{aligned}
$$

where $F_{S}^{Y}\left(F_{L}^{Y}\right)$ denotes the marginal product of $S(L)$ in the production of $Y$, while the remaining terms such as $z_{L}$ and $T_{S}$ are defined in the same manner. Rewrite $(A 2.5)$ as

$$
-\xi=\psi\left[1-g^{\prime}(Z) z\right]
$$

Substituting $\left(A 2.5^{\prime}\right)$ into $(A 2.4)$, we obtain

$$
-\gamma T_{L}+\psi g(Z) z_{L}+\psi\left[1-g^{\prime}(Z) z\right] a T_{L}=0
$$

Solving for $\psi$ yields

$$
\psi=\frac{\gamma T_{L}}{g(Z) z_{L}+\left[1-g^{\prime}(Z) z\right] a T_{L}}
$$

Now substituting $(A 2.6)$ into $(A 2.2)$ and solving $\gamma$, we have

$$
\gamma=-\left(\frac{F_{L}^{Y}}{T_{L}}+\frac{F_{L}^{Y} a\left(1-g^{\prime}(Z) z\right)}{g(Z) z_{L}}\right)
$$

Profit maximization requires equality between the value of the private marginal product of each factor and the return to that factor, which leads to the following equations:

$$
\begin{aligned}
V T_{L} & =W_{L}, \\
P_{Z} g(Z) z_{L} & =W_{L}, \\
P_{Y} F_{L}^{Y} & =W_{L} .
\end{aligned}
$$


Using $(A 2.8),(2.1)$ and $(5)$, it follows after simple manipulation that

$$
\gamma=-\left(\frac{P_{X}}{P_{Y}}-a \varepsilon \frac{P_{Z}}{P_{Y}}\right) .
$$

\section{Comparative Statics and Analytical Relationships}

To generalize the well-known Jones's $(1965,1968)$ algebra for our purpose, start by totally differentiating $(7.1),(7.2)$ and $(6.1)-(6.3)$, after appropriate substitution we obtain:

$$
\begin{aligned}
& a_{T S} d T+a_{z S} d z+a_{Y S} d Y=d S-\left(T d a_{T S}+z d a_{z S}+Y d a_{Y S}\right), \\
& a_{T L} d T+a_{z L} d z+a_{Y L} d Y=d L-\left(T d a_{T L}+z d a_{z L}+Y d a_{Y L}\right), \\
& a_{T S} d W_{S}+a_{T L} d W_{L}+a d P_{Z}=d P_{X}-\left(W_{S} d a_{T S}+W_{L} d a_{T L}\right), \\
& a_{Y S} d W_{S}+a_{Y L} d W_{L}=d P_{Y}-\left(W_{S} d a_{Y S}+W_{L} d a_{Y L}\right), \\
& a_{z S} d W_{S}+a_{z L} d W_{L}-g(Z) d P_{Z}=P_{Z} g^{\prime}(Z) d Z-\left(W_{S} d a_{z S}+W_{L} d a_{z L}\right),
\end{aligned}
$$

where $a_{i j}$ denotes the quantity of factor $j(=S, L)$ required to produce unit of good $i(=T, z, Y)$. Since each firm minimizes unit cost taking the factor prices as fixed, the minimum-unit-cost condition of equality between the marginal rate of technical substitution (among the two factors) and the ratio of factor prices implies

$$
W_{S} d a_{i S}+W_{L} d a_{i L}=0, \quad i=T, z, Y
$$

Equation (A3.2) embodies the idea that, while holding other things unchanged, alternations in factor proportion must be balanced out such that the wage rate weighted average of the changes in input coefficients of each industry is zero. Note that although $z$ and $Z$ are two different measures, they represent the same industry and the actual amount of factors utilized in $z$ and $Z$ are exactly the same. Total differentiation of $(2.1)$ 
and (5) yields

$$
\begin{aligned}
& d Z=\frac{g(Z)}{(1-\varepsilon)} d z, \\
& a d X=a d T=d Z,
\end{aligned}
$$

where $\varepsilon$ is the elasticity of the externality. Let the "hat" notation indicate the proportionate change of a variable, so that $\hat{X}$ denotes $d X / X$ and $\hat{P}$ denotes $d P / P$. Following this, $(A 3.3)$ and $(A 3.4)$ can be rewritten as

$$
\begin{aligned}
& \hat{Z}=\frac{\hat{z}}{(1-\varepsilon)}, \\
& \hat{X}=\hat{T}=\hat{Z} .
\end{aligned}
$$

Substituting $(A 3.2),\left(A 3.3^{\prime}\right)$ and $\left(A 3.4^{\prime}\right)$ into $(A 3.1)$, we obtain:

$$
\begin{aligned}
& \lambda_{T S} \hat{X}+\lambda_{Z S}(1-\varepsilon) \hat{X}+\lambda_{Y S} \hat{Y}=\hat{S}-\left(\lambda_{T S} \hat{a}_{T S}+\lambda_{Z S} \hat{a}_{Z S}+\lambda_{Y S} \hat{a}_{Y S}\right), \\
& \lambda_{T L} \hat{X}+\lambda_{Z L}(1-\varepsilon) \hat{X}+\lambda_{Y L} \hat{Y}=\hat{L}-\left(\lambda_{T L} \hat{a}_{T L}+\lambda_{Z L} \hat{a}_{Z L}+\lambda_{Y L} \hat{a}_{Y L}\right), \\
& \theta_{T S} \hat{W}_{S}+\theta_{T L} \hat{W}_{L}+\theta_{X Z} \hat{P}_{Z}=\hat{P}_{X}, \\
& \theta_{Y S} \hat{W}_{S}+\theta_{Y L} \hat{W}_{L}=\hat{P}_{Y}, \\
& \theta_{Z S} \hat{W}_{S}+\theta_{Z L} \hat{W}_{L}-\hat{P}_{Z}=(\varepsilon / 1-\varepsilon) \hat{z} .
\end{aligned}
$$

Two types of coefficients appear in these equations: $\lambda_{i j}$ and $\theta_{i j}, i=T, Z, Y ; j=S, L, Z$.

Here $\lambda_{i j}$ denotes the fraction of factor $j$ employed in industry $i$ while $\theta_{i j}$ refers to factor $j$ 's distributive share in industry $i$. Specifically, these coefficients are defined as follows: 


$$
\begin{aligned}
& \lambda_{T S} \equiv \frac{a_{T S} T}{S}, \lambda_{Y S} \equiv \frac{a_{Y S} Y}{S}, \lambda_{Z S} \equiv \frac{a_{z S} z}{S}, \\
& \lambda_{T L} \equiv \frac{a_{T L} T}{L}, \lambda_{Y L} \equiv \frac{a_{Y L} Y}{L}, \lambda_{Z L} \equiv \frac{a_{z L} z}{L}, \\
& \theta_{T S} \equiv \frac{a_{T S} W_{S}}{P_{X}}, \theta_{T L} \equiv \frac{a_{T L} W_{L}}{P_{X}}, \theta_{X Z} \equiv \frac{a P_{Z}}{P_{X}}, \\
& \theta_{Y S} \equiv \frac{a_{Y S} W_{S}}{P_{Y}}, \theta_{Y L} \equiv \frac{a_{Y L} W_{L}}{P_{Y}}, \\
& \theta_{Z S} \equiv \frac{a_{z S} W_{S}}{P_{Z} g(Z)}, \theta_{Z L} \equiv \frac{a_{Z L} W_{L}}{P_{Z} g(Z)} .
\end{aligned}
$$

It is straightforward to derive the following relationships:

$$
\begin{aligned}
& \lambda_{T S}+\lambda_{Z S}+\lambda_{Y S}=1, \\
& \lambda_{T L}+\lambda_{Z L}+\lambda_{Y L}=1, \\
& \theta_{T S}+\theta_{T L}+\theta_{X Z}=1, \\
& \theta_{Y S}+\theta_{Y L}=1, \\
& \theta_{Z S}+\theta_{Z L}=1 .
\end{aligned}
$$

Now consider coefficient $\hat{a}_{i j}$ in $(A 3.5)-(A 3.9)$. Given the homothetic production function, $a_{i j}$ only depends on the wage ratio $\omega$. Define $\sigma_{i}$ as the elasticity of substitution between skilled labor and unskilled labor:

$$
\sigma_{i} \equiv \frac{d\left(S_{i} / L_{i}\right)}{d\left(W_{L} / W_{S}\right)} \frac{\left(W_{L} / W_{S}\right)}{\left(S_{i} / L_{i}\right)}, \quad i=T, Z, Y .
$$

Rewrite $\sigma_{i}$ in terms of coefficient $a_{i j}$ as follows:

$$
\sigma_{i} \equiv \frac{\hat{a}_{i S}-\hat{a}_{i L}}{\hat{W}_{L}-\hat{W}_{S}}, \quad i=T, Z, Y .
$$

Using (A3.2), we can derive

$$
\theta_{i S} \hat{a}_{i S}+\theta_{i L} \hat{a}_{i L}=0 .
$$

Now we could solve for $\hat{a}_{i j}$ from $(A 3.10)$ and $\left(A 3.2^{\prime}\right)$. For example, for industry $T$ we 
have

$$
\left(\theta_{T S}+\theta_{T L}\right) \hat{a}_{T S}=\theta_{T L} \sigma_{T}\left(\hat{W}_{L}-\hat{W}_{S}\right)
$$

Solving for $\hat{a}_{T S}$ yields

$$
\hat{a}_{T S}=\frac{P_{X} \theta_{T L} \sigma_{T}\left(\hat{W}_{L}-\hat{W}_{S}\right)}{V} .
$$

Similarly, we can obtain

$$
\begin{aligned}
& \hat{a}_{T L}=-\frac{P_{X} \theta_{T S} \sigma_{T}\left(\hat{W}_{L}-\hat{W}_{S}\right)}{V}, \\
& \hat{a}_{Y S}=\sigma_{Y} \theta_{Y L}\left(\hat{W}_{L}-\hat{W}_{S}\right), \\
& \hat{a}_{Y L}=-\sigma_{Y} \theta_{Y S}\left(\hat{W}_{L}-\hat{W}_{S}\right), \\
& \hat{a}_{Z S}=\sigma_{Z} \theta_{Z L}\left(\hat{W}_{L}-\hat{W}_{S}\right), \\
& \hat{a}_{Z L}=-\sigma_{Z} \theta_{Z S}\left(\hat{W}_{L}-\hat{W}_{S}\right) .
\end{aligned}
$$

By substitution of $(A 3.11)-(A 3.16)$, we simplify $(A 3.5)$ and $(A 3.6)$ to

$$
\begin{aligned}
& {\left[\lambda_{T S}+\lambda_{Z S}(1-\varepsilon)\right] \hat{X}+\lambda_{Y S} \hat{Y}=\hat{S}+R_{S}\left(\hat{W}_{S}-\hat{W}_{L}\right),} \\
& {\left[\lambda_{T L}+\lambda_{Z L}(1-\varepsilon)\right] \hat{X}+\lambda_{Y L} \hat{Y}=\hat{L}-R_{L}\left(\hat{W}_{S}-\hat{W}_{L}\right),}
\end{aligned}
$$

where $R_{S} \equiv \lambda_{T S} \frac{P_{X} \theta_{T L} \sigma_{T}}{V}+\lambda_{Z S} \theta_{Z L} \sigma_{Z}+\lambda_{Y S} \theta_{Y L} \sigma_{Y}, R_{L} \equiv \lambda_{T L} \frac{P_{X} \theta_{T S} \sigma_{T}}{V}+\lambda_{Z L} \theta_{Z S} \sigma_{Z}+\lambda_{Y L} \theta_{Y S} \sigma_{Y}$.

Now $\left(A 3.5^{\prime}\right),\left(A 3.6^{\prime}\right)$ and $(A 3.7)-(A 3.9)$ constitute the key equations $(12.1)-$ (12.5) above in section 3.2.

\section{The Normal Output Response to Price of the CRS Intermediate Good}

Rewrite (33.1) and (33.2) as follows: 


$$
\begin{aligned}
& \frac{d P_{X}}{d X}=\frac{P_{X}}{\mu_{X} X}\left[|\lambda|\left(\left(\theta_{T S} \theta_{Y L}-\theta_{T L} \theta_{Y S}\right)+\theta_{X Z}\left(\theta_{Z S} \theta_{Y L}-\theta_{Z L} \theta_{Y S}\right)\right)-\theta_{X Z} \varepsilon \mu_{X}\right], \\
& \frac{d P_{Z}}{d X}=\frac{P_{Z}}{\mu_{X} X}\left[|\lambda|\left(\theta_{Z S} \theta_{Y L}-\theta_{Z Z} \theta_{Y S}\right)-\varepsilon \mu_{X}\right] .
\end{aligned}
$$

Totally differentiating equation $V=P_{X}-a P_{Z}$ with respect to $X$ yields

$$
\frac{d V}{d X}=\frac{d P_{X}}{d X}-a \frac{d P_{Z}}{d X}
$$

By substitution of $(A 4.1)$ and $(A 4.2)$, we rewrite $(A 4.3)$ as

$$
\frac{d V}{d X}=\frac{1}{\mu_{X} X}\left[P_{X}|\lambda|\left(\theta_{T S} \theta_{Y L}-\theta_{T L} \theta_{Y S}\right)\right]
$$

Given the skill-intensity ranking $k_{T}>k_{Y}$, it follows that $\theta_{T S} \theta_{Y L}-\theta_{T L} \theta_{Y S}>0$ which implies $\frac{d V}{d X}>0$

\section{The Form of the Externality}

The assumption $\frac{d \varepsilon}{d Z}=0$ requires $g(Z)$ to take an exponential form $g(Z)=K Z^{\varepsilon}$, where $K$ is a constant, and $K=1$ in our case. From the definition of $\varepsilon$,

$$
\frac{g^{\prime}(Z)}{g(Z)}=\frac{\varepsilon}{Z}
$$

Integrating both sides of this equation with respect to $d Z$, we have

$$
\begin{aligned}
\int \frac{g^{\prime}(Z)}{g(Z)} d Z=\int \frac{\varepsilon}{Z} d Z, \\
\log [g(Z)]=\varepsilon \log Z+\log K, \\
=\log \left(K Z^{\varepsilon}\right), \\
=\log \left(Z^{\varepsilon}\right),
\end{aligned}
$$


after setting $K=1$. Therefore,

$$
g(Z)=Z^{\varepsilon}
$$

From the properties of power functions, it is known that $g(Z)<1$ when $0<Z<1$ given that $0<\varepsilon<1$. Considering the production function $Z=g(Z) z\left(S_{Z}, L_{Z}\right)$, it is clear that $Z<z\left(L_{Z}, S_{Z}\right)$ when $Z<1$, which indicates a DRS production technology. Here, for illustrative purposes and to avoid this inconsistency, we simply assume that Home will produce more than one unit if she chooses to produce that good.

\section{Discussion Regarding the Assumption of Complete Outsourcing}

Due to the technology difference across countries, free trade in both final goods as well as fragment $T$ is not consistent with the situation where both countries produce all three goods ( $Z, T$ and $Y$ ). This can be easily illustrated using the Lerner diagram. Therefore, if the foreign country fully diversifies while having free trade in final goods and intermediate good $T$, the home country must specialize in producing no more than two goods. The assumption of complete outsourcing above where the home country produces only $Z$ and $Y$, whereas no restriction is placed on the foreign production, is simply adopted in order to deal with this matter.

In fact, the main idea underpinning the discussion in Chapter 5 is applicable for $\varphi$ increasing from zero to any arbitrary level $\bar{\varphi}$. In our paper, $\bar{\varphi}$ is simply assumed to reflect the entire quantity required by Home (complete outsourcing). In addition, the assumption of complete outsourcing seems to be quite reasonable for a small open economy, though perhaps less appropriate for a large country. In the paper, we adopt this 
assumption for simplicity, as have others in their research. For example, see Feenstra and Hanson (1996 a, b), Arndt (1997) and Deardorff (2001).

\section{The Slope of the $P_{P F}^{Z Y}$ at Outsourcing}

Equation $(A 7.1)$ states equality between the value of the total production and the national income:

$$
P_{Z} Z+P_{Y} Y=W_{S} S+W_{L} L
$$

Total differentiation of $(A 7.1)$ yields

$$
Z d P_{Z}+P_{Z} d Z+d Y=S d W_{S}+L d W_{L}
$$

The full-employment conditions of both factors imply that

$$
\begin{aligned}
& a_{z S} z+a_{Y S} Y=S, \\
& a_{z L} z+a_{Y L} Y=L .
\end{aligned}
$$

Recall that (6.2) and (6.3) are given by

$$
\begin{aligned}
& a_{Y S} W_{S}+a_{Y L} W_{L}=1, \\
& a_{z S} W_{S}+a_{z L} W_{L}=P_{Z} g(Z),
\end{aligned}
$$

after setting $P_{Y}=1$ for the numeraire good. Totally differentiating these two equations, we obtain

$$
\begin{aligned}
& a_{Y S} d W_{S}+a_{Y L} d W_{L}=0, \\
& a_{z S} d W_{S}+a_{z L} d W_{L}=g(Z) d P_{Z}+P_{Z} \frac{d g(Z)}{d Z} d Z .
\end{aligned}
$$

Now substituting $(A 7.3)$ and $(A 7.4)$ into $(A 7.2)$, it follows that

$$
\frac{d Y}{d Z}=-\frac{P_{Z}}{P_{Y}}(1-\varepsilon)
$$




\section{The Curvature of the $\mathrm{PPF}^{\mathrm{ZY}}$ at Outsourcing}

The derivations here are similar to that as in autarky, except that all the coefficients related to $T$ disappear due to the assumption of complete outsourcing. Following this, we have

$$
\begin{aligned}
& \lambda_{z S}(1-\varepsilon) \hat{Z}+\lambda_{Y S} \hat{Y}=\hat{S}+U_{S}\left(\hat{W}_{S}-\hat{W}_{L}\right), \\
& \lambda_{z L}(1-\varepsilon) \hat{Z}+\lambda_{Y L} \hat{Y}=\hat{L}-U_{L}\left(\hat{W}_{S}-\hat{W}_{L}\right), \\
& \theta_{Y S} \hat{W}_{S}+\theta_{Y L} \hat{W}_{L}=\hat{P}_{Y}, \\
& \theta_{Z S} \hat{W}_{S}+\theta_{Z L} \hat{W}_{L}-\hat{P}_{Z}=(\varepsilon / 1-\varepsilon) \hat{z},
\end{aligned}
$$

where $U_{S} \equiv \lambda_{Y S} \theta_{Y L} \sigma_{Y}+\lambda_{Z S} \theta_{Z L} \sigma_{Z}, U_{L} \equiv \lambda_{Y L} \theta_{Y S} \sigma_{Y}+\lambda_{Z L} \theta_{Z S} \sigma_{z}$. All other coefficients are defined in the same manner as in autarky. Solving $(A 8.1)$ and $(A 8.2)$ for $\hat{Z}$ yields

$$
\hat{Z}=\frac{\mu_{Z}}{\left|\lambda_{z}\right|}\left(\hat{W}_{S}-\hat{W}_{L}\right)
$$

where $\left|\lambda_{z}\right| \equiv\left(\lambda_{Z S} \lambda_{Y L}-\lambda_{Z L} \lambda_{Y S}\right)(1-\varepsilon)$ and $\mu_{Z} \equiv U_{S} \lambda_{Y L}+U_{L} \lambda_{Y S}$. Both $\left|\lambda_{Z}\right|$ and $\mu_{Z}$ are positive, given $0<\varepsilon<1$ and the assumed skill-intensity ranking. Recall that $\hat{z}=(1-\varepsilon) \hat{Z}$ and then substitute $(A 8.5)$ into $(A 8.4)$ yields

$$
\left(\theta_{z S}-\frac{\varepsilon \mu_{Z}}{\left|\lambda_{z}\right|}\right) \hat{W}_{S}+\left(\theta_{z L}+\frac{\varepsilon \mu_{Z}}{\left|\lambda_{z}\right|}\right) \hat{W}_{L}=\hat{P}_{Z} .
$$

Now $(A 8.3)$ and $(A 8.6)$ constitute a system relating factor returns and commodity prices:

$$
\begin{aligned}
& \theta_{Z S}^{\prime} \hat{W}_{S}+\theta_{Z L}^{\prime} \hat{W}_{L}=\hat{P}_{Z}, \\
& \theta_{Y S}^{\prime} \hat{W}_{S}+\theta_{Y L}^{\prime} \hat{W}_{L}=\hat{P}_{Y} .
\end{aligned}
$$

Define $\boldsymbol{\theta}_{\mathrm{z}}^{\prime}$ as the two-by-two matrix: 


$$
\boldsymbol{\theta}_{\mathbf{Z}}^{\prime} \equiv\left(\begin{array}{cc}
\theta_{Z S}^{\prime} & \theta_{Z L}^{\prime} \\
\theta_{Y S}^{\prime} & \theta_{Y L}^{\prime}
\end{array}\right) \equiv\left(\begin{array}{c}
\left.\theta_{Z S}-\frac{\varepsilon \mu_{Z}}{\left|\lambda_{Z}\right|}\right) \\
\theta_{Y S}
\end{array}\left(\begin{array}{c}
\left.\theta_{Z L}+\frac{\varepsilon \mu_{Z}}{\left|\lambda_{Z}\right|}\right) \\
\theta_{Y L}
\end{array}\right) .\right.
$$

Clearly, the relationship between factor returns and commodity prices relies on the signs of each element $\theta_{i j}^{\prime}, i=Z, Y ; j=S, L$ and $\left|\theta_{Z}^{\prime}\right|$, the determinant of matrix $\boldsymbol{\theta}_{\mathrm{Z}}^{\prime}$. Using $P_{Y}=1$, we solve for the relative change in $\omega$ due to a change in $P_{Z}$ :

$$
\hat{\omega}=\hat{W}_{S}-\hat{W}_{L}=\frac{1}{\left|\theta_{Z}^{\prime}\right|}\left(\hat{P}_{Z}-\hat{P}_{Y}\right)=\frac{1}{\left|\theta_{Z}^{\prime}\right|} \hat{P}_{Z}
$$

where $\left|\theta_{Z}^{\prime}\right| \equiv\left(\theta_{Z S} \theta_{Y L}-\theta_{Z L} \theta_{Y S}\right)-\frac{\varepsilon \mu_{Z}}{\left|\lambda_{Z}\right|}$. Substituting $(A 8.7)$ into $(A 8.5)$ yields

$$
\hat{P}_{Z}=\frac{\left|\lambda_{z}\right|\left|\theta_{Z}^{\prime}\right|}{\mu_{z}} \hat{Z}
$$

Given that both $\left|\lambda_{z}\right|$ and $\mu_{z}$ are positive, the output response to price depends on the sign of $\left|\theta_{Z}^{\prime}\right|$ which is ambiguous. Define $\left|\theta^{*}\right| \equiv\left(\theta_{Z S} \theta_{Y L}-\theta_{Z L} \theta_{Y S}\right)$ which is certainly positive, we have $\left|\theta_{z}^{\prime}\right|=\left|\theta^{*}\right|-\frac{\varepsilon \mu_{Z}}{\left|\lambda_{z}\right|}$. Now $(A 8.8)$ can be rewritten in the following way:

$$
\hat{P}_{z}=\frac{1}{\mu_{z}}\left[\left|\lambda_{z}\right|\left|\theta^{*}\right|-\varepsilon \mu_{z}\right] \hat{Z}
$$

which is (43) in section 5.1. As discussed in that section, it is known that the curvature of the $\operatorname{PPF}^{Z Y}$ is dependent only on whether the output response to price of good $Z$ is normal or perverse. Since the sign of the overall coefficient in (43) is ambiguous, the $\mathrm{PPF}^{\mathrm{ZY}}$ can be either concave or convex.

Now consider the neighborhoods of the end points. In the neighborhood of $Z=0$, 
$\mu_{Z}$ approaches $\lambda_{Y S} \lambda_{Y L} \sigma_{Y}$ while $\left|\lambda_{Z}\right|$ goes to zero. Thus, (43) indicates that the output response to price is given by $\frac{d P_{Z}}{d Z}=-\frac{\varepsilon P_{Z}}{Z}$ which is negative. Substituting this equation into (42) $\frac{d^{2} Y}{d Z^{2}}=-\frac{d P_{Z}}{d Z}(1-\varepsilon)\left|\lambda_{Z}\right|$, it is clear that the sign of $\frac{d^{2} Y}{d Z^{2}}$ is positive which implies the convexity of the $\mathrm{PPF}^{\mathrm{ZY}}$. On the other hand, when the production of good $Y$ goes to zero, both terms $\mu_{Z}$ and $\left|\lambda_{z}\right|$ approach zero. However, the approaching speed of $\mu_{z}$ is faster than that of $\left|\lambda_{z}\right|$, which implies that $\frac{\left|\lambda_{z}\right|}{\mu_{z}}$ must go to positive infinity. Following this, the sign of $\frac{d P_{Z}}{d Z}$ is positive and the $\mathrm{PPF}^{\mathrm{ZY}}$ is therefore concave in the neighborhood of $Y=0$.

\section{Multiple Equilibria of the Minimum-Wage Model}

Figure 14 illustrates our discussion below.

a. When the price ratio $P$ goes to infinity, there must be an excess supply of good $X$; when $P$ approaches zero, there must be an excess demand of $\operatorname{good} X$. Therefore, the two end-range of the excess supply/demand curve $a b$ and $j k$ must be upward sloping. (specialization)

b. Suppose point $f$ denotes the autarky equilibrium. In order to ensure this equilibrium to be stable, the section of the excess supply/demand curve through this point must be upward slopping, which implies that there is an excess supply of good $X$ as the price increases and an excess demand of good $X$ as the price falls. (diversification) 
c. Due to the perverse output response to price along the constrained transformation curve $R_{2} R_{1}$, we shall move toward $R_{2}$ with a falling production of $X$ if there is an increase in $P$. When we reach $R_{2}$ on the transformation curve, there is an excess demand for good $X$ which can be represented by point $c$ on the excess supply/demand curve. Conversely, as $P$ decreases we move toward $R_{1}$ with a rising production of $X$. When we reach $R_{1}$, there is an excess supply of good $X$ which is illustrated as point $i$ on the excess supply/demand curve. (specialization)

d. Points $c$ and $i$ imply that the curves $f e$ and $f g$ must cross back over the vertical price axis again, which yields another two intersection points $d$ and $h$. It is straightforward to see that these two equilibria are unstable. (diversification)

Figure 14: Multiple Equilibria of the Minimum-Wage Model

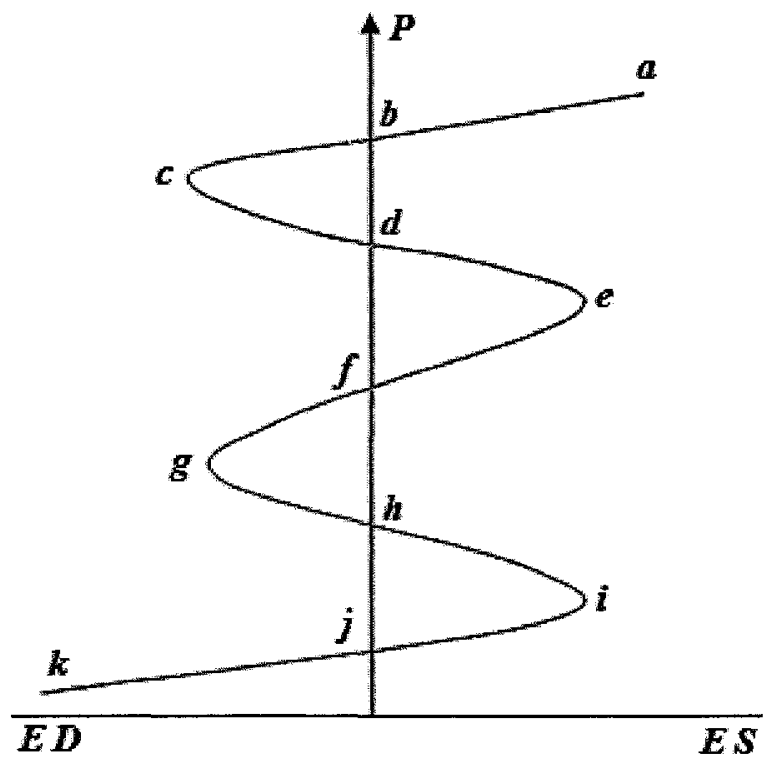

In summary, we cannot rule out the possibility of multiple equilibria in the present 
situation. Since we are interested in diversified and stable equilibria, assume that there is exactly one such equilibrium, such as $f$, and that the following condition holds at interior points along the entire constrained transformation curve $R_{2} R_{1}$ :

$$
\left|\frac{d(X / Y)}{d P}\right|<\left|\alpha^{\prime}(P)\right|
$$

10. The Positive Relationship between the Real Wage of Unskilled Labor and the Demand for Unskilled Labor at Constant Terms of Trade

We now show that at constant terms of trade, the relationship between the real wage of unskilled labor and the demand for unskilled labor is positive. To begin, recall the production function for good $Z$ given by (48). Allowing unemployment of unskilled labor to occur in the minimum-wage model, we rewrite the function here as

$$
Z=Z(\varphi, \omega, \bar{S}, L)
$$

Next, recall that the Lerner diagram implies the following equation

$$
Z=\tilde{Z}\left(\omega, P_{X}^{*}\right) \equiv \tilde{g}\left(\frac{h(\omega)}{P_{Z}\left(\omega, P_{X}^{*}\right)}\right)
$$

where $\tilde{g}(\cdot)$ is the inverse function of $g(\cdot)$; and $\frac{\partial \tilde{Z}}{\partial \omega}=\tilde{g}^{\prime}(\cdot)\left(\frac{1}{P_{Z}} \frac{d h(\cdot)}{d \omega}-\frac{h}{P_{Z}^{2}} \frac{\partial P_{Z}}{\partial \omega}\right)>0$ since $\tilde{g}^{\prime}(\cdot)>0, \frac{d h(\cdot)}{d \omega}>0$ and $\frac{\partial P_{Z}}{\partial \omega}<0$

Note that $Z$ from $(A 10.1)$ and $(A 10.2)$ must be equal, we therefore have

$$
Z(\varphi, \omega, \bar{S}, L)=\tilde{Z}\left(\omega, P_{X}^{*}\right)
$$


Holding $\varphi$ at an arbitrary level of (say) zero and totally differentiating $(A 10.3)$ at constant $P_{X}^{*}$, we obtain

$$
\frac{\partial Z}{\partial \omega} d \omega+\frac{\partial Z}{\partial L} d L=\frac{\partial \tilde{Z}}{\partial \omega} d \omega
$$

Therefore, the solution we are seeking is given by

$$
\left.\frac{d \omega}{d L}\right|_{\bar{P}_{X}^{*}}=\frac{\frac{\partial Z}{\partial L}}{\left(\frac{\partial \tilde{Z}}{\partial \omega}-\frac{\partial Z}{\partial \omega}\right)},
$$

where $\left(\frac{\partial \tilde{Z}}{\partial \omega}-\frac{\partial Z}{\partial \omega}\right)$ is positive as demonstrated in section 5.2.1 and $\frac{\partial Z}{\partial L}$ is the standard Rybczynski term. Recalling that the Rybczynski Theorem holds under the assumption $\left|\theta^{\prime}\right|>0$, we have $\frac{\partial Z}{\partial L}<0$ since $Z$ is the good most intensive in skilled labor. Taken together, these results and $(A 10.5)$ implies that $\frac{d \omega}{d L}<0$, which ensures that $\frac{d W_{L}}{d L}>0$. This positive relationship between the wage rate of unskilled labor and the employment level of unskilled labor is illustrated in Figure 15, where the employment level is measured on the horizontal axis and the wage rate is measured on the vertical axis.

In the full-employment model with flexible wages, we have shown that outsourcing leads to a rise in $\omega$ and hence a decrease in $W_{L}$, thereby shifting the $R$ curve down to $R^{\prime}$. On the other hand, with a binding minimum-wage constraint, this shift will result in a greater level of employment of unskilled labor (via the decline in the production of good $Z$ ). 
Figure 15: The Positive Relationship between the Real Wage of Unskilled Labor and the Demand for Unskilled Labor at Constant Terms of Trade

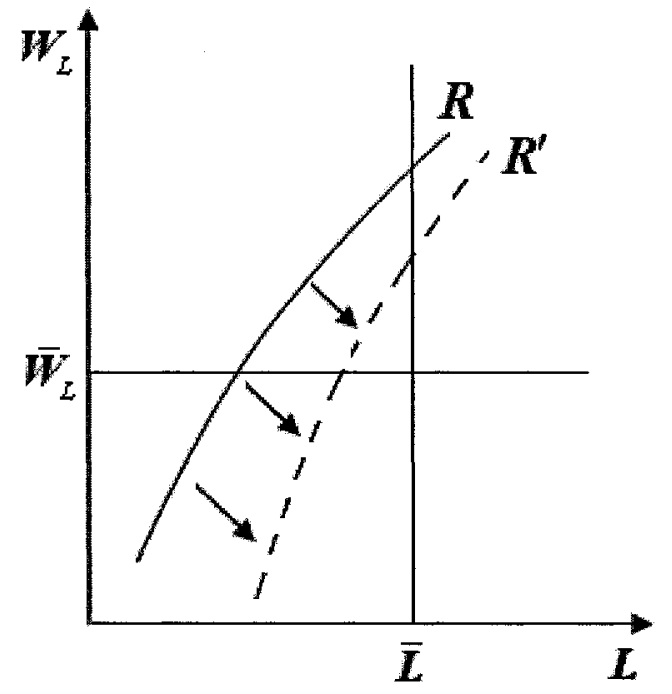

11. Analytical Relationships for the Minimum-Wage Model at Outsourcing

Complete outsourcing leads to zero domestic production of $T$. Since skilled labor $S$ is always fully utilized, we have

$$
\bar{S}=\frac{Z}{g(Z) f_{Z}\left(\bar{k}_{Z}\right)} \bar{k}_{Z}+\frac{Y}{f_{Y}\left(\bar{k}_{Y}\right)} \bar{k}_{Y} .
$$

Solving $(A 11.1)$ for $Y$, we obtain

$$
Y=\frac{f_{Y}}{\bar{k}_{Y}} \bar{S}-\frac{\bar{k}_{Z} f_{Y}}{g(Z) \bar{k}_{Y} f_{Z}} Z
$$

Taking the first and second derivatives of $Y$ with respect to $Z$ yields

$$
\begin{aligned}
& \frac{d Y}{d Z}=-\frac{(1-\varepsilon)}{g(Z)} \frac{\bar{k}_{Z} f_{Y}}{\bar{k}_{Y} f_{Z}}<0, \\
& \frac{d^{2} Y}{d Z^{2}}=\frac{\varepsilon(1-\varepsilon)}{g(Z) Z} \frac{\bar{k}_{Z} f_{Y}}{\bar{k}_{Y} f_{Z}}>0 .
\end{aligned}
$$


Equations $(A 11.3)$ and $(A 11.4)$ confirm that in the presence of complete outsourcing, the constrained transformation curve is also downward sloping and convex. Recall that

$$
L=\frac{Z}{g(Z) f_{Z}\left(\bar{k}_{Z}\right)}+\frac{Y}{f_{Y}\left(\bar{k}_{Y}\right)} .
$$

Totally differentiating $(A 11.5)$, it follows that

$$
\begin{aligned}
& \frac{d L}{d Y}=\frac{1}{f_{Y}\left(\bar{k}_{Y}\right)}\left(1-\frac{\bar{k}_{Y}}{\bar{k}_{Z}}\right)>0, \\
& \frac{d L}{d X}=\frac{a(1-\varepsilon)}{f_{Z} g(Z)}\left(1-\frac{\bar{k}_{Z}}{\bar{k}_{Y}}\right)<0,
\end{aligned}
$$

which imply that employment of unskilled labor is positively (negatively) related to the production of good $Y(X)$. With complete outsourcing, the home country purchases $T$ at the foreign price $V^{*}$, so that the domestic commodity-price ratio now can be written as

$$
P=\frac{\left(1+\bar{\omega} \bar{k}_{Z}\right) a f_{Y}}{\left(1+\bar{\omega} \bar{k}_{Y}\right) g(Z) f_{Z}}+\frac{V^{*} f_{Y}}{\left(1+\bar{\omega} \bar{k}_{Y}\right)}
$$

By substitution of the fixed-proportion condition $a X=Z$ and taking total derivative of (A11.6), we obtain

$$
\frac{d X}{d P}=-\frac{X}{\varepsilon\left(P-\frac{V^{*} f_{Y}}{\left(1+\bar{\omega} \bar{k}_{Y}\right)}\right)}
$$

Recall that $P_{Y}=1$ for the numeraire good $Y,(A 11.7)$ can be simplified to

$$
\frac{d X}{d P}=-\frac{X}{\varepsilon\left(P-V^{*}\right)}
$$

which indicates the perverse output response to price. 


\section{Appendix $B$}

\section{The Curvature of the PPF: Some Special Cases}

1. Production of good $X$ approaches zero:

In the neighborhood of $X=0$, coefficients $\lambda_{T j}$ and $\lambda_{z j}, j=S, L$ approach zero. If both the production functions of $T$ and $Z$ are continuous, there would be a continuous relationship between $\lambda_{T j}$ and $\lambda_{z j}$ associated with the production functions, which would ensure the existence of the limit of $|\lambda|$ and $\mu_{X}$. Recall that $\mu_{X} \equiv R_{S} \lambda_{Y L}+R_{L} \lambda_{Y S}$ and $|\lambda| \equiv\left(\lambda_{T S} \lambda_{Y L}-\lambda_{T L} \lambda_{Y S}\right)+(1-\varepsilon)\left(\lambda_{Z S} \lambda_{Y L}-\lambda_{Z L} \lambda_{Y S}\right)$. By inspection of these expressions, it is known that $\mu_{X}$ will approach a constant value $\lambda_{Y S} \lambda_{Y L} \sigma_{Y}$ and $|\lambda|$ will approach zero as $X$ goes to zero. In this case, $(30)$ and $(31)$ in section 3.5 can be modified to

$$
\begin{aligned}
& \hat{P}_{X}=-\theta_{X Z} \varepsilon \hat{X}, \\
& \hat{P}_{Z}=-\varepsilon \hat{X} .
\end{aligned}
$$

Using the assumption that $\frac{d \varepsilon}{d X}=0\left(\frac{d \varepsilon}{d Z}=0\right)$, we rewrite $(B .1)$ and $(B .2)$ as follows:

$$
\begin{aligned}
& \frac{d P_{X}}{d X}=-\theta_{X Z} \varepsilon \frac{P_{X}}{X}=-\frac{a \varepsilon}{X} P_{Z} \\
& \frac{d P_{Z}}{d X}=-\frac{\varepsilon}{X} P_{Z}
\end{aligned}
$$

Substituting $\left(B .1^{\prime}\right)$ and $\left(B .2^{\prime}\right)$ into (32), we obtain

$$
\frac{d^{2} Y}{d X^{2}}=-\varepsilon(\varepsilon-1) \frac{a P_{Z}}{X}
$$

Given that $0<\varepsilon<1, \frac{d^{2} Y}{d X^{2}}$ is certainly positive, which indicates the convexity of the PPF in the neighborhood of $X=0$. 
2. Production of good $Y$ approaches zero:

Using similar logic to that applied in the previous case, if the production function of good $Y$ is continuous which ensures the existence of the limits of $\lambda_{Y S}$ and $\lambda_{Y L}$, then both $\lambda_{Y S}$ and $\lambda_{Y L}$ will approach zero. It follows that both $|\lambda|$ and $\mu_{X}$ would also approach zero. However, since the approaching speed of $\mu_{X}$ is faster than that of $|\lambda|$, the term $|\lambda| / \mu_{X}$ must approach positive infinity. Recall that equation (34) is given by

$$
\frac{d^{2} Y}{d X^{2}}=-\left[\frac{1}{\mu_{X}}(|\lambda||\tilde{\theta}|) \frac{P_{X}}{X}+(1-\varepsilon) \frac{1}{\mu_{X}}\left(|\lambda|\left|\theta^{*}\right|-\varepsilon \mu_{X}\right) \frac{a P_{Z}}{X}\right]
$$

Clearly, equation (34) simply indicates a negative sign of $\frac{d^{2} Y}{d X^{2}}$, which confirms the concavity of the PPF in the neighborhood of $Y=0$.

The conclusions of the above two cases are partly consistent with the results found by Hergberg and Kemp (1969), Panagariya (1981), Choi and Yu (1984) and other authors, who show, given homothetic production functions with IRS in one industry and DRS in the other, that the PPF is strictly concave to the origin near the IRS axis and strictly convex to the origin near the DRS axis.

3. External effect $\varepsilon$ approaches zero:

If $\varepsilon$ goes to zero, both terms $|\lambda|$ and $\left|\theta^{\prime}\right|$ will be positive. This returns our discussion to the standard CRS case where both the Stolpher-Samuelson and Rybczynski theorems hold and the PPF is concave.

4. External effect $\varepsilon$ approaches one: 
When $\varepsilon$ goes to $1,|\lambda|$ will approach $|\tilde{\lambda}| \equiv \lambda_{T S} \lambda_{Y L}-\lambda_{T L} \lambda_{Y S}>0$. Following this, we could rewrite (30) and (31) as

$$
\begin{aligned}
& \hat{P}_{X}=\left(\frac{|\tilde{\lambda}||\theta|}{\mu_{X}}-\theta_{X Z}\right) \hat{X}, \\
& \hat{P}_{Z}=\left(\frac{|\tilde{\lambda}|\left|\theta^{*}\right|}{\mu_{X}}-1\right) \hat{X} .
\end{aligned}
$$

Now we show that given $\sigma_{i} \geq 1, i=Z, T, Y$, the sign of the coefficient in $(B .3)$ is uncertain whereas the coefficient in $(B .4)$ is negative. First, suppose $\sigma_{X}=\sigma_{Z}=\sigma_{Y}=1$, then we have

$$
\mu_{X} \equiv \frac{\theta_{X L}}{1-\theta_{X Z}} \lambda_{X S} \lambda_{Y L}+\frac{\theta_{X S}}{1-\theta_{X Z}} \lambda_{X L} \lambda_{Y S}+\lambda_{Y S} \lambda_{Y L}+\lambda_{Z S} \lambda_{Y L} \theta_{Z L}+\lambda_{Z L} \lambda_{Y S} \theta_{Z S}
$$

Recall that coefficients $\lambda_{i j}$ and $\theta_{i j}$ must satisfy the following conditions:

$$
\begin{aligned}
& \lambda_{T S}+\lambda_{Y S}+\lambda_{Z S}=1, \\
& \lambda_{T L}+\lambda_{Y L}+\lambda_{Z L}=1, \\
& \theta_{T S}+\theta_{T L}+\theta_{X Z}=1, \\
& \theta_{Y S}+\theta_{Y L}=1, \\
& \theta_{Z S}+\theta_{Z L}=1 .
\end{aligned}
$$

Math software MATHMATICA shows that the sign of $\left(\frac{|\tilde{\lambda}||\theta|}{\mu_{X}}-\theta_{X Z}\right)$ is uncertain while the value of $\left(\frac{|\tilde{\lambda}|\left|\theta^{*}\right|}{\mu_{X}}-1\right)$ is negative. The procedure for doing this is to have each variable changed from 0 to 1 by setting the step length equal to 0.001 . In addition to $\sigma_{i}$ there are 13 variables, 5 of which can be determined by the above 5 conditions whereas 
the other 8 variables are undetermined. Therefore, the time of total calculations is $1000^{\wedge} 8$.

If $\left(\frac{|\tilde{\lambda}|\left|\theta^{*}\right|}{\mu_{X}}-1\right)<0$ holds for $\sigma_{X}=\sigma_{Z}=\sigma_{Y}=1$, it must also hold for $\sigma_{X}=\sigma_{Z}=\sigma_{Y}>1$

given that the denominator $\mu_{X}$ is getting larger with a higher value of $\sigma_{i}$. Similarly, an increase in $\sigma_{i}$ would also increase the probability for the term $\left(\frac{|\tilde{\lambda}||\theta|}{\mu_{X}}-\theta_{X Z}\right)$ being negative.

Substituting (B.3) and (B.4) into (32), we obtain

$$
\begin{aligned}
\frac{d^{2} Y}{d X^{2}} & =-\frac{1}{X}\left[\frac{|\tilde{\lambda}||\tilde{\theta}| P_{X}}{\mu_{X}}+\left(\frac{\left|\tilde{\lambda} \| \theta^{*}\right| a P_{Z}}{\mu_{X}}-a P_{Z}\right)-\varepsilon\left(\frac{\left|\tilde{\lambda} \| \theta^{*}\right| a P_{Z}}{\mu_{X}}-a P_{Z}\right)\right], \\
& =-\frac{1}{X} \frac{|\tilde{\lambda} \| \tilde{\theta}| P_{X}}{\mu_{X}}
\end{aligned}
$$

where $|\tilde{\theta}| \equiv\left(\theta_{T S} \theta_{Y L}-\theta_{T L} \theta_{Y S}\right)>0,\left|\theta^{*}\right| \equiv\left(\theta_{Z S} \theta_{Y L}-\theta_{Z L} \theta_{Y S}\right)>0,|\tilde{\lambda}| \equiv \lambda_{T S} \lambda_{Y L}-\lambda_{T L} \lambda_{Y S}>0$. The second line is obtained by using the fact that $\varepsilon$ is approaching one, so that the last two parenthesized expressions in the square brackets offset each other. Therefore, it is clear that $\frac{d^{2} Y}{d X^{2}}<0$, which implies the concavity of the PPF when $\varepsilon$ goes to 1 .

5. Elasticity of substitution $\sigma_{i}$ approaches zero:

If the elasticity of substitution $\sigma_{i}$ approaches zero, it is easy to see that $\mu_{X}$ will go to zero. Recall that (30) and (31) are given by 


$$
\begin{aligned}
& \hat{P}_{X}=\left(\frac{|\lambda||\theta|}{\mu_{X}}-\theta_{X Z} \varepsilon\right) \hat{X}, \\
& \hat{P}_{Z}=\left(\frac{|\lambda|\left|\theta^{*}\right|}{\mu_{X}}-\varepsilon\right) \hat{X},
\end{aligned}
$$

Substituting (B.7) and (B.8) into (32), we obtain

$$
\frac{d^{2} Y}{d X^{2}}=-\frac{1}{X}\left[\frac{|\lambda||\tilde{\theta}| P_{X}}{\mu_{X}}+(1-\varepsilon)\left(\frac{a P_{Z}|\lambda|\left|\theta^{*}\right|}{\mu_{X}}-a P_{Z} \varepsilon\right)\right]
$$

Clearly, (B.9) indicates that $\frac{d^{2} Y}{d X^{2}}$ will approach negative infinity as the denominator $\mu_{X}$ goes to zero, which confirms the concavity of the PPF.

6. Elasticity of substitution $\sigma_{i}$ approaches infinity:

In this case of perfect-substitution technology $\mu_{X}$ will go to infinity. Therefore, we can rewrite (30) and (31) as

$$
\begin{aligned}
& \hat{P}_{X}=-\theta_{X Z} \varepsilon \hat{X}, \\
& \hat{P}_{Z}=-\varepsilon \hat{X} .
\end{aligned}
$$

By substitution of (B.10) and (B.11) into (32), we obtain

$$
\frac{d^{2} Y}{d X^{2}}=\frac{1}{X}(1-\varepsilon) \varepsilon a P_{Z}
$$

which implies the convexity of the PPF given that $0<\varepsilon<1$. 